\author{
UNIVERSIDADE DE SAO PAULO \\ FACULDADE DE CIENCIAS FaRMACEUTICAS \\ Curso de Pós-Graduação em Fármaco e Medicamentos \\ Área: Produção e Controle Farmacêuticos
}

\title{
ESTUDO DE INTERAÇÃO ENTRE A RANITIDINA E O DICLOFENACO EM VOLUNTÁRIOS SÁDIOS APÓS ADMINISTRAÇÃO PERORAL DE VOLTAREN 50
}

\author{
VALENTINA PORTA
}

Dissertação para obtenção do grau de MESTRE

Orientador:

Prof. Assoc. SIlVIa R. C. J. SANTOS

São Paulo 
AOs meus pais, Franco e Gianna

Aos meus irmâos, Michele, Enrico,

Stefano e Luis Gustavo

Ao José Carios 


\section{Agradecimentos}

A Prolessora Silvia R. C. J. Santos, pela orientaçào e estimulo.

A Coordenadorá do curso de Pós-Graduação em Fármaco e Medicamentos da Faculdade de Ciências Farmacêuticas, Professora Érika R. M. Kedor, pelo incentivo

A Fundação de Amparo à Pesquisa do Estado de São Paulo (FAPESP), pelas bolsas de Mestrado I e II (processo 89/3138-2).

A CAPES, pela complementação de bolsa recebida.

As Professoras Elfriede M. Bacchi e Silvia Storpinis, pela importante colaboração

A Moema R. dos Santos, pela revisão das referēncias bibliográficas.

Aos funcionarios e amigos do Laboratóno de Pesquisa do Instituto do Coração do Hospital das Clinicas: Cèlia E. Omosako, Elisabeth A. Romão, Maria Aparecida Beroline, Maria das Dores Pereira, Heloisa Donzella, Amara Barbosa, Edna Nogueira. Mana Luiza Silva de Paula e José de Souza Filho pelo apoio e colaboração

Aos amigos Adalgisa L. Teixeira Alino S. dos Reis, Lenilson Moreira Filho, Maria Aparecida Nicoletti e Omar Zerino Jr. 
A codos aqueles que, direta ou indiretamente, possibilitaram a realização deste trabalho. 
Valentina Pona

ESTUDO DE INTERAÇĀO ENTRE A RANITIDINA

E O DICLOFENACO EM VOLUNTÁRIOS SADIOS APÓS

ADMNISTR CCÃO DE DOSE ŨNICA DE

VOLTAREN ${ }^{\circledR} 50$

Comissão Julgadora

Dissenação para obtenção do grau de Mestre

SILVIA REGINA C.J.SANTOS

Presidente e Orientador

SEIZIOQA

$1^{\circ}$ Examinador

DERMEVAL D.E CARUALHO

$2^{\varsigma}$ Examinador

São Paulo, g7 de jourivo de 1993. 


\section{Apresentação}

O objetivo principal deste trabalho foi a verificação da existência ou não de interação entre a ranitidina e o diclofenaco em voluntários sadios, através da avaliação da cinética do diclofenaco em plasma e da excreção urinária do fármaco inalterado e de seus produtos de biotransformação hidroxilados. Para isso foi necessário, inicialmente, estabelecer métodos analiticos para a quantificação de diclofenaco em plasma e urina e de seus metabólitos hidroxilados em urina através de técnica de cromatografia liquida de alta eficiència (CLAE), uma vez que, até o momento, não se encontrou reportada na literatura metodologia adequada para tais determinações utilizando CLAE. Estes métodos estão descritos nos Capitulos I e III. Em seguida, foi necessário avaliar a biodisponibilidade de formulações do mercado contendo diclofenaco de sodio para determinar a mais adequada ao estudo de interação. Este estudo de biodisponibilidade encontra-se descrito no Capitulo II Finalmente, no Capitulo IV, está relatado o estudo de interação entre ranitidina e diclofenaco propriamente dito, utilizando a formulação mais adequada escolhida a partir do estudo desenvolvido no Capitulo II. 


\section{Índice geral}



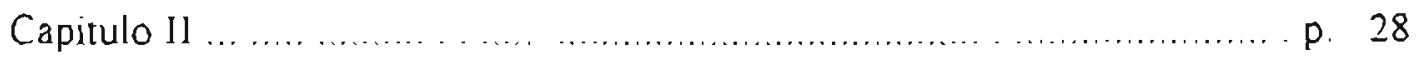

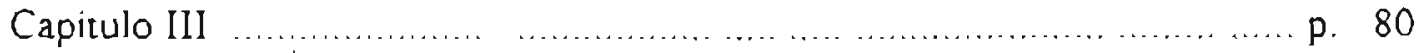

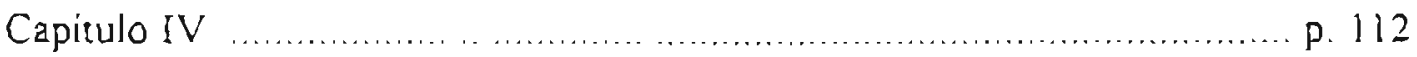




\section{Micrométodo para determinação de diclofenaco em plasma por cromatografia líquida de alta eficiência}

Capítulo I 


\section{Índice}



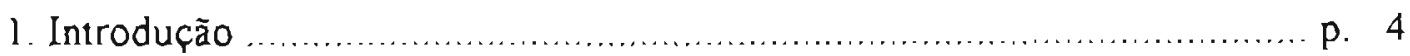

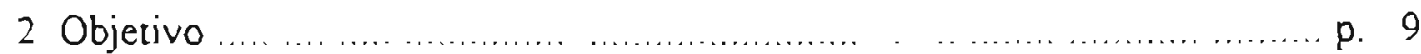

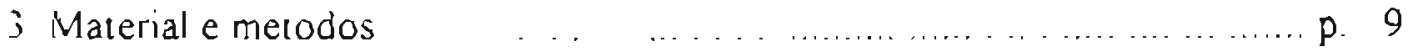



32 Preparação de padrões …................................................ p. 11

3.3. Determinaçào de diclofenaco em plasma .................................. p. 12

34. Limites de confiança do método de determinação de diclofenaco em plasma ............................................... p. 14

4 Resultados ............................................................... 15

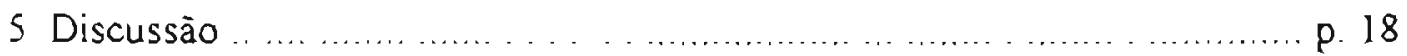

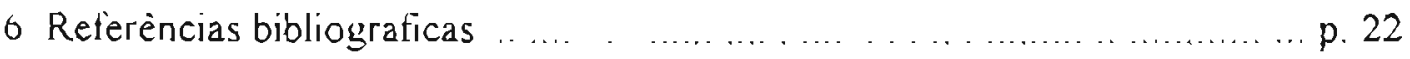






\section{Resumo}

O diclofenaco de sódio é um antiinflamatório nào-esteroidal que, alèm de atividade antiinflamatória, apresenta também propriedades analgésica e antipirética Seus efeitos farmacológicos estão relacionados à inibição da sintese de prostaglandinas. Vários métodos utilizando técricas cromatográficas têm sido propostos para a determinação de diclofenaco em plasma, incluindo a cromatografia gás-liquido com deteç̧ão por captura de elétrons ou por ionização de chama, a cromatografía gás-liquido-espectrometria de massa e a cromatografia líquida de alta eficiència com deteção eletroquimica ou no ultravioleta. Descreve-se aqui um método rápido, sensivel e especifico para a determinação de diclofenaco em plasma usando apenas $200 \mu$ de amostra e envolvendo extração simples e cromatografia líquida de alta eficiência (CLAE) com detecção no uliravioleta. Extraiu-se o diclofenaco adicionando-se $200 \mu l$ de plasma a tubos contendo 500 ng de padrào interno (ácido 2-(p-ciclo-hexen-l'-il-fenil)propiònico e $100 \mu l$ de acido orofosfórico $2,5 \mathrm{~N}$, A seguir adicionaram-se $4 \mathrm{ml}$ de diclorometano e extraiu-se a mistura em agitador de tubos durante 60 segundos. Após centrifugação a $3000 \mathrm{rpm}$ por 20 minutos a fase aquosa foi desprezada e a fase orgânica foi filtrada em membrana Millipore ${ }^{\circledR}$ FHLP 01300 de $0,4 \mu \mathrm{m}$ e evaporada em corrente de nitrogênio a $37^{\circ} \mathrm{C}$. O residuo foi dissolvido em 100 a $1000 \mu l$ de fase movel para injeçāo em CLAE. Empregou-se para a separação coluna Novapak ${ }^{\circledR} \mathrm{C}_{18}, 150 \times 3,9 \mathrm{~mm}, 4 \mu \mathrm{m}$ e fase móvel constituída por mistura de tampão acetato $0,75 \mathrm{M}, \mathrm{pH} 5,0$ e acetonitrila $(55: 45, \mathrm{v} / \mathrm{v})$. A deteç̧ão foi feita em $\lambda=282 \mathrm{~nm}$. O diclofenaco e seu padrão interno foram eluidos respectivamente a 3,3 e 6,5 minutos em fluxo de $0,9 \mathrm{ml} / \mathrm{min}$. Os limites de confiança do método foram: $10-10000 \mathrm{ng} / \mathrm{ml}$, linearidade; I $\mathrm{ng} / \mathrm{ml}$, sensibilidade; $95 \%$, recuperação

relativa e 3,5 e $5,7 \%$, precisão intra e interdias, respectivamente. Este micrométodo mostrou-se suficientemente sensivel, preciso e exato para estudos de disposiçăo cinética e bioequivalência de formulações contendo diclofenaco. 


\section{Introdução}

O diclofenaco de sodio é um antiinflamatório nāo-esteroidal (AINE) com atıvidade analgésica e antipiretica, derivado do àcido fenil-acético. Corresponde ao sal sodico do ácido [o-[(2,6-diclorofenil)amino]fenil]acético, apresentando constante de dissociaçāo igual a 4,0 e coeficiente de parnição (n-octanol / tampão aquoso, $\mathrm{pH} 7,4$ ) de 13,4. Sua estrutura química é mostrada na Figura 1 [19].<smiles>O=C(Cc1ccccc1Nc1c(Cl)cccc1Cl)O[Na]</smiles>

Diclofonaco de sodio



Ácido $2 \cdot(p-c i c l o-h e \times e n-l '-i l-(e n i l)$ propiônico (Pi)

Figura l Diclofenaco de sódıo e seu padrào intemo.

O diclofenaco é capaz de suprimir inflamação em vários modelos animais, apresentando potência semelhante $\dot{a}$ da indometacina, superior à da aspirina, ibuprofeno, naproxeno e fenilbutazona e inferior à do piroxicam. Como analgésico apresenta ação rápida e de longa duração, com potência semelhante à da indometacina e do piroxicam e maior que a da aspirina, ibuprofeno, naproxeno e fenilbutazona. A atividade analgésica do diclofenaco administrado em dose simples 
de $150 \mathrm{mg}$ mostrou ser superior à da codeina administrada em dose simples de 60 Ing, provavelmente devido ao envolvimento de $\beta$-endorfinas na açāo analgésica do diclofenaco. A atividade antipiretica do diclofenaco em ratos foi superior à da indometacina, ibuprofeno, fenilbutazona e aspirina [19]

Os efeitos farmacológicos do diclofenaco estāo relacionados à inibição da sintese de prostaglandinas, através da competiçāo com o ácido araquidônico pela enzima cicloxigenase (Figura 2) [18,19].

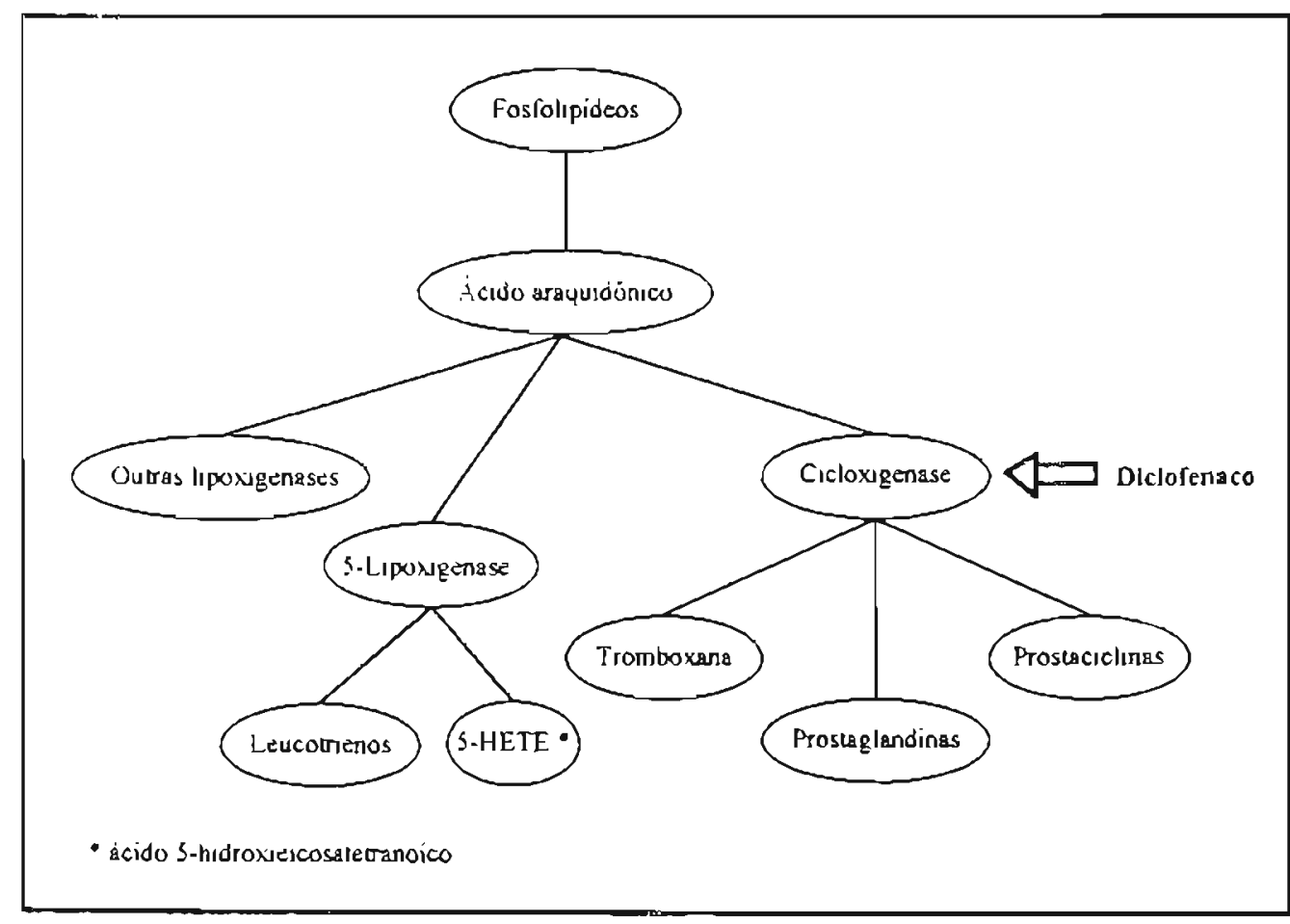

Figura 2: Cascata do ácido araquidónico e mecanismo de ação do diclofenaco.

Este fármaco é bem absorvido após administraçāo peroral, mas, por sofrer eliminação prè-sısıèmica, apenas cerca de $60 \%$ da dose administrada alcançam a 
circulação na forma inalterada. E altamente ligado às proteinas plasmáticas ( 99.5 $\%$ ) e rapidamente distribuido, penetrando no fluido sinovial de pacientes com osteoanrite e anrite reumatóide de onde é eliminado mais lentamente que no plasma. Sua eliminação se dá principalmente por biotransformacão e posterior excreção biliar e urinária dos produtos de biotransformaçào na forma de conjugados sulfúricos e glicurónicos $[18,19]$.

Em comparação a outros antiinflamatórios não-esteroidais o diclofenaco é bem tolerado, raramente produzindo úlceras gástricas ou outros efeitos colaterais graves. Em vista disso ele é considerado um dos poucos antiinflamatórios não-esteroidais de primeira escolha no tratamento de condiçōes inflamatórias e dolorosas agudas ou crònicas [19].

Vários métodos utilizando diversas técnicas cromatográficas têm sido propostos para a quantificação de diclofenaco em plasma, incluindo-se a cromatografia em camada deigada [16], a csomatografia gás-líquido $[1,5,7-11]$ e a cromatografia liquida de alta eficiência $[2,4,6,12-15,17,20-22]$

Devido à presença de dois átomos de halogênio na molécula do diclofenaco, a primeira escolha para sua determinação em amostras biológicas recaiu sobre a cromatografia gás-liquidó $(C G)$ após derivatização do grupo carboxila por esterificação ou ciclização direta ou indireta (esterificação seguida de ciclização) [3], obtendo-se, respectivamente, ésteres do diclofenaco $[1,7,11]$ ou derivados do tipo indolinonas $[5,10]$ (Figura 3). Em geral estes métodos utilizam a detecção por captura de elétrons com detectores de niquel-63 (CG-DCE 63Ni) $[5,7]$, por espectrometria de massa $[10,11]$ ou por ionização de chama [\}$]$ 
Os métodos utilizando cromatografia gás-liquido mostraram-se bastante sensiveis na quantificaçào do diclofenaco, especialmente aqueles que empregam detecçào por espectrometria da massa $[10,11]$. Entretanto, por necessitarem de um procedimento laborioso de extração e derivatização do fármaco e por empregarem grandes quantidades de plasma $(0,5$ a $2,0 \mathrm{ml})$, estes métodos foram substituidos por outros utilizando a cromatografia liquida de alta eficiência (CLAE), com procedimentos de extração mais simples e sem necessidade de derivatização pré-coluna.

A

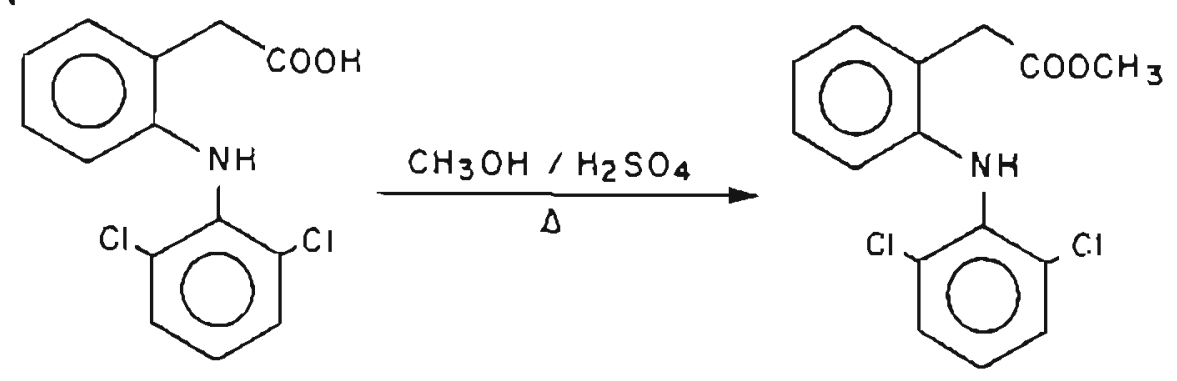

8<smiles>O=C(O)Cc1ccccc1Nc1c(Cl)cccc1Cl</smiles>

Figura 3. Estenficaçào (A) e cıclização (B) do diclofenaco. 
Em 1980 foi descrito um método urilizando a cromatografia em camada delgada com monitoramento em $290 \mathrm{~nm}$ para determinaçăo de diclofenaco em plasma $\{16\}$

Os primeiros métodos para a determinação de diclofenaco plasmático utilizando cromatografia líquida de alta eficiência surgiram no início da década de $80[14,2]$ e utilizaram extração simples com solvente orgânico em meio ácido para purificação das amostras. A separação foi obtida em coluna cromatográfica de fase reversa tipo $C_{18}$, utilizando-se detecção ultravioleta no comprimento de onda de $254 \mathrm{~nm}$ [14] ou $215 \mathrm{~nm}$ [2]. Em 1985 foi proposto um método com separação em coluna $C_{8}$ e deteç̧ão em $\lambda=282 \mathrm{~nm}$ [6]. A. partir de então vários outros métodos empregando técnica de cromatografia liquida de alta eficiência foram propostos para a quantificação do diclofenaco plasmático $[4,12,13,15,17,20-22]$. A maioria utilizou coluna de fase reversa tipo $C_{18}[12,15,17,20,22\}$, mas o uso de colunas de fase reversa tipo $\mathrm{C}_{8}[4]$ ou $\mathrm{NH}_{2}$ [13] e de coluna de troca iônica tipo AAX [21] tambem e reponado. A deteç̧ão foi feita no ultravioleta $\operatorname{com} \lambda=254 \mathrm{~nm}$ [12], $275 \mathrm{~nm}$ [21], $280 \mathrm{~nm}$ [4] ou $282 \mathrm{~nm}$ [15.17] ou utilizando-se detectores eletroquimicos $[13,22]$ ou de fluorescência [20].

Devido à boa sensibilidade, à facilidade na purificação das amostras e à necessidade de pequenas quantidades de plasma $(50 \mu \mathrm{l}$ a $1,0 \mathrm{ml})$ os métodos de quantificaçào de diclofenaco plasmático utilizando cromatografia liquida de alta eficiència subscituiram atualmente aqueles utilizando cromatografia liquido-gás. 
O método desenvolvido no presente trabalho utiliza a cromatografia liquida de alta eficiència em fase reversa com detecção no ultravioleta, em $\lambda=282 \mathrm{~nm}$, utilizando apenas $200 \mu \mathrm{l}$ de plasma por ensaio [15].

\section{Objetivo}

O objetivo deste trabalho é desenvolver um método de determinação de dielofenaco plasmático através de cromatografia líquida de alta eficiência para aplicação em estudos farmacocinéticos.

\section{Material e métodos}

\subsection{Material}

Todos os solventes utilizados para extração (diclorometano), cromatografia (acetonitrila) ou preparo de padrōes (metanol) foram de grau espectroscópico ou cromatográfico (E. Merck, Grupo Química). Para evaporação dos extratos orgânicos usou-se nitrogênio de pureza 99,99\% (White Martins). As soluçōes ácidas, básicas, iônicas ou tampões foram preparadas a partir de reagentes pró-análise (grau p.a.). A água destinada tanto à limpeza do cromatógrafo quanto ao preparo de soluçōes foi filtrada em membrana Millipore $e^{\circledR}$ de 0,4 $\mu$ m, tipo HA. 
Para a analise cromatografica utilizou-se coluna Novapak ${ }^{\otimes} C_{18}$, Waters - Millipore, de $150 \times 3,9 \mathrm{~mm}$ e pariculas de $4 \mu \mathrm{m}$.

O material de vidro usado foi cuidadosamente lavado com detergente e solução sulfocrômica e enxaguado com agua destilada A secagem foi feita em estufa. Imediatamente antes do uso o material foi enxaguado com diclorometano.

\section{Padrões}

Usaram-se os seguintes compostos.

- diclofenaco de sódio - doado pela Biogalênica - utilizado como padrão para doseamento de diclofenaco em plasma e;

- ácido-2-(p-ciclo-hexen-1'-il-fenil)propiônico - doado pela Biogalênica - utilizado como padrão interno no doseamento de diclofenaco em plasma.

\section{Equipamento}

Para a cromatografia utilizou-se equipamento Shimadzu constituido por bomba modelo LC-6A controlada por microprocessador modelo SCL-6B, injetor automático modelo SIL-6B, detector de absorbância variável modelo SPD-6AV $(\lambda=282 \mathrm{~nm})$ e integrador automático modelo $\mathrm{CR}-6 \mathrm{~A}$. 
Para as exiraçōes utilizou-se agitador de tubos Phoenix. modelo AT 56 e centrifuga refrigerada Du Pont, modelo Sorvali ${ }^{\circledR}$ RC-5B. Para a evaporação dos extratos utilizou-se banho-maria Fanem ${ }^{\circledR}$ Lida. equipado com sistema de evaporaçào

No preparo da fase móvel usou-se banho de ultrassom Mini-Som Thornton para a desgaseificação.

\subsection{Preparação de padrôes}

Os padrōes de diclofenaco em plasma foram preparados a partir de soluçăo metanólica contendo exatamente cerca de $1 \mathrm{mg} / \mathrm{ml}$ de diclofenaco. Essa solução foi diluida inicialmente com àgua e em seguida com plasma branco previamente testado, obtendo-se padrões com as concentrações de $843 \mathrm{ng} / \mathrm{ml}, 169$ $\mathrm{ng} / \mathrm{ml} \mathrm{e} 34 \mathrm{ng} / \mathrm{ml}$

O padrão interno foi preparado por dissolução do ácido 2-(p-cicio-hexen-1'-il-fenil)propiônico em metanol obtendo-se uma solução com concentração de $10 \mu \mathrm{g} / \mathrm{ml}$.

Tanto os padrōes em plasma quanto o padrāo interno foram armazenados em congelador a $-20^{\circ} \mathrm{C}$. 


\subsection{Determinação de diclofenaco em plasma}

A concentração plasmática de diclofenaco em padrões e amostras foi determinada atraves de cromatografia líquida de alta eficiência (CLAE) em fase reversa precedida de extraçào conforme micrometodo desenvolvido no presente trabalho e ja publicado [15].

A integração dos picos do cromatograma foi realizada pelo método da padronização interna utilizando-se como padrão interno (Pi) um análogo estruturaj do diclofenaco, o ácido 2-(p-ciclo-hexen-1'-il-fenil)propiônico (Figura 1).

\section{Procedimento de extração}

A purificaçào de branco, padrōes e amostras biologicas foi feita através de exıração do diclofenaco plasmático com solvente orgānico em meio ácido. Adicionaram-se volumes de $200 \mu$ de plasma a tubos contendo $50 \mu$ l de padrão interno (solução metanólica de ácido 2-(p-ciclo-hexen-l'-il-fenil)propiônico a 10 $\mu g / m l)$ previamente evaporados em corrente de nitrogênio a $37^{\circ} \mathrm{C}$. A seguir acidificou-se o plasma com $100 \mu$ de ácido ortofosfórico $2,5 \mathrm{~N}$ e extraiu-se-o com $4 \mathrm{ml}$ de diclorometano durante 60 segundos em agitador de tubos. Após centrifugação a 3000 rpm por 20 minutos para quebra da emulsão aspirou-se a fase aquosa e imergiu-se o extrato orgànico remanescente em banho de gelo seco e acetona para congelamento da fase aquosa restante. Decantou-se cuidadosamente o exirato orgànico que, em seguida, foi filtrado em sistema Millipore ${ }^{\circledR}$ com 
membrana FHLP 01300 de $0.4 \mu \mathrm{m}$. transferido para tubo cônico e evaporado em corrente de nitrogênio a $37^{\circ} \mathrm{C}$. Dissoiveu-se o residuo em volumes de 100 a 1000 $\mu l$ de fase móvel para injeção em CLAE (Esquema analítico).

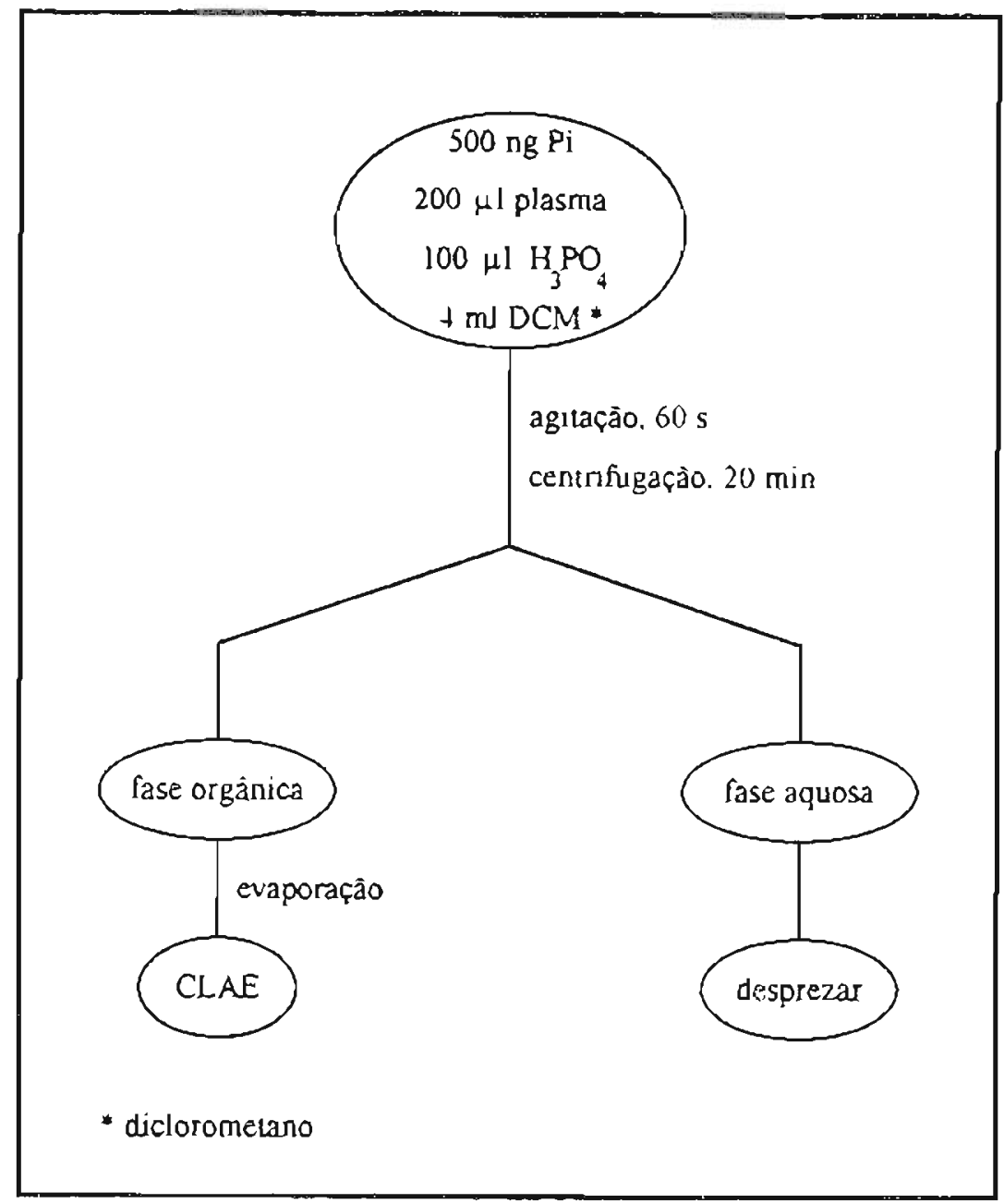

Esquema analitico. Procedumento de extração para determinaçào de diclofenaco em plasma. 


\section{Condições para cromatografia líquida de alta eficiência}

Empregou-se para a separação uma coluna Novapak ${ }^{\circledR} \mathrm{C}_{18}$ de $150 \mathrm{~mm}$ de comprimento e $3.9 \mathrm{~mm}$ de diàmetro interno contendo particulas de $4 \mu \mathrm{m}$ e 25000 pratos teoricos Diariamente, antes do uso, a coluna mantida em metanol e água $(75: 25 \mathrm{v} / \mathrm{v})$ foi condicionada com acetonitrila seguida de água ultrapura durante 30 minutos.

A fase móvel, constituida por mistura de tampāo acetato $0,75 \mathrm{M}, \mathrm{pH} 5,0$ e acetonitrila na proporção de 55:45 (v/v), foi desgaseificada a vácuo em ultrassom antes do uso e bombeada para o sistema cromatográfico em fluxo de $0,9 \mathrm{~mL} / \mathrm{min}$. A estabilização do sistema exigiu cerca de $30 \mathrm{~min}$.

\subsection{Limites de confiança do método de determinação de diclofenaco em plasma}

A curva de calibração foi construida a partir de padrões obtidos pela adiçāo de diferentes quantidades de diclofenaco a branco de plasma. A linearidade foi avaliada utilizando-se ajuste pelo método dos minimos quadrados e regressão linear. O limite de quantificação do método foi estabelecido após purificação por extração dos padrões utilizados na construção da curva de calibraçāo. A reprodutibilidade foi determinada a parir da precisão intra e interdias. Para a determinação da recuperação relativa da extração, padrōes de diclofenaco em 
plasma foram extraıdos e analisados em CLAE contra injeção direta da mistura de diclofenaco e seu padrão interno. Finalmente a estabilidade dos extratos orgânicos foi avaliada reinjerando-se em CLAE extratos submetidos a diferentes condições de armazenamento (temperatura ambiente e congelador a $-20^{\circ} \mathrm{C}$ ).

\section{Resultados}

O diclofenaco e o padrão intemo apresentaram boa separação entre si e lambém dos componentes do plasma. Os tempos de retenção foram de 3,3 e 6,5 minutos respectivamente para o diclofenaco e o padrão interno, correspondendo a volumes de retenção de 3,0 e $5,9 \mathrm{ml}$ (Figura 4). 


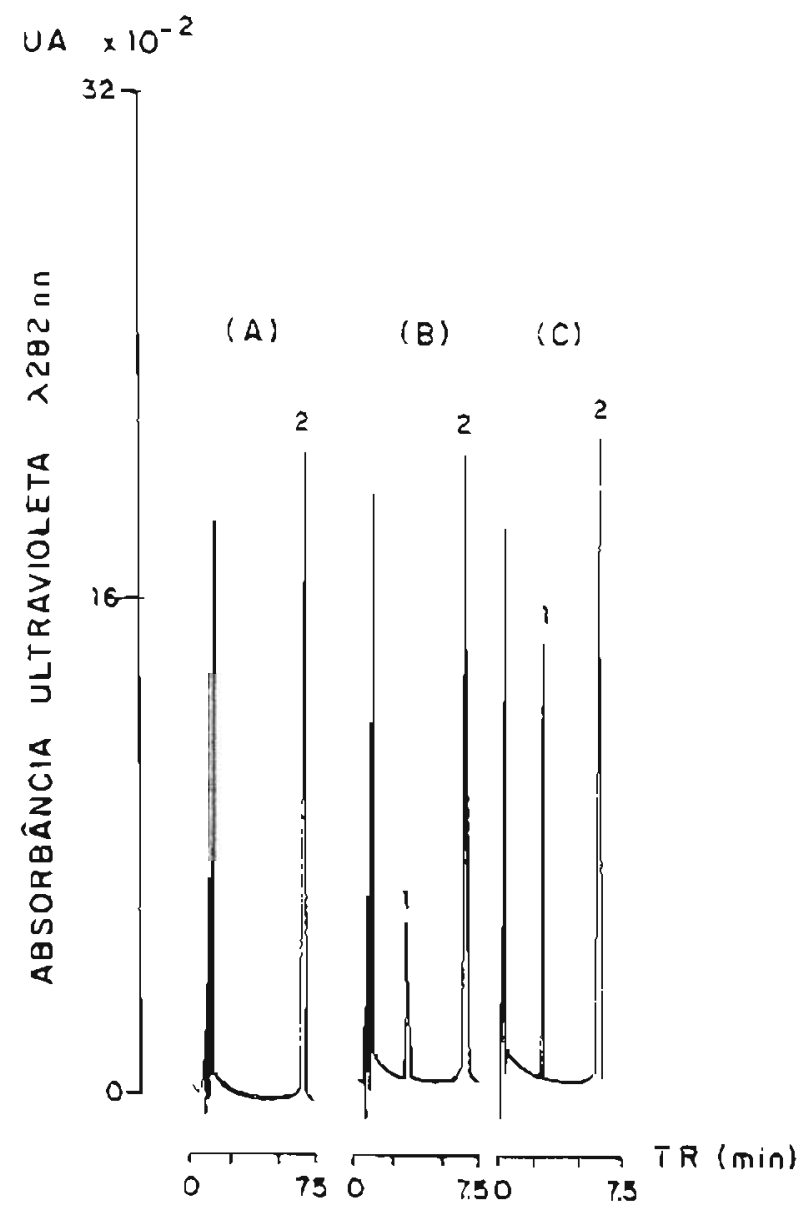

Figura 4: Perfil cromatográfico do diclofenaco e seu padrão intemo. A: plasma branco + padrão intemo: B: padrão (plasma branco + $10 \mathrm{ng}$ diclofenaco/ml) + padrão interno; C: plasma de voluntário após administração peroral de dıclofenaco de sódio + padrão intemo. 1: diclofenaco; 2 : padrão intemo.

O limite de quantificação do método foi de $1 \mathrm{ng} / \mathrm{ml}$. Obteve-se uma relaçào linear entre as concentraçōes de 10 e $10000 \mathrm{ng} / \mathrm{ml}$ (Figura 5). O coeficiente de variação foi de $3.5 \%$ para amostras analisadas no mesmo dia e de $5,7 \%$ para amostras analisadas em dias diferentes. A recuperação relativa da extração foi de $95 \%$ (Tabela 1 ). 
CURVA de CALIBRACÃo do diclofenaco

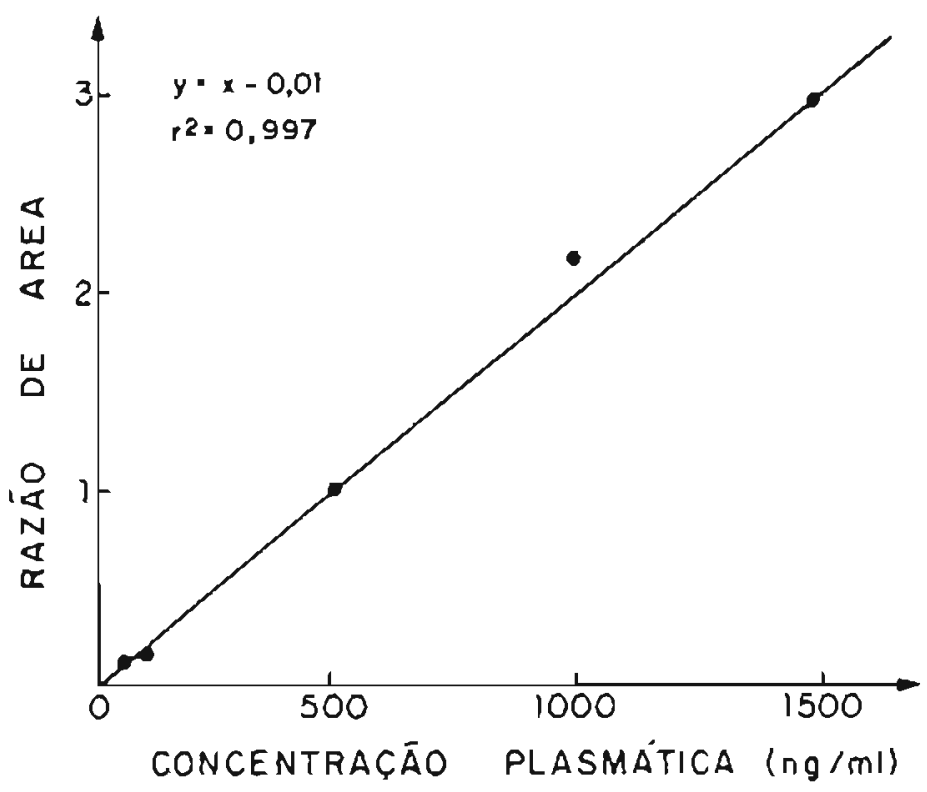

Figura 5: Curva de calibração do diclofenaco em plasma. 
Tabeia 1. Limıtes de confiança do metodo de determinaçăo de diclofenaco em plasma.

\begin{tabular}{|c|c|c|}
\hline Parâmetro & Unidade & Valor \\
\hline limule de quantificaçăo & $\mathrm{ng} / \mathrm{ml}$ & 1 \\
\hline Ineandade & $\mathrm{ng} / \mathrm{ml}$ & $10-10000$ \\
\hline recuperaçào da extraçăo & $\%$ & 95 \\
\hline \multicolumn{3}{|l|}{ reprodusibilidade } \\
\hline inuradia & $\%$ & 3.5 \\
\hline interdias & $\%$ & 5.7 \\
\hline
\end{tabular}

Os extratos orgànicos não reconstituidos com fase móvel mantém-se estáveis por quatro dias quando conservados em congelador a $-20^{\circ} \mathrm{C}$ e os extratos reconstituidos mantem-se estaveis por dois dias quando conservados a $-20^{\circ} \mathrm{C}$ e por 24 horas quando conservados à temperatura ambiente.

\section{Discussão}

A grande vantagem do método de determinação de diclofenaco em plasma atraves de cromatografia liquida de alta eficiência (CLAE) aqui apresentado [15] em relação aos anteriormente descritos na literatura $[2,4,6,12-14,17,20-22]$ consiste na pequena quantidade de plasma, apenas $200 \mu \mathrm{l}$, necessária para a análise quantitativa do fármaco, enquanto a maioria dos métodos utilizou $0,5 \mathrm{ml}$ $[4,13,17,21,22]$ ou $1,0 \mathrm{ml}[2,6]$ de plasma por ensaio. Outros autores descrevem 
ainda métodos utilizando volumes de plasma inferiores a $0,5 \mathrm{ml}: 200 \mu \mathrm{l}$ [12], $100 \mu$ ] [14] ou $50 \mu$ [20]. Entretanto, nenhum destes métodos utilizando microvolumes de plasma apresentou sensibilidade comparàvel àquela do método aqui apresentado. Enquanto o presente método permitiu a quantificação de amostras contendo até 1 $\mathrm{ng} / \mathrm{ml}$ de diclofenaco, os très métodos anteriormente referidos apresentaram limites de quantificação de, respectivamente, $0,4 \mu \mathrm{g} / \mathrm{ml}[12], 10 \mu \mathrm{g} / \mathrm{ml}[14]$ e $6 \mathrm{ng} / \mathrm{ml}$ [20] sendo que apenas este último apresentou sensibilidade suficiente para estudos farmacocinéticos.

Alguns dos métodos de determinação de diclofenaco em plasma através de cromatografia líquida de alta eficiência descritos na literatura propōem, para purificação das amostras, apenas a precipitação de proteinas com acetonitrila $[4,12,20]$. Este procedimento, apesar de simples e rápido, não é eficiente na remoçāo de componentes endógenos presentes no material biológico e sua utilização pode levar a um bloqueio por entupimento do sistema de injeção do cromatógrafo, além de encurtar a vida útil da coluna cromatográfica. Outros autores propōem a extração do diclofenaco com solvente orgânico em meio ácido, utilizando benzeno $[13,21]$, clorofórmio [14], diclorometano $[15,22]$ ou ainda mistura de hexano e álcool isopropilico na proporção de $9: 1(\mathrm{v} / \mathrm{v})[2,6]$. O solvente adotado no método aqui descrito foi o diclorometano, que, além de ser mais eficiente que o benzeno na extraçào do diclofenaco, apresenta a vantagem de um menor ponto de ebulição, resultando em evaporação mais rápida dos extratos orgânicos com consequente diminuição do consumo de nitrogênio e do tempo de evaporação. 
Como acidificante do meio de extração repona-se a utilização de vários ácidos. como o ácido onofosfórico l $\mathrm{M}[22]$ ou $2.5 \mathrm{~N}[2.6 .13]$ e o ácido clorídrico $0.3 N[21]$ ou $0,1 \mathrm{~N}[14]$ em quantidades variando entre 0.5 e $4 \mathrm{ml} 0$ método aqui descrito [15] utiliza apenas $100 \mu$ de ácido ortofosfórico $2,5 \mathrm{~N}$, o que permite a obtenção de extratos em faixa mais branda de $\mathrm{pH}$, resultando em prolongamento da vida útil da coluna de cromatografia sem prejuizo da recuperaçāo de diclofenaco na extração.

Entre os métodos descritos para determinação de diclofenaco em plasma através de cromatografia líquida de alta eficiência (CLAE), apenas dois propōem procedimentos para purificação das amostras que não a extração simples do diclofenaco com solvente orgânico. Um deles é o método descrito por Plavsic e Culig [13], que propõem extração tripla, sendo duas extrações em meio ácido intercaladas por uma em meio básico, num procedimento bastante laborioso e semelhante ao descrito por Geiger e colaboradores [5] para determinação de diclofenaco plasmático através de cromatografia gas-líquido. O outro é o método descrito por Sioufi e colaboradores [17], que propõem a extração em coluna $C_{18}$ utilizando sistema automatizado de analise. A extração simples desenvolvida no presente trabalho e aqui descrita [15] demonstrou ser suficiente para extrair diclofenaco de amostras de plasma com uma boa recuperação e sem interferência analítica dos componentes endógenos presentes em amostras purificadas apenas por precipitação das proteínas do plasma com acetonitrila $[4,12.20]$.

A grande maioria dos métodos referidos $[2,12,14,15,17,20,22]$ propõe a utlização de coluna cromatografica de fase reversa, tipo $C_{18}$, para separação do diclofenaco e seu padrão interno dos componentes endógenos. Entretanto outras 
colunas de fase reversa também tèm sido usadas para esta separaçăo, lais como a RP- $\mathrm{C}_{8}[4,6]$ e a Lichrosorb ${ }^{\circledR} \mathrm{NH}_{2}$ [13]. Repora-se ainda a utilização da coluna Permaphase ${ }^{\circledR}$ AAX, de troca iònica [21]. Entre as fases móveis refere-se a utilização de misturas de acetonitrila e água ou tampōes, contendo de 32 a $50 \%$ de acetonitrila $[4,12,13,15,20,22]$, de metanol, acetonitrila e tampão acetato $0,02 \mathrm{M}$ (25 $2055, v / v)$ [2], de etanol e água $(1: 2, v / v)$ [14] ou de metanol e tampão fosfato, contendo de 56 a $60 \%$ do solvente orgànico $[6,17]$ para cromatografia de

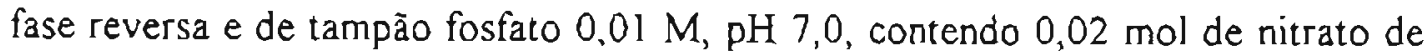
sódio para cromatografia de troca iònica [21]. A urilização de coluna Novapak ${ }^{\circledR}$ $\mathrm{C}_{18}$ e fase móvel constituida por mistura de tampăo acetato $0,75 \mathrm{M}$, pH 5,0 e acetonitrila $(55: 45, v / v)$ para separação do diclofenaco e seu padrão intemo dos componentes endógenos no método aqui descrito mostrou ser uma boa escolha em vinude da alta seletividade alcançada.

Finalmente, a maioria dos métodos referidos utiliza deteç̧ào no ultravioleta nos comprimentos de onda de $215 \mathrm{~nm}$ [2], $254 \mathrm{~nm}[12,14], 275 \mathrm{~nm}$ [21], $280 \mathrm{~nm} \mathrm{[4]} \mathrm{ou} 282 \mathrm{~nm}[6,15,17]$. O espectro do diclofenaco no ultravioleta apresenta dois picos de absorbância, em 215 e em $278 \mathrm{~nm}$. Assim, os métodos mais sensiveis são aqueles que utilizam comprimentos de onda próximos a estes. Repona-se também o uso de detectores eletroquímicos [13,22] ou de fluorescência [20]. Neste último caso o diclofenaco sofre derivatização pós-coluna originando um derivado fluorescente. O método aqui descrito utiliza deteç̧ão em $\lambda=282 \mathrm{~nm}$, obtendo boa sensibilidade e seletividade.

Em conclusão, o procedimento analitico aqui apresentado para a quantificação de diclofenaco em plasma mostrou-se seletivo, sensivel, linear na 
laixa de estudo. com boa recuperação da exiração e precisão das medidas. possibilitando estudos farmacocinéticos e de bioequivalência de formulaçōes.

\section{Referências bibliográficas’}

1. BROMBACHER, P.J., CREMERS, H.M.H.G., VERHEESEN, P.E., QUANJEL-SCHREURS. Quantitative determination of sodium-o-[(2,6-dichlorophenyl)-amino]phenylacetate (diclofenac) in human blood plasma or serum Arzneim. Forsch., Aulendorf, v. 27, n. 8, p. $1597-$ 1599, 1977.

2. CHAN, K.K.H., VYAS, K.H., WNUCK, K. A rapid and sensitive method for the determination of diclofenac sodium in plasma by high-performance liquid chromatography. Anal. Lett., New York, v 15, n. B21/22, p. 1649$1663,1982$.

3. DEGEN, P.H. The assay of diclofenac and metabolites: a review. Methodol. Surv. Biochem. Anal, New York, v. 18, p. 107-114, 1988.

\footnotetext{
-De acordo com a norma NBR 6U23/89 preconzada pela ASSOCIAÇĀO BRASILEIRA DE NORMAS TÉCNICAS (ABNT). As abreviaturas dos útulos dos penódicos seguem o CHEMICAL ABSTRACTS SERVICE SOURCE INDEX (CASSI). 1990
} 
4. EL-SAYED, YM . ABDEL-HAMEED, M.E., SULEIMAN, M S NAJIB, NM A rapıd and sensitive high performance liquid chromatographic method for the determination of diclofenac sodium in serum and its use in pharmacokinetic studies. J. Pharm. Pharmacol., London, v 40, p. $727-$ $729,1988$.

5. GEIGER, U.P., DEGEN, P.H., SIOUFI, A. Quantitative assay of diclofenac in biological material by gas-liquid chromatography. J. Chromatogr., Amsterdam, v. 111, p. 293-298, 1975.

6. GODBILLON, J., GAURON, S., METAYER, J.P. High performance liquid chromatographic determination of diclofenac and its monohydroxilated metabolites in biological fluids. J. Chromatogr., Amsterdam, v. 338, p. $151-159.1985$

7. IKEDA, M, KAWASE, M HIRAMATSU. M., HIROTA, K., OHMORI, S Improved gas chromatographic method of determining diclofenac in plasma. J. Chromatogr., Amsterdam, v. 183, p. 41-47, 1980

8. IKEDA, M., KAWASE, M, KISHIE, T., OHMORI, S. Supplementary data for improved gas chromatographic method of determining diclofenac in plasma - behavior of the methyl ester and the indolone derivative of diclofenac in gas-liquid chromatography with electron-capture detection. J. Chromatogr., Amsterdam, v 223, p. 486-491, 1981 
9. JACK, D.B., WLLIS, JV Comments to the article "Improved gas chromatographic method of determining diclofenac in plasma". J. Chromatogr., Amsterdam, v. 223, p. 484-485, 1981

10. KADOWAKI, H. SHIINO, M, UEMURA, I. Sensitive method for the determination of diclofenac in human plasma by gas-chromatography-mass spectrometry. J. Chromatogr., Amsterdam, v. 308, p. 329-333, 1984.

11. MÖLLER, H., STÜBER, W., DING, R. Bioverfügbarkeit, in vivo- und in vitro-Freisetzung von oralen diclofenac-retardformen - 1. Mitteilung. Pharm. Zig., Frankfun, v. 129, n. 41, p. 2387-2392, 1984.

12. OWEN, S.G., ROBERTS, M.S., FRIESEN, W.T. Rapid high-performance liquid chromatographic assay for the simultaneous analysis of non-steroidal anti-inflammatory drugs in plasma. J. Chromatogr., Amsterdam, v. 416, p. 293-302, 1987

13. PLAVSIC, F., CULIG, J. Determination of serum diclofenac by highpertormance liquid chromatography by electromechanical detection. Hum. Toxicol., Basingstoke, v. 4, p. 317-322, 1985.

14. SAID, S.A., SHARAF, A.A. Pharmacokinetics of diclofenac using a developed HPLC method. Arzneim. Forsch., Aulendorf, v. 31, n. 12, p. 2089-2092, 1981

15. SANTOS, S.R.C.J., DONZELLA, H., BERTOLINE, M.A. PEREIRA, M.D., OMOSAKO, C.E.. PORTA, V. Simplified micromethod for the HPLC 
measurement of diclofenac in plasma. Braz. J. Med. Biol. Res., Ribeirão Prero, v 25, p. 125-128, 1992

16. SCHUMACHER, A., GEISSLER, H.E., MUTSCHLER, E. Quantitative Bestimmung von Diclofenac-Natrium aus Plasma durch Absorptionsmessung mit Hilfe der direkten Auswertung von Dünnschichtchromatogrammen. J. Chromatogr., Amsterdam, v. 181, p $512.515,1980$

17. SIOUFI, A, RICHARD, J , MANGONI, P, GODBILLON, J Determination of diclofenac in plasma using a fully automated analytical system combining liquid-solid extraction with liquid chromatography. J. Chromatogr., Amsterdam, v 565, p. 401-407, 1991.

18. SMALL, R.E. Diclofenac sodium. Clin. Pharm., Bethesda, v. 8, p.545-558, 1989

19. TODD, P.A., SORKNN, E.M. Diclofenac sodium. A reappraisal of its pharmacodynamic and pharmacokinetic properties, and theurapetic efficacy. Drugs, Auckland, v.35, p.244-285, 1988.

20. WIESE, B. HERMANSSON, J. Bioanalysis of diclofenac as its fluorescent carbazole aceric acid derivative by a post-column photoderivatization high-performance liquid chromatographic method. J. Chromatogr., Amsterdam, v. 567, p. 175-183, 1991.

21. YAGINUMA, H. NAKATA, T, TOYA, H., MURAKAMU, T., YAMAZAKI. M., KAMADA, A. Rectal delivery of antiinflammatory drugs. I. The 
influence of antiinflammatory drugs on rectal absorption of B-lactam antibioncs. Chem. Pharm. Bull., Tokyo, v. 29, n 10, p 2974-2982, 1981.

22. ZECCA, L., FERRARIO, $P$ Determination of diclofenac in plasma and synovial fluid by high-performance liquid chromatography with electrochemical detection. J. Chromatogr., Amsterdam. v. 495, p. 303308,1989 


\begin{abstract}
Diclofenac sodium is a non-steroid anti-inflammatory agent which shows a high degree of antı-inflammatory, anaigesic and antipyretic acrivizy. It inhibits prostaglandin biosynthesis in vitro and in vivo, and this inhibitory effect at least parly explains the mecharism of action of the drug. Several methods have been described for the determination of diclofenac in human plasma or serum, including gas chromatography with electron-capture or flame jonization detection, gas-chromatography-mass spectrometry, and high-performance liquid chromatography with UV-detection. We describe a rapid, sensitive and specific procedure for the determination of diclofenac in plasma, using only $200 \mathrm{\mu l}$ of biological sample, involving single extraction and high-performance liquid chromatography (HPLC) with UV-detection. An extraction with dichlormethane was performed by adding $200 \mu$ l of plasma to a test uube containing $500 \mathrm{ng}$ internal standard (2-(p-ciclohexen-l'-fenil)propionic acid) and $100 \mu \mathrm{l} 2,5 \mathrm{~N}$ phosphoric acid. HPLC grade dichlormethane (4 ml) was added and the mixture was agitated with a vortex mixer and centrifuged at $3000 \mathrm{rpm}$ for 20 minutes. The aqueous phase was discarded and the organic phase filtered through a $0,4 \mu \mathrm{m}$ FHLP 01300 Millipore ${ }^{\circledR}$ filter and evaporated in a stream of nitrogen at $37^{\circ} \mathrm{C}$. The residue was dissolved in 100-1000 $\mu$ mobile phase and injected into the liquid chromatograph. Analytical separation was performed in an isocratic system on a reverse-phase column (Novapk ${ }^{\circledR} \mathrm{C}_{18}, 150 \times 3,9 \mathrm{~mm}, 4 \mu \mathrm{m}$ ). The mobile phase was $0,75 \mathrm{M}$ acetate buffer, $\mathrm{pH} 5.0$ and acetonitrile $(55: 45, v / v)$. Peaks were monitored at $\lambda=282 \mathrm{~nm}$. Diclofenac and its intemal standard were eluted at 3,3 and 6,5 minutes, respectively, at a flow rate of $0,9 \mathrm{~mL} / \mathrm{min}$. Confidence limits for diclofenac measurements in plasma were: $10-10000 \mathrm{ng} / \mathrm{ml}$, linearity; $1 \mathrm{ng} / \mathrm{ml}$, sensitivity; $95 \%$, relative recovery, and intra and interassay precision of 3,5 and $5,7 \%$, respectively. This micromethod proved to be sufficiently sensible, precise and accurate for kinetic disposition or bioequivalence studies.
\end{abstract}




\section{Bioequivalência de formulações contendo diclofenaco de sódio}

Capítulo II 
Índice



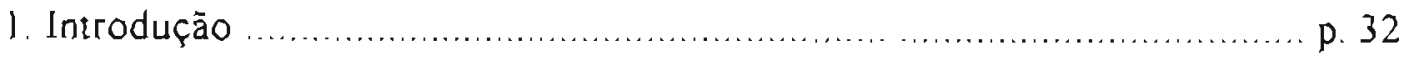





3.1. Protocolo de estudo ........................................................ p. 40

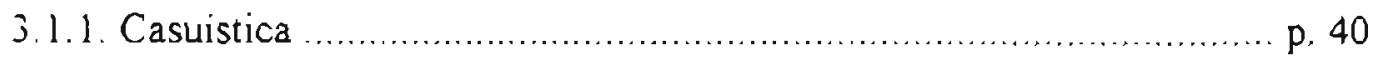

3.1.2. Administraçào do fármaco ........................................... p. 40

3.1 3. Coleta e armazenamento de amostras ................................. p. 42

3.2. Procedimento analítico ............................................ p. 42

3.3. Cálculos e análise estatistica ............................................. p. 44

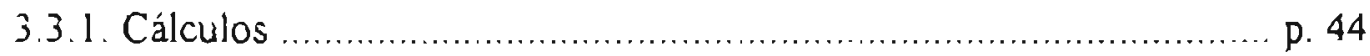

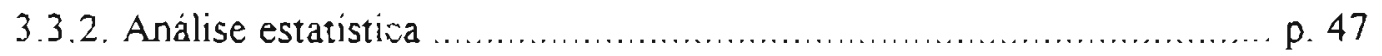

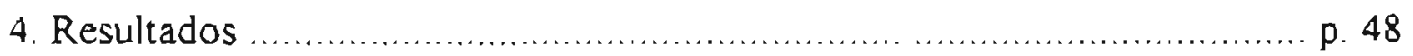

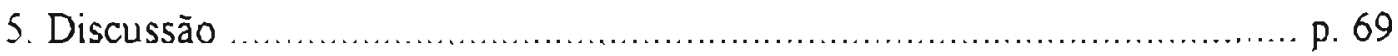

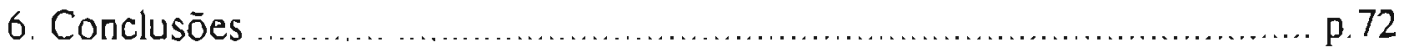


7 Referèncias bibliográficas

p. 73

Abstract

p. 78

Apêndice

p. 79 


\section{Resumo}

Estudou-se a biodisponibilidade do diclofenaco nos produtos Voltaren ${ }^{\circledR} 50$ (A), Voltaren Retard ${ }^{\circledR} 100$ (B) e Arren ${ }^{\circledR} 100$ (C) após administraçăo de dose única peroral de um comprimido a oito voluntários de ambos os sexos, adultos e sadios. As formulações foram administradas seguindo protocolo de estudo estabelecido por sorteio. Os voluntários em jejum receberam os medicamentos em dose única pela manhã e as amostras de sangue foram colhidas 1 , 2. $3,4,6,8,10,12$ e 24 horas após a administração. A concentração plasmática de diclofenaco foi determinada por técnica em cromatografia líquida de alta eficiência (CLAE) de fase reversa com deteç̧ão no ultravioleta em $\lambda=282 \mathrm{~nm}$ após extração com solvente orgànico em meio ácido. Com base nas curvas "concentração plasmatica (C) vs tempo" e "logC vs tempo" foram determinados os parâmetros da fase absoriva para os très produtos, em $\overline{\mathrm{X}} \pm \mathrm{EPM}: \mathrm{C}_{\max }=741 \pm 137 \mathrm{ng} / \mathrm{ml} \mathrm{e}$ $t_{\max }=2,6 \pm 0,4 \mathrm{~h}$ para o produto $\mathrm{A}, C_{\max }=1399 \pm 326 \mathrm{ng} / \mathrm{ml}$ e $t_{\max }=2,4 \pm 0,2 \mathrm{~h}$ para o produto $B, C_{\max }=192 \pm 70 \mathrm{ng} / \mathrm{ml}$ e $t_{\max }=2,3 \pm 0,2 \mathrm{~h}$ para o produto $\mathrm{C}$. Os valores de $A U C_{T}$, calculados pelo método dos trapezöides e extrapolação a infinito, foram, em X \pm EPM: $1603 \pm 253 \mathrm{ng} \cdot \mathrm{h} / \mathrm{ml}$ para o produto A, $3177 \pm 606$ $\mathrm{ng} \cdot \mathrm{h} / \mathrm{ml}$ para o produto B. $2237 \pm 529 \mathrm{ng} \cdot \mathrm{h} / \mathrm{ml}$ para o produto C. A extensão da biodisponibilidade (EBA) do diclofenaco nos produtos Voltaren ${ }^{\circledR} 50$ (A) e Anren 100 (C) foi calculada usando-se como referência o produto Voltaren Retard ${ }^{\circledR} 100(B)$. Foram obtidos os seguintes valores, em $\bar{X} \pm$ EPM (mediana): $138 \pm 35$ (123) \% para o produto A, $102 \pm 35$ (68) \% para o produto C. A parir dos resultados obtidos sugere-se que $O$ produto $B$, citado como de liberação prolongada e usado como referència neste trabalho, apresentou caracteristicas de rápida liberação, semelhantes às do produto $A$, sugerindo possivel falha de impermeabilização no revestimento dos núcleos contendo diclofenaco de sódio durante o processamento industrial do lote do qual provieram os comprimidos aqui avaliados. 


\section{Introdução}

O diclofenaco de sódio é um antiinflamatorio não-esteroidal derivado do ácido fenil-acetico, cuja estrutura química é indicada na Figura 1.



DIclotenoco oe sódio

Figura 1: Diclofenaco de sódio

Para exercer atividade. um antiinflamatorio não-esteroidal deve apresentar pKa entre 4 e 5, coeficiente de parição ao redor de 10 e dois anéis aromázicos em planos diferentes um em relação ao outro. O diclofenaco apresenta todas estas propriedades [25].

O diclofenaco exerce sua ação farmacológica por inibição reversível da enzima cicloxigenase (Figura 2), o que resulta em diminuição da formação de prostaglandina $E_{2}$, prostaglandina $F_{2 \alpha}$, prostaciclina e tromboxana $A_{2}$. Inibindo a produção destas prostaglandinas o diclofenaco reduz a inflamação, o inchaço e a dor que acompanham a artrite [25] 


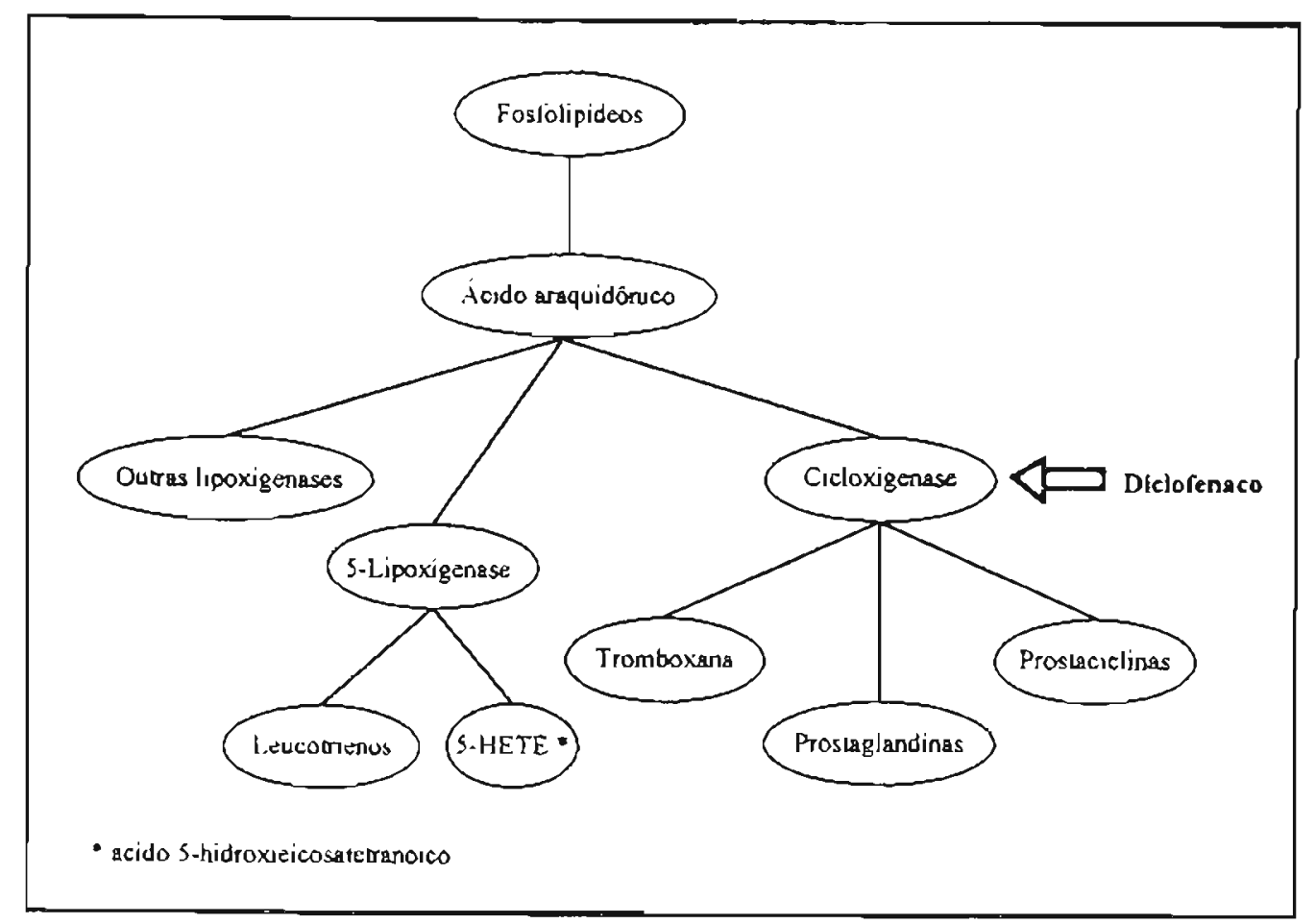

Figura 2: Cascata do ácido araquidônico e mecanusmo de açāo do diclofenaco.

Além de atividade antiinflamatória o diclofenaco apresenta também atividade analgesica e antipirética $[12,25]$.

Este fármaco mostrou eficácia no tratamento de pacientes com artrite reumatoide [3,4], osteoartrite [7] e outros estados inflamatórios de origem reumática ou não [28].

No tratamento de pacientes com arrite reumatóide o diclofenaco foi mais eficiente que a aspirina e o diflunisal e equivalente à indometacina $\{7,18,26]$, ao sulindaco, ao ibuprofeno [13], ao naproxeno, e ao quetoprofeno. Em pacientes ponadores de osteoanrite o diclofenaco foi mais eficiente que a aspinina e o 
ibuprofeno; equivalente ao diflunisal, à indometacina. ao sulindaco, ao naproxeno. ao quetoprofeno, ao flurbiprofeno, ao carprofeno e ao ácido mefenàmico e inferior ao piroxicam. O diclofenaco mostrou-se tão eficiente quanto a fenilbutazona e a indometacina no tratamento de pacientes com gota aguda $[25,28]$.

O diclofenaco é usado como analgésico no alívio da dor em cólicas renais ou biliares, dismenorréia, enxaqueca e estados pós-cirúrgicos $[25,28]$. É usado também no alívio de dores de pacientes com càncer sendo, nestes casos, tāo eficiente quanto o naproxeno [30] e mais eficiente que alguns analgésicos narcóticos [28]. A concentraçāo plasmática de $\beta$-endorinas em pacienzes que receberam diclofenaco aumenta cerca de quatro vezes quando comparada à de pacientes que receberam placebo. Este fato pode explicar a potente atividade analgésica deste antiinflamatório [25].

O diclofenaco produz menos efeitos colaterais que a aspirina [29], o diflunisal, a indometacina $[3,7,18,26]$, o ibuprofeno, a fenilbutazona [26] e é equivalente ao naproxeno [5,29], ao quetoprofeno, ao furbiprofeno, ao carprofeno, ao ácido mefenàmico e ao piroxicam $[25,28]$.

Devido às excelentes atividades antiinflamatória, analgésica e antipirética e ao fato de ser bem tolerado, raramente produzindo ulceraçōes gastrointestinais e outros efeitos colaterais graves, o diclofenaco é hoje considerado um dos poucos antijinflamatórios de primeira escolha no tratamento de pacientes portadores de condições inflamatórias dolorosas, agudas ou crônicas [28].

O diclofenaco é rapidamente absorvido quando administrado por via peroral na forma de comprimidos de revestimento entérico, alcançando seu pico de 
concentração plasmatica 1.5 a 2,5 horas após a administração. A presença de alimento prolonga o tempo de absorção sem, no entanto, alterar a extensão da absorção [31,32]. Também é absorvido quando administrado por via retal ou cutànea. O diclofenaco sofre biotransformaçào pré-sistèmica, com cerca de $60 \%$ da dose administrada alcançando a circulação sanguınea na forma inaiterada $[25,28]$. $\dot{E}$ um fármaco altamente ligado às proteinas plasmaticas $(99,7 \%)$, principalmente a albumina $[6,24]$. E capaz de penetrar no fluido sinovial, de onde é eliminado mais lentamente que no plasma, o que explica seu prolongado tempo de ação, apesar da curta meia-vida plasmática $[6,28]$. Atravessa a placenta de ratos e camundongos e pode ser encontrado em leite humano. mesmo quando administrado em doses terapêuticas [28] É eliminado principalmente por biotransformação, sofrendo fundamentalmente processo de oxidação em várias posições do seu anel e subseqüente conjugaçăo, originando glicuronatos e sulfatos que são excretados na urina e na bile [28]. Dentre os produtos de biotransformação oxidados destacam-se os derivados hidroxilados 3'-hidroxidiclofenaco, 4'-hidroxidiclofenaco, 5-hidroxidiclofenaco e 4',5-di-hidroxidiclofenaco que possuem atividade antiinflamatória desprezivel quando comparados ao diclofenaco inalterado. Sua meia-vida de eliminaçào plasmática varia entre 1,2 e 1,8 h $[25,28]$.

O diclofenaco e encontrado em diversas formas farmacêuticas, entre as quais destacam-se comprimidos de revestimento entérico, comprimidos ou cápsulas de liberação prolongada, supositórios e injeções intramusculares $[16,28]$.

Por ser um fármaco de primeira escolha no tratamento de pacientes portadores de doenças inflamatórias de origem reumática, sendo administrado cronicamente nestes casos, e devido à grande variedeade de especialidades 
farmacêuticas contendo diclofenaco de sódio existentes no mercado, torna-se importante avaliar a possibilidade de se substituir uma formulaçāo por outra, sem prejuizo do tratamento. Usa-se o termo "bioequivalentes" para designar duas formulaçōes contendo o mesmo principio ativo e que, quando administradas, são absorvidas de forma igual pelo paciente, isto e, apresentam a mesma velocidade de absorção e a mesma extensão da absorção. Estas duas características da absorção de um fármaco a partir de uma determinada forma farmacêutica, a velocidade e a exnensão, determinam a biodisponibilidade deste färmaco naquela forma farmacèutica. Assim, podemos afirmar que duas formulações são bioequivalentes quando o fármaco nelas contido apresenta a mesma biodisponibilidade [9]

Vários fatores interferem na absorçāo de fảrmacos pelo organismo, sendo responsáveis, poranto, por alteraçōes na biodisponibilidade destes färmacos. Entre estes fatores podemos citar aqueles relacionados ao fármaco propriamente dito, aqueles relacionados à forma farmacêutica e aqueles relacionados ao organismo do paciente. Com relação ao fámnaco, os fatores que podem aiterar sua absorção pelo organismo são a solubilidade (e sua dependència ao pH), a constante de dissociação $(\mathrm{pK})$, a lipofilicidade, a massa molecular, o tipo e tamanho de particulas e a estabilidade quimica e enzimática (indicando se o fármaco sofre ou não metabolismo pré-sistèmico), entre outros. Tomando-se a forma farmacêutica temos que a biodisponibilidade depende do transpore gastrointestinal desta forma farmacèutica e tambèm da sua cinética de dissolução. Finalmente, a biodisponibilidade pode ser alterada por inúmeros fatores relacionados ao organismo do paciente, entre os quais estão $0 \mathrm{pH}$ do trato gastrointestinal, a atividade das enzimas do trato gastrointestinal, a motilidade intestinal, a 
constituição da flora intestinal, o fluxo sanguíneo, a presença ou ausência de alimento no trato gastrointestinal, a idade do paciente e a presença de patologias $[15]$

Embora pouco possa ser feito para alterar propriedades fisico-quimicas dos fármacos ou fatores metabólicos ou fisiológicos relacionados ao paciente que sejam desfavoráveis a uma boa biodisponibilidade, o mesmo não ocorre com as formas farmacêuticas. Durante a última década observou-se uma maior conscientização sobre o papel da forma farmacèutica na biodisponibilidade e eficácia clinica dos fármacos levando, conseqüentemente, à obtenção de melhores formas farmacêuticas [9]. Existem diversas razōes para a bioinequivalência entre formulaçōes, incluindo diferenças no processo de produção e nos excipientes. Um produto pode conter cerca de 30 ingredientes inativos, entre conservantes, corantes, agregantes e outros e qualquer um deles pode afetar de forma importante a biodisponibilidade do farmaco [14]

Devido à imponância da formulação para a biodisponibilidade de um fármaco, a F.D A. (Food and Drug Administration) passou a exigir testes de bioequivalência para novas fomas farmacêuticas a serem introduzidas no mercado âmericano. Um teste de bioequivalência consiste geralmente em comparaçōes entre a área sob a curva "concentração plasmática vs tempo" do fármaco, concentração máxima e tempo necessário para atingir concentração máxima após administração de dose única do produto teste e do produto referência, em estudo aleatório cruzado em voluntários sadios [9]. 
Recentemente tèm havido tentativas de se estabelecer testes de dissolução In viro como uma alternativa aos restes de bioequivalència, que são realizados in $v v o$, embora não exisıam evidèncias de que os testes de dissoluçāo possam garantir a bioequivalência entre duas formulaçōes [9]. Especificamente em relação ao diclofenaco, Terhaag e colaboradores relatam a comparaçāo entre cinco supositórios através de teste de dissoluçāo $m$ vitro e através de teste de bioequivalência [27]. Os autores conseguem estabelecer uma correlaçāo entre o tempo necessárjo para liberaçào de $63,2 \%$ do diclofenaco contido nos supositórios no teste in vitro e os valores de concentração máxima e tempo necessário para atingir a concentração maxima in vivo, sugerindo que o comporamento desse fármaco, em supositorios, in vivo pode ser previsto a partir de estudos de dissoluçào in vitro. Por outro lado, Möller, em estudo semelhante, descreve a comparaçăo entre duas forma farmacèuticas de liberação prolongada também através de teste de dissolução in vitro e através de teste de bioequivalência [15]. Foram comparados comprimidos de liberação prolongada e cápsulas contendo microgrânulos de liberação prolongada. No teste de dissolução in vitro o diclofenaco das cápsulas contendo microgrânulos de liberação prolongada foi completamente liberado em cinco horas, enquanto que apenas $50 \%$ do diclofenaco dos comprimidos foi liberado em 12 horas. No teste de bioequivalência a liberação de diclofenaco a partir das duas formas farmacêuticas foi comparável. Assim. enquanto que o seste $m$ viro revelou diferença de disponibilidade entre as duas formulações, o mesmo nāo ocorreu no teste $m$ vivo, no qual as duas formulações se mostraram bioequivalentes. Essa diferença pode ser explicada em funçāo do transporte das formas farmacèuticas ao longo do trato gastrointestinal. A liberação In vivo do diclofenaco de microgrànulos de liberação prolongada é amplamente 
influenciada peio esvaziamento gástrico. Os microgrànulos presentes no estômago passam gradualmente para o intestino ao longo de um periodo de cinco horas $(\mathfrak{r}(1 / 2)=2,5 \mathrm{~h})$ e. uma vez no intestino. alcançam as condições de $\mathrm{pH}$ necessárias à liberaçăo do diclofenaco. Durante a passagem pelo intestino delgado que, no caso dos microgrânulos, demora de quatro a cinco horas, o färmaco é liberado e absorvido. A passagem dos microgrânulos para o intestino delgado em função do tempo de esvaziamento gástrico nāo é simulada no teste in vitro. Isto explica por que a liberação in vivo ocorte com consideravel atraso em relação à liberação in vitro.

Atualmente os testes de dissolução não são capazes de reproduzir in vitro todos os fatores que, in vivo, são responsáveis por alterações na biodisponibilidade de um fármaco. Assim, embora sejam importantes para garantir a uniformidade entre lotes de um determinado produto e também para o desenvolvimento de novas formas farmacèuticas [11], os testes de dissolução não devem ser considerados substitutos para os testes de bioequivalência.

\section{Objetivo}

O objetivo deste trabalho e avaliar a existència ou não de bioequivalência entre duas formulações teste contendo diclofenaco de sodio frente a uma formulação referência 


\section{Material e métodos}

\subsection{Protocolo de estudo}

\subsubsection{Casuística}

O estudo aleatório cruzado foi desenvolvido em oito voluntários sadios de ambos os sexos com idade variando entre 19 e 41 anos e pesando de 55 a $80 \mathrm{~kg}$ (Quadro a.1, Apêndice). Os voluntários foram informados em detalhes sobre o estudo e forneceram o consentimento de participação por escrito (Consentimento de Participaçāo Pós-informação, Apêndice). Nenhum deles tomou qualquer medicação nas três semanas que precederam o estudo.

\subsubsection{Administração do fármaco}

A biodisponibilidade das formulaçōes estudadas foi determinada em três fases (Fases I, II e III), intercaladas por períodos de uma semana para eliminação 
completa do färmaco do organismo, conforme o esquema a seguir:

\begin{tabular}{|c|c|c|}
\hline $\begin{array}{l}\text { Fase I } \\
\text { la semana }\end{array}$ & $\begin{array}{l}\text { Fase II } \\
2^{a} \text { sernana }\end{array}$ & $\begin{array}{l}\text { Fase U } \\
3^{\mathrm{a}} \text { semana }\end{array}$ \\
\hline $\begin{array}{l}1^{\circ} \text { dia } \\
\text { Produto A. B ou C }\end{array}$ & $\begin{array}{l}\text { lo dia }^{\circ} \\
\text { Produro B, C ou A }\end{array}$ & $\begin{array}{l}1^{\circ} \text { dia } \\
\text { Produlo C. A ou } B\end{array}$ \\
\hline
\end{tabular}

Produto A: Voltaren ${ }^{(\mathbb{B})}$ Gelgy - comprimidos com revestimento entérico contendo $50 \mathrm{mg}$ de diclofenaco de sódio por comprimido: formulação teste 1 ou $T_{1}$.

Produto B: Voitaren Rezard ${ }^{(\bar{B})}$ Geigy - comprimidos de liberação prolongada contendo 100 mg de diclofenaco de sodio por comprimido: formulação referência ou $\mathrm{R}$.

Produto C Artren ${ }^{B}$ Merck - cápsulas gelatinosas duras com microgrãnulos de liberação prolongada contendo $100 \mathrm{mg}$ de diclofenaco de sódio por comprimido: formulaçào teste 2 ou $\mathrm{T}_{2}$.

A bioequivalência foi avaliada sempre entre uma formulação teste e a formulação referência.

Os produtos $A, B$ ou $C$ foram administrados aos voluntários em jejum em dose unica peroral de um comprimido pela manhã acompanhado por $100 \mathrm{ml}$ de água. Os voluntários receberam desjejum, almoço e lanche padronizados 
respectivamente 3,5 e 8 horas após a administraçăo do medicamento. Depois disso, seguiram uma dieta normal.

A ordem de administração das três formulaçōes a cada voluntário foi estabelecida por sorteio (Quadro a.2, A pêndice).

\subsubsection{Coleta e armazenamento de amostras}

Foram coletadas amostras de sangue $1,2,3,4,6,8,10,12$ e 24 horas após a administração do diclofenaco nas très fases. Esta coleta foi feita com seringas plásticas descartáveis mantendo-se a veia dos volunzários com Butterfly Abbott heparinizado. O plasma foi separado por centrifugaçāo e mantido em congelador a $-20^{\circ} \mathrm{C}$ até a execução da análise.

\subsection{Procedimento analítico}

As amostras de sangue foram ensaiadas em duplicata paralelamente a padrões em três concentraçōes em triplicata, conforme método descrito anteriormente no Capitulo I (Esquema analítico) [23] 


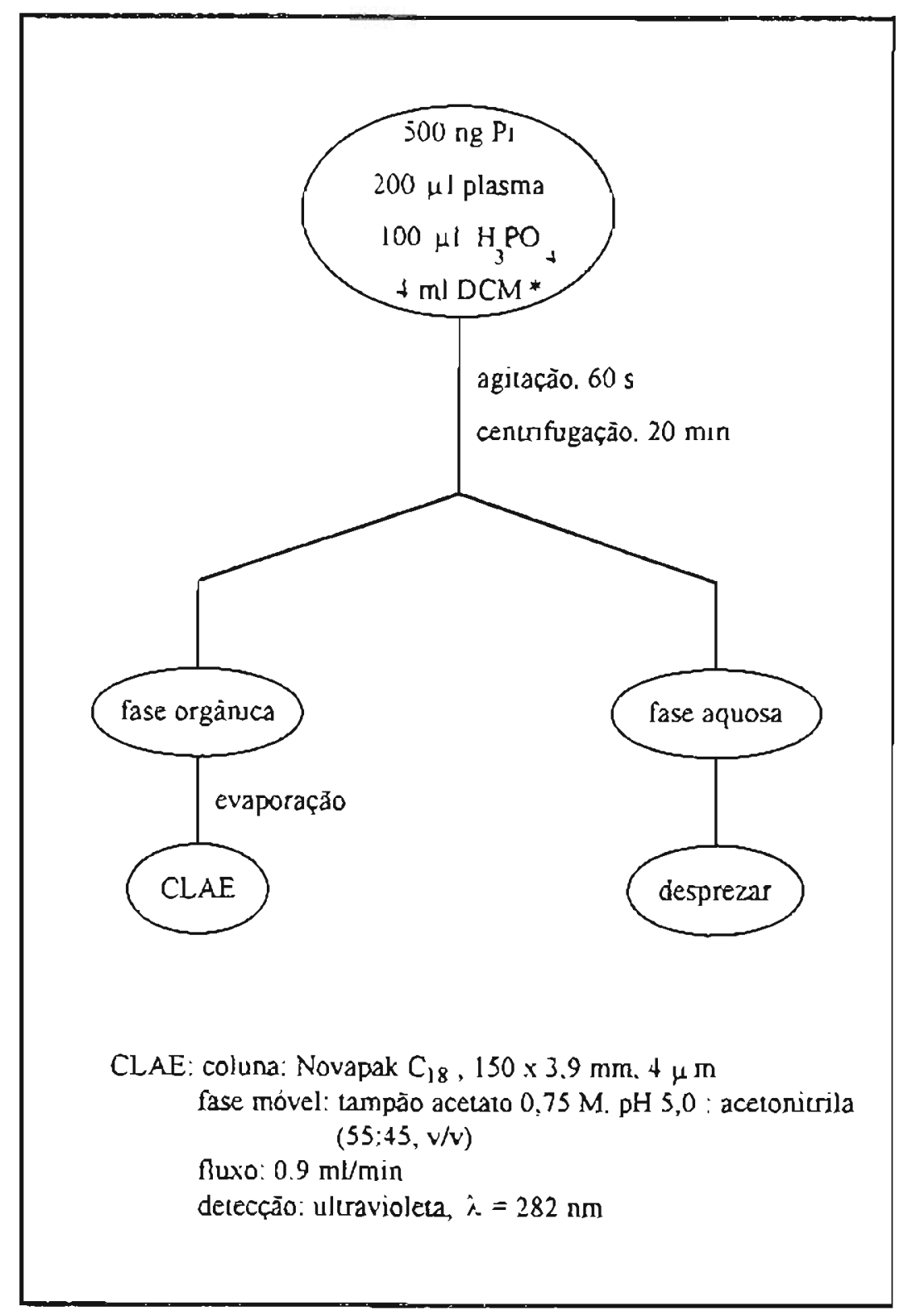

Esquema analítico: Micromérodo para determinação de diclofenaco em plasma através de cromatografia líquida de aita eficiência (CLAE). 


\subsection{Cálculos e análise estatística}

\subsubsection{Cálculos}

A bioequivalência das formulaçōes teste contendo diclofenaco de sódio frente à referência foi avaliada com base nos seguintes parâmetros farmacocinéticos $[9,21]$

- $\mathrm{C}_{\max }$ concentração plasmática máxima que o färmaco atinge após a administração peroral. É obtida a partir da curva "concentração plasmática (ng/mL) vs tempo (h)":

- $t_{\text {max }}$ : tempo necessario para que a concentração plasmática do fármaco atinja o valor de $C_{\max }$. Também é obtido a partir da curva "concentração plasmática (ng/mL) vs tempo (h)";

- UUC $_{\mathrm{T}}$ : área sob a curva "concentração plasmática $(\mathrm{ng} / \mathrm{mL})$ vs tempo (h)", calculada da seguinte forma:

$$
\mathrm{AUC}_{\mathrm{T}}=\mathbf{A U C _ { 0 . 2 4 }}+\mathbf{A U C} \mathrm{C}_{2\lrcorner-\infty} \quad(\mathrm{ng} \cdot \mathrm{h} / \mathrm{ml})
$$

onde:

$\mathrm{AUC}_{0-24}$ = área sob a curva "concentração plasmatica (ng/mL) vs tempo (h)" no intervalo de 0 a 24 horas, calculada pelo método dos trapezóides através da equaçào. 

$\mathrm{AUC}_{0.24}=\sum \mathrm{AUC}_{\text {incernato }}$
e:
AUC $_{\text {intervalo }}=\frac{\left(t_{2}-t_{1}\right)\left(C_{1}+C_{2}\right)}{2} \quad t_{1}=$ instante inicial do intervalo em que se quer determinar AUC;
$t_{2}=$ instante final do intervalo em que se quer determinar AUC;
$C_{1}=$ concentração plasmática de diclofenaco em ly e;
$\mathrm{C}_{2}=$ concentração plasmática de diclofenaco em $t_{2}$.

e:

$\mathrm{AUC}_{24-\infty}=$ área sob a curva "concentraçào plasmática $(\mathrm{ng} / \mathrm{mL})$ vs tempo (h) no intervalo de 24 h a $x$, calculada por extrapolação até infinito através da equaçāo: 


$$
\begin{aligned}
& \text { AUC }_{2\lrcorner-\infty}=\frac{C_{I\lrcorner}}{\beta} \quad C_{24}=\text { concentração plasmática de } \\
& \text { diclofenaco em } \mathrm{t}=24 \mathrm{~h} \mathrm{e} \text {; } \\
& \beta=\text { constante de velocidade de } \\
& \text { eliminação, calculada através da } \\
& \text { fórmula: } \\
& \beta=\frac{0,693}{\mathrm{t}(1 / 2)_{\beta}} \quad\left(\mathrm{h}^{-1}\right) \\
& t(1 / 2)_{\beta}=\text { meia-vida de eliminaçāo do } \\
& \text { diclofenaco, que corresponde ao } \\
& \text { tempo necessário para que a } \\
& \text { concentração plasmàtica do fármaco } \\
& \text { se reduza em } 50 \% \text {. É obtida } \\
& \text { graficamente a partir da curva } \\
& \text { "concentração plasmática (ng/mL) vs } \\
& \text { tempo }(h)^{\prime \prime} \text {. }
\end{aligned}
$$

Também determinou-se a extensão da biodisponibilidade (EBA) dos produtos teste em relação ao produto referência. A extensão da biodisponibilidade é expressa em porcentagem e caiculada através da equação: 


$$
\begin{aligned}
& \text { EBA }=\frac{\mathrm{AUC}_{\mathrm{TI}}}{\mathrm{AUC}_{\mathrm{T} r}} \times \frac{\mathrm{D}_{\mathrm{r}}}{\mathrm{D}_{1}} \times 100 \quad \mathrm{AUC}_{\mathrm{Tr}}=\mathrm{AUC}_{\mathrm{T}} \text { do produto usado } \\
& \text { como referência; } \\
& \mathrm{AUC}_{\mathrm{Tt}}=\mathrm{AUC}_{\mathrm{T}} \text { do produto teste; } \\
& \mathrm{D}_{\mathrm{r}}=\text { dose do fármaco no produto } \\
& \text { referència } e \text {; } \\
& \mathrm{D}_{\mathrm{t}}=\text { dose do fármaco no produto } \\
& \text { teste. }
\end{aligned}
$$

\subsubsection{Análise estatística}

Os resultados para os parâmetros $t_{\max }, C_{\max }$ e $A U C_{T}$ nas três fases do estudo foram comparados através de testes paramétricos (análise de variància - ANOVA "two-way" e teste de Friedman) e testes não-paramétricos (teste de Wilcoxon) [22]. Utilizaram-se na análise de variância os valores obtidos para $t_{\max }, C_{\max }$ e $A U C_{T}$ bem como a transformação logaritmica de $C_{\max }$ e $A U C_{T}$, isto $\dot{e}, \ln C_{\max }$ e $\ln A U C_{T}, A$ variação entre individuos, ou efeito individuo, foi obtida através da comparaçăo de linhas na análise de variăncia, enquanto que a variação entre formulações, ou efeito formulação, foi obtida através da comparação de colunas. Nos testes de Friedman e Wilcoxon utilizaram-se os valores obtidos para $t_{\max }, C_{\max } \in A U C_{\Upsilon}$. 


\section{Resultados}

A partir das concentraçōes plasmáticas de diclofenaco nas amostras de sangue provenientes dos voluntários foram construidas as curvas de decaimento plasmático do diclofenaco (concentração plasmática vs tempo) para cada voluntário e para cada formulação. As curvas individuais dos oito voluntários, acompanhadas dos valores dos parâmetros farmacocinéticos mais importantes para cada uma das três formulações, estão ilustradas no Apêndice. As curvas médias e medianas de decaimento plasmático do diclofenaco para cada formulaçāo podem ser vistas nas Figuras 3, 4 e 5 respectivamente para a formulação A (Voltaren ${ }^{\circledR} 50$, teste 1 ou $T_{1}$ ), a formulação B (Voltaren Retard ${ }^{\circledR} 100$, referência ou $R$ ) e a formulação C (Arien 100 , teste 2 ou $\mathrm{T}_{2}$ ).

A Figura 6 permite comparar o decaimento plasmático médio do diclofenaco após a administração de cada formulação a voluntários sadios, enquanto que a Figura 7 permite uma comparação das medianas. 


\section{CURVA DAS MEDIAS E MEDIANAS \\ Voltaren ${ }^{\mathrm{B}} 50$}
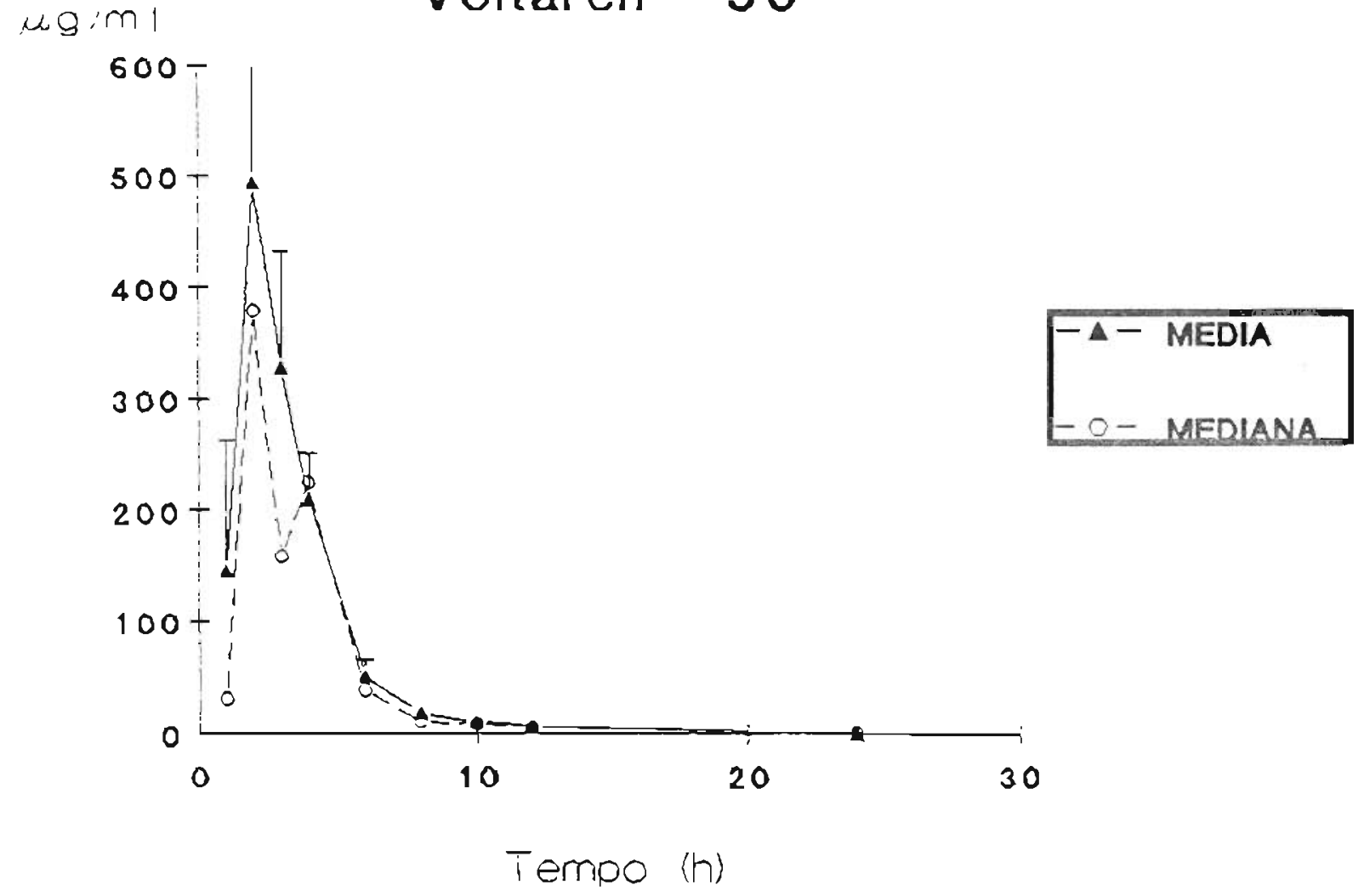

Figura 3: Curvas de decaimento plasmático do diclofenaco após adminiseração de Voltaren 50 a voluntános sadios $(n=8)$ - média e mediana. 


\section{CURVA DAS MEDIAS E MEDIANAS \\ $\mu g / m ~ I$ \\ Voltaren ${ }^{\mathrm{B}} 100$}

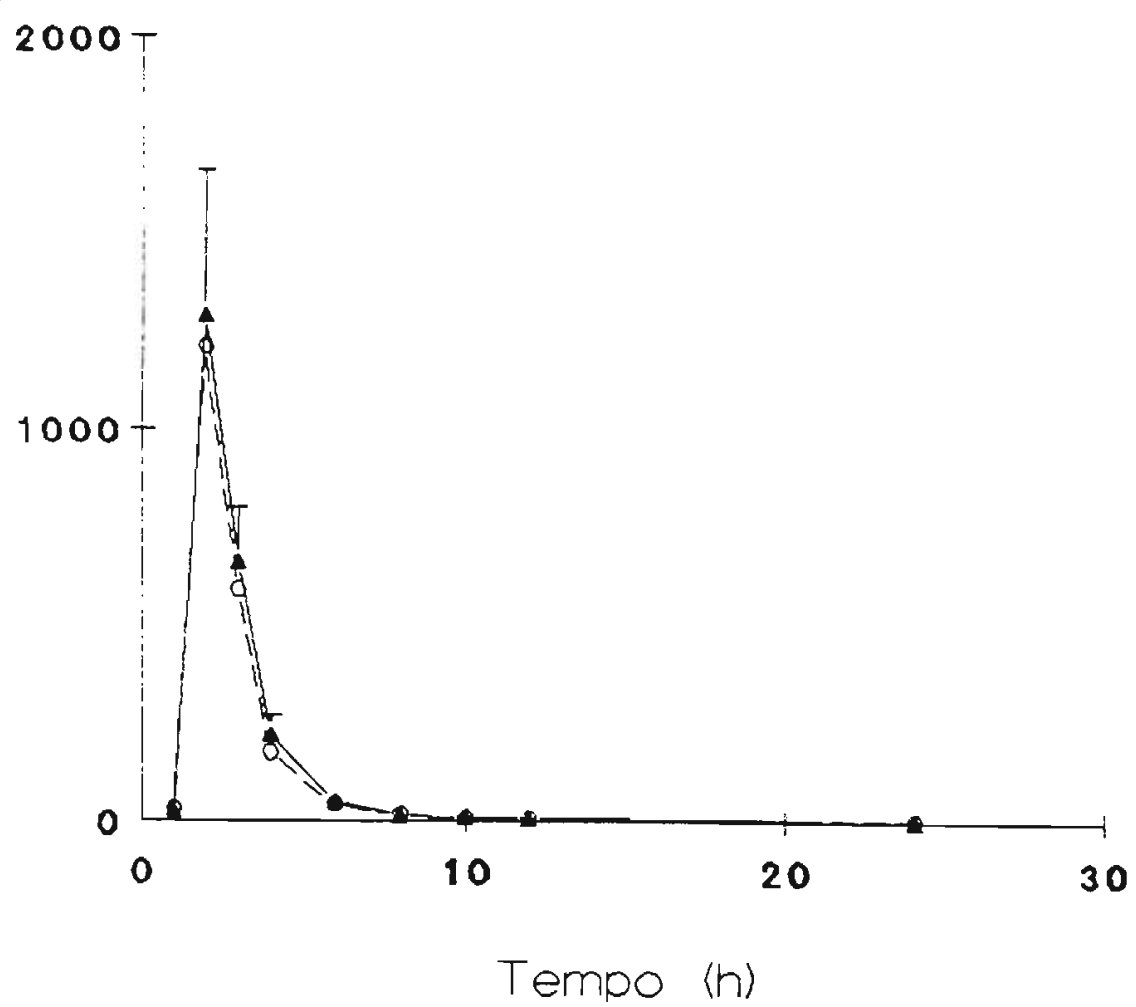

Figura 4: Curvas de decaimento plasmático do diclofenaco após administração de Voltaren Retard $^{\circledR} 100$ a voluntários sadios $(n=8)$ - média e mediana. 


\section{CURVA DAS MEDIAS E MEDIANAS Artren $^{R} 100$}

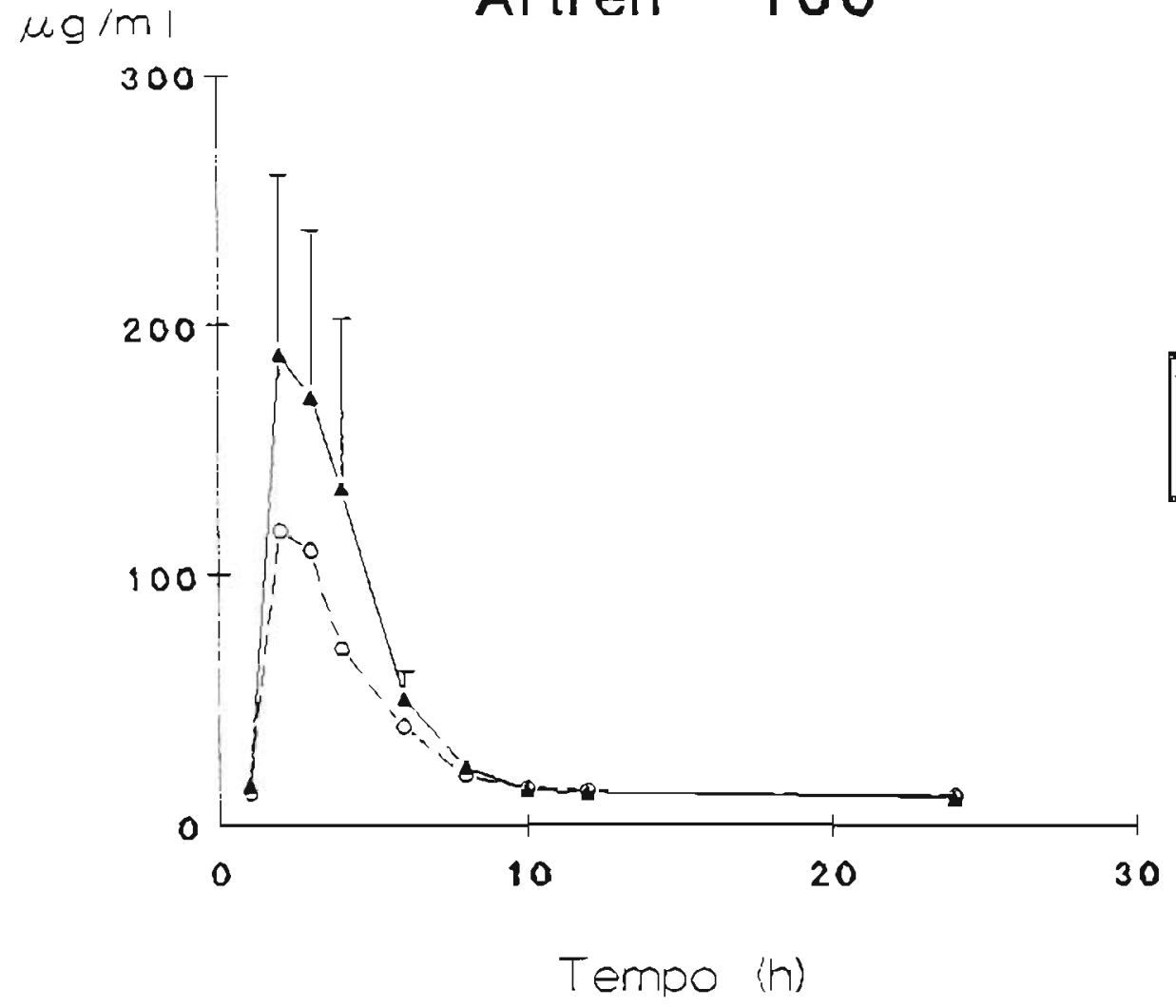

Figura 5: Curvas de decaumento plasmático do diclofenaco após administração de Artren ${ }^{(\hat{B})} 100$ a voluntarios sadios $(n=8)$ - media e mediana. 


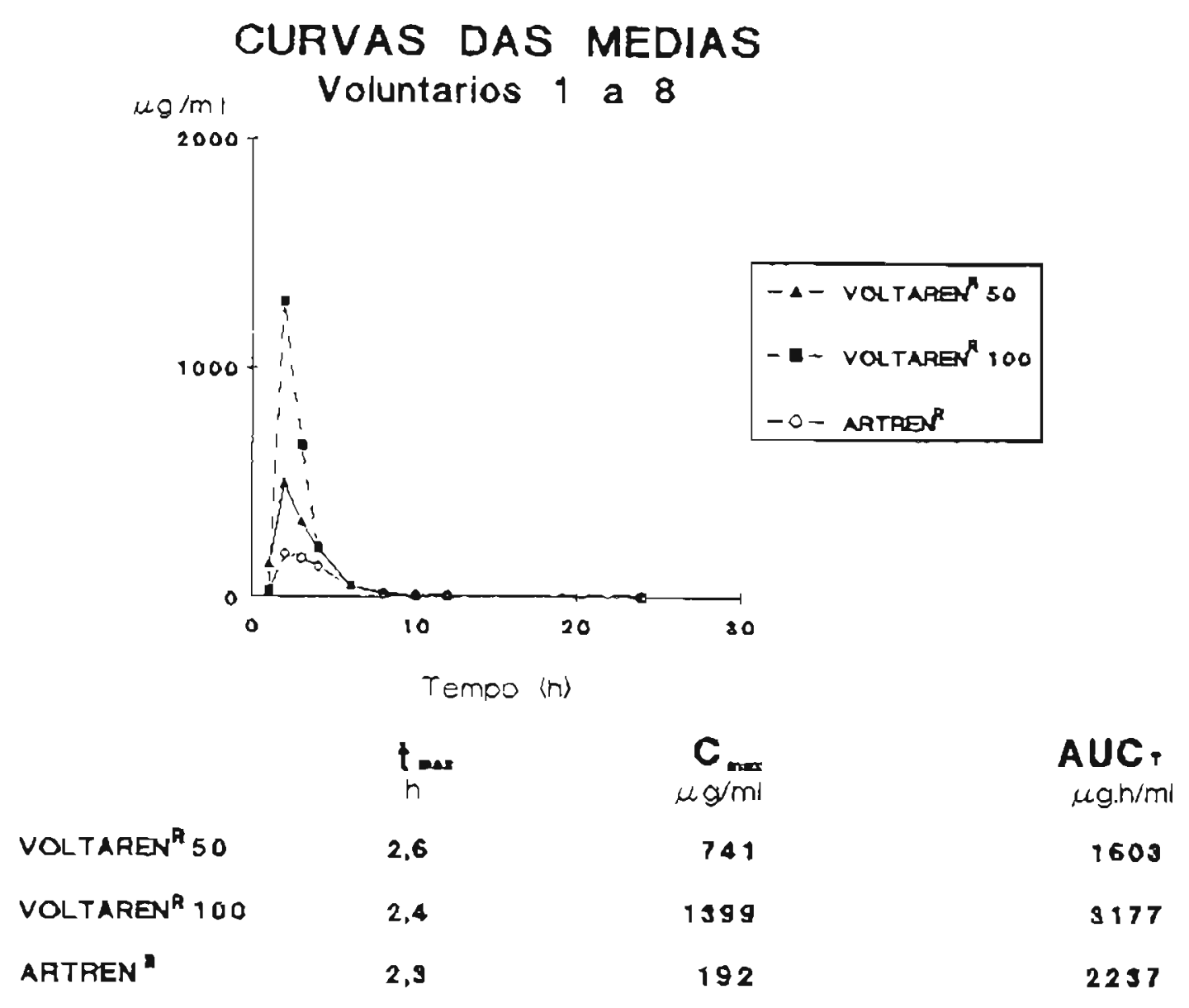

Figura 6: Curvas médias de decaimento plasmático do diclofenaco após administração de três formulaçōes contendo diclofenaco de sódio a voluntários sadios $(n=8)$. 


\section{CURVAS DAS MEDIANAS}

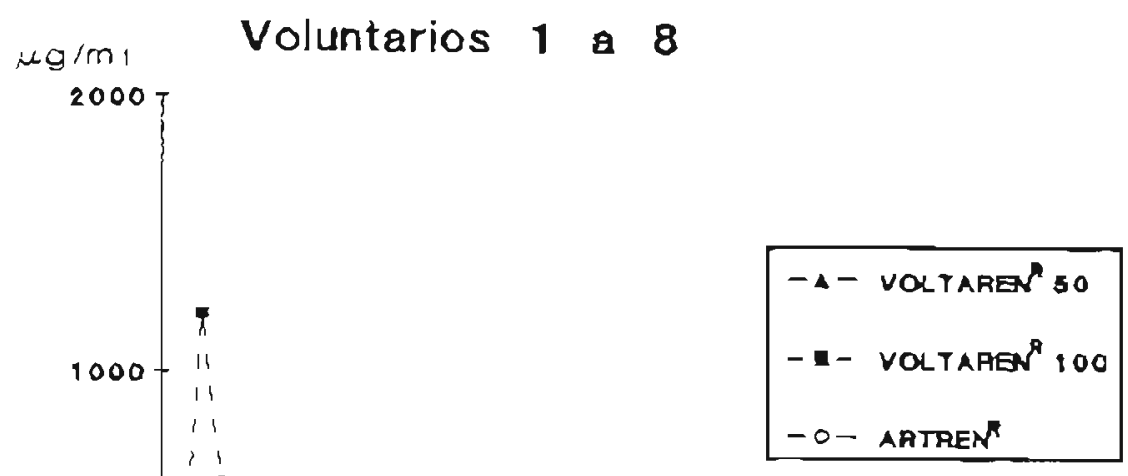

\begin{tabular}{|c|c|c|c|}
\hline VOLTAREN ${ }^{R} 50$ & 2,5 & 746 & 1666 \\
\hline VOLTAREN 100 & 2.0 & 1215 & 3081 \\
\hline ARTREN" & 2,0 & 124 & 1559 \\
\hline
\end{tabular}

Figura 7 Curvas medianas de decaimento plasmático do diclofenaco após administração de três formulações contendo diclofenaco de sódio a voluntários sadios $(n=8)$. 
As Figuras 8, 9 e 10 ilustram os valores das médias, acompanhados do respectivo erro padrão da média (EPM), e das medianas dos parâmetros $t_{\max }, C_{\max }$ e AUC $_{\mathrm{T}}$ respectivamente, obtidos a partir das curvas "concentração plasmática vs tempo" da população de voluntários investigada após ad́ministração das três formulações. 


\section{$t_{\max }$}

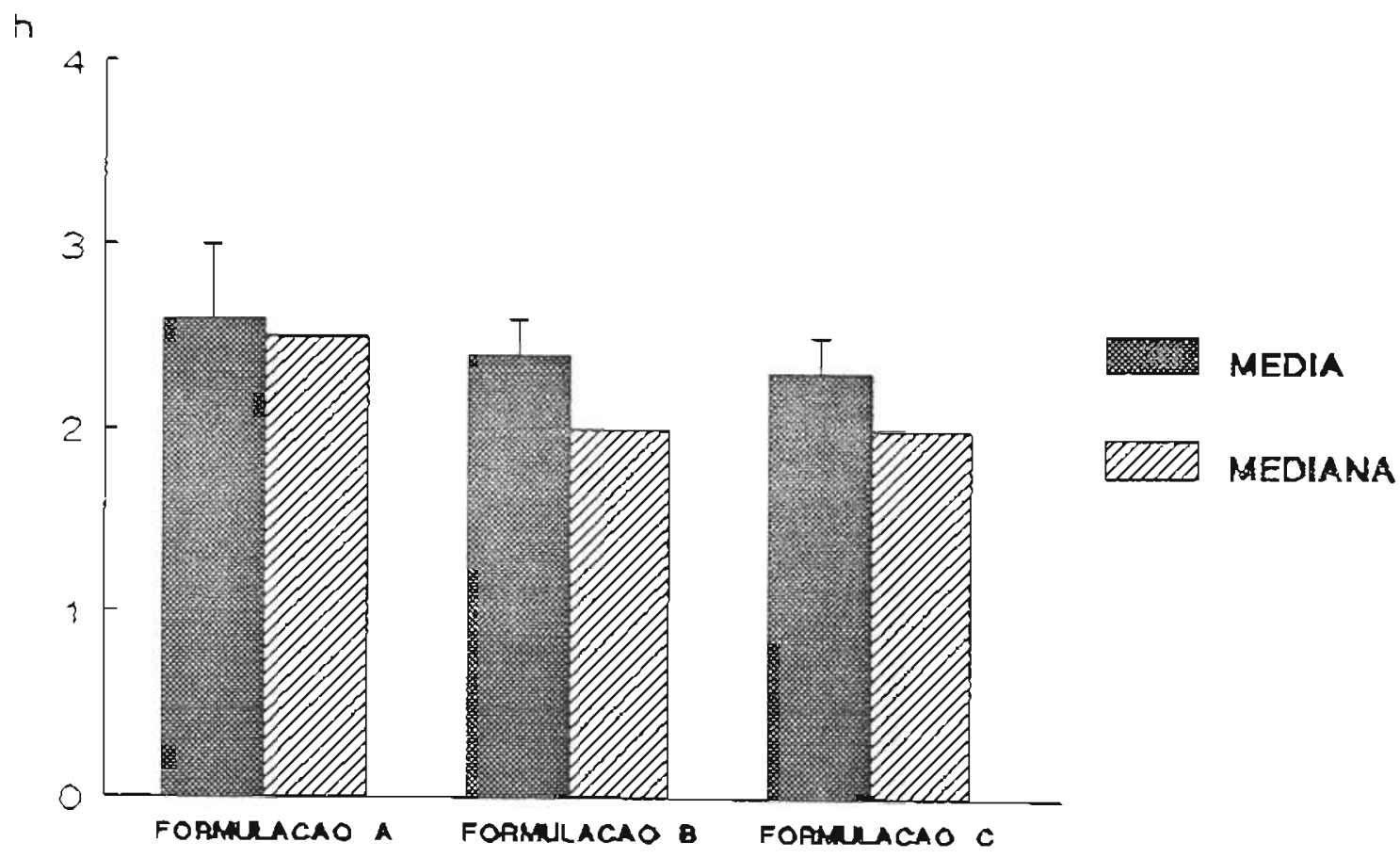

Figura 8: Valores das médias, acompanhados do respectivo erro padrão da média, e das medianas do parâmetro $t_{\max }$ após administração de três formulações contendo diclofenaco de sódio a voluntários sadios $(n=8)$. A: Voltaren ${ }^{\circledR} 50$; B: Voltaren Retard $^{(\mathbb{B}} 100 ;$ C: Artren ${ }^{\circledR} 100$. 


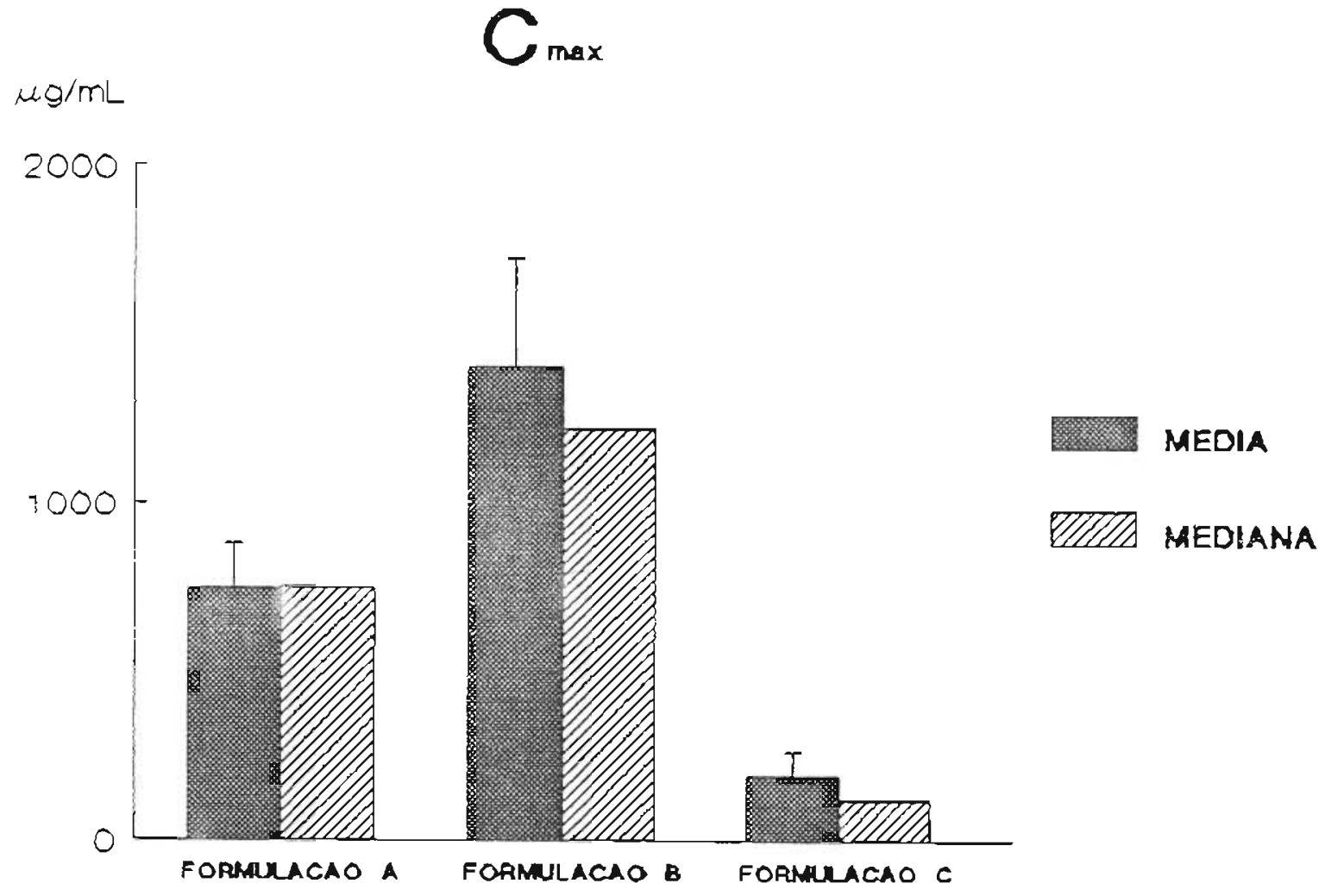

Figura 9: Valores das médias, acompanhados do respectivo erro padrão da média, e das medianas do parâmetro $\mathrm{C}_{\max }$ após administração de três formulações contendo diclofenaco de sódio a voluntários sadios $(n=8)$. A: Voltaren ${ }^{\circledR} 50$; B: Voltaren Retard $^{(\mathbb{R})}$ 100; C: Artren ${ }^{\circledR} 100$. 

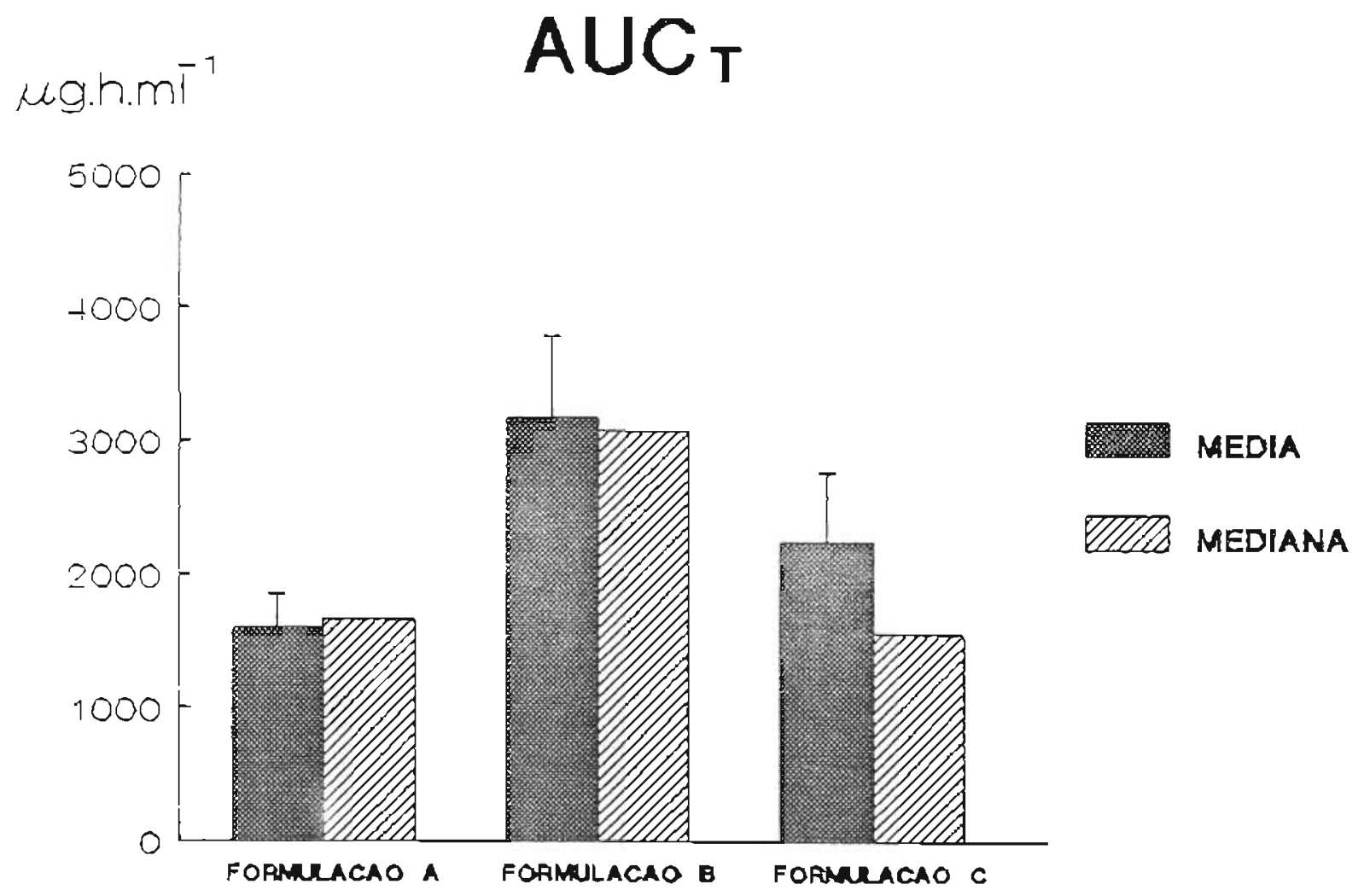

Figura 10: Valores das médias, acompanhados do respectuvo erro padrão da média, e das medianas do parâmetro $A U C_{T}$ após administração de três formulações contendo diclofenaco de sódio a voluntários sadios $(n=8)$. A: Voltaren 80 ; B: Voltaren Retard ${ }^{\circledR 1}$ 100: C: Artren ${ }^{\circledR} 100$. 
A bioequivalència das formulações teste (Voltaren ${ }^{\circledR} 50$ ou $\mathrm{T}_{1}$ e Artren ${ }^{\circledR} 100$ ou $T_{2}$ ) em relação à referência (Voltaren Retard ${ }^{\circledR} 100$ ) foi avaliada comparando-se as formulações duas a duas (teste contra referência), com base nos parâmetros $t_{\max }, C_{\max } \in A U C_{T}$.

O estudo de bioequivalência entre as formulaçōes $A$ (Voltaren ${ }^{\circledR} 50$ ou $T_{1}$ ) e B (Voltaren Retard ${ }^{\circledR}$ ou R) é ilustrado nas Tabelas 1 e 2, nas Figuras 11, 12 e 13 e no Apêndice. Verifica-se que o paràmetro $t_{\max }$ apresentou valores, em $\overline{\mathrm{X}} \pm$ EPM (mediana), de $2,4 \pm 0,2(2,0) h$ e de $2,6 \pm 0,4(2,5)$ h respectivamente para $R$ e $T_{1}$, sem diferença significativa entre as duas formulações (Tabela 1, Figura 11). Também não houve diferença significativa entre as duas formulações quando se compararam os valores $C_{\max }$ e $A U C_{T}$. Para $C_{\max }$ obtiveram-se valores, em $\bar{X} \pm$ EPM (mediana), de $1399 \pm 326(1215) \mathrm{ng} / \mathrm{ml}$ para $R$ e de $741 \pm 137(746) \mathrm{ng} / \mathrm{ml}$ para $\Upsilon_{1}$ (Tabela 1, Figura 12). Com relação ao parâmetro $A U C_{T}$ obtiveram-se valores, em $\bar{X} \pm E P M(m e d i a n a)$, de $3177 \pm 607$ (3081) $\mathrm{ng} \cdot \mathrm{h} / \mathrm{ml}$ para $\mathrm{R}$ e de $1603 \pm$ 253 (1666) $\mathrm{ng} \cdot \mathrm{h} / \mathrm{ml}$ pará $\mathrm{T}_{1}$ (Tabela 1, Figura 13) A comparação entre as transformaçōes logaritmicas dos valores de $C_{\text {max }}$ e $A U C_{\Upsilon}$ também não evidenciou diferença significativa entre $T_{1}$ e $R$. Os testes estatisticos paramétricos e não paramétricos aplicados ná análise dos dados obtidos não evidenciaram diferença significativa entre estas duas formulações. Analisando os valores das médias e as medianas obtidos para os parâmetros $\mathrm{AUC}_{\mathrm{T}}$ e $\mathrm{C}_{\max }$ (Tabela $\mathbf{1}$ ) ou para a transformação logarímica destes parâmetros observou-se que a variação do parâmetro foi proporcional à dose, isto é, uma razão de $\mathrm{AUC}_{\mathrm{T}}$ ou de $\mathrm{C}_{\max }$ entre $T_{1}$ e R de 1:2, equivale à razão de doses entre estas duas formulações. 
Tabela 1: Estudo de broequivalência entre as formulaçōes T, (Voltaren ${ }^{8}$ 50) e R (Voltaren Retard $^{(\mathbb{B})}$ 100). Paràmetros: $t_{\max }, \mathrm{C}_{\max }$ e $A U C_{\mathrm{T}}$.

\begin{tabular}{|c|c|c|c|c|}
\hline & & $\begin{array}{l}t_{\max } \\
\text { (h) }\end{array}$ & $\begin{array}{c}\mathrm{C}_{\max } \\
(\mathrm{ng} / \mathrm{ml})\end{array}$ & $\begin{array}{c}\mathrm{AUC}_{\mathrm{T}} \\
(\mathbf{n g} \cdot \mathbf{h} / \mathbf{m l})\end{array}$ \\
\hline Formulação R & & $\begin{array}{c}2.4 \pm 0.2 \\
(2,0)\end{array}$ & $\begin{array}{c}1399 \pm 326 \\
(1215)\end{array}$ & $\begin{array}{c}3177 \pm 607 \\
(3081)\end{array}$ \\
\hline Formulação $T_{1}$ & & $\begin{array}{c}2,6 \pm 0,4 \\
(2,5)\end{array}$ & $\begin{array}{c}741 \pm 137 \\
(746)\end{array}$ & $\begin{array}{c}1603 \pm 253 \\
(1666)\end{array}$ \\
\hline \multirow[t]{2}{*}{ Testes paramétricos: } & ANOVA & $p>0.05$ & $p>0,05$ & $p>0,05$ \\
\hline & Friedman & $p>0,05$ & $p>0,05$ & $p>0.05$ \\
\hline Teste não-paramétrico: & Wilcoxon & $p>0,05$ & $p>0.05$ & $p>0.05$ \\
\hline Significância & & NS* & NS & NS \\
\hline
\end{tabular}

*NS = diferença nāo significativa.

Tabela 2: Estudo de bioequivalência entre as formulaçōes $T_{I}$ (Voltaren ${ }^{\circledR} 50$ ) e R (Voltaren Retard $^{\circledR}$ 100). Parâmetros: $\ln _{\text {max }}$ e $\ln A U C_{T}$.

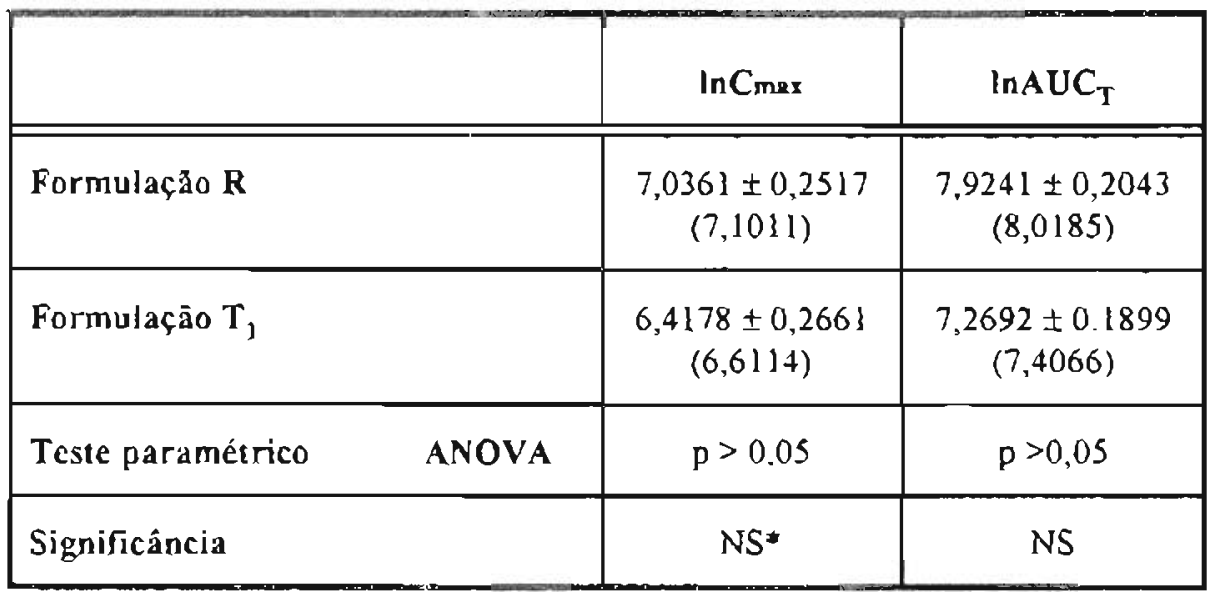

*NS = diferença năo sıgnuficautıva. 


\section{TESTE DE BIOEQUIVALENCIA - PARAMETRO $t_{\max }$}
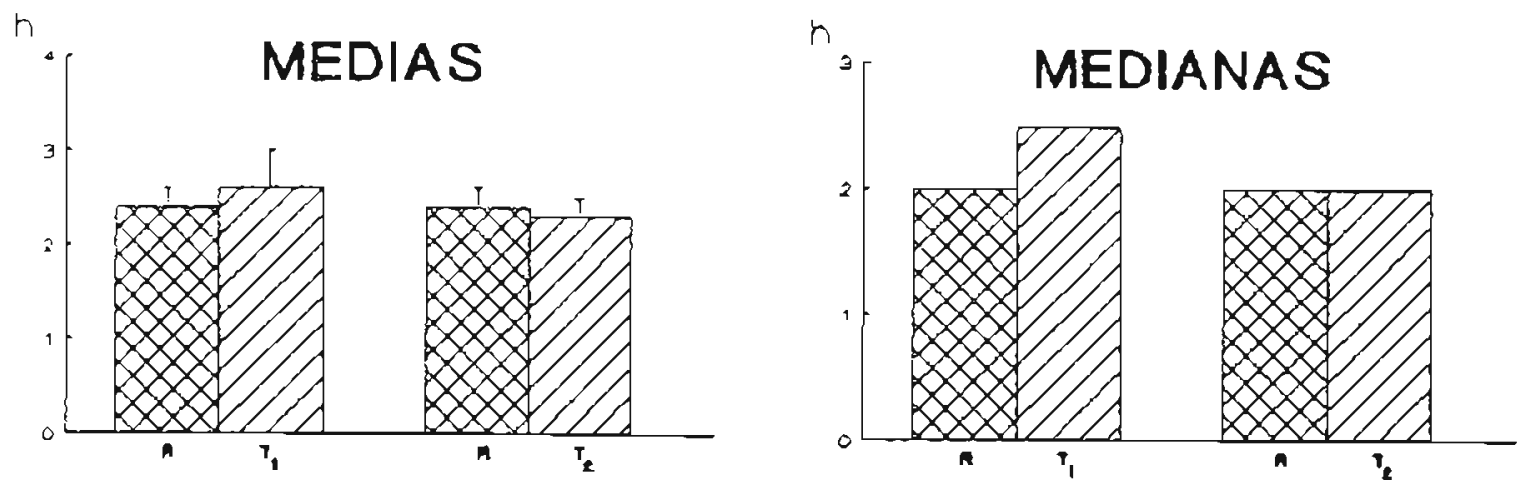

Figura 11: Comparação entre os valores médios de thax e respectivos erros padrōes da média apos adminustraçào das formulações $T_{1}$ (Voltaren ${ }^{\circledR} 50$ ), $T_{2}$ (Artren $\left.{ }^{(B)} 100\right)$ e $R\left(\right.$ Voltaren Retard $\left.{ }^{(\mathbb{R}} 100\right)$ a voluntários sadios $(n=8)$. 


\section{TESTE DE BIOEQUIVALENCIA - PARAMETRO $C_{\max }$}
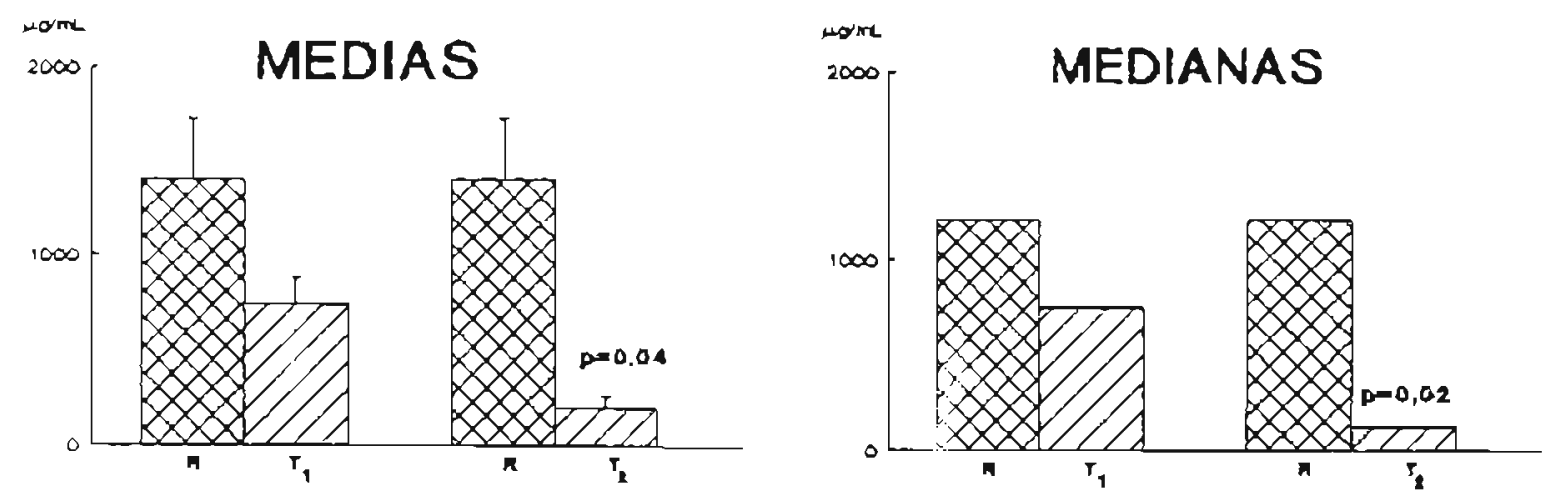

Figura 12: Comparação entre os valores médios de $C_{\max }$ e respectivos erros padrões da média após administração das formulações $T_{1}$ (Voltaren 8 50), $T_{2}$ (Artren $\left.{ }^{\circledR} 100\right)$ e R (Voltaren Retard ${ }^{(100)}$ ) a voluntários sadios $(n=8)$. 


\section{TESTE DE BIOEQUiVALENCIA - PARAMETRO AUC}
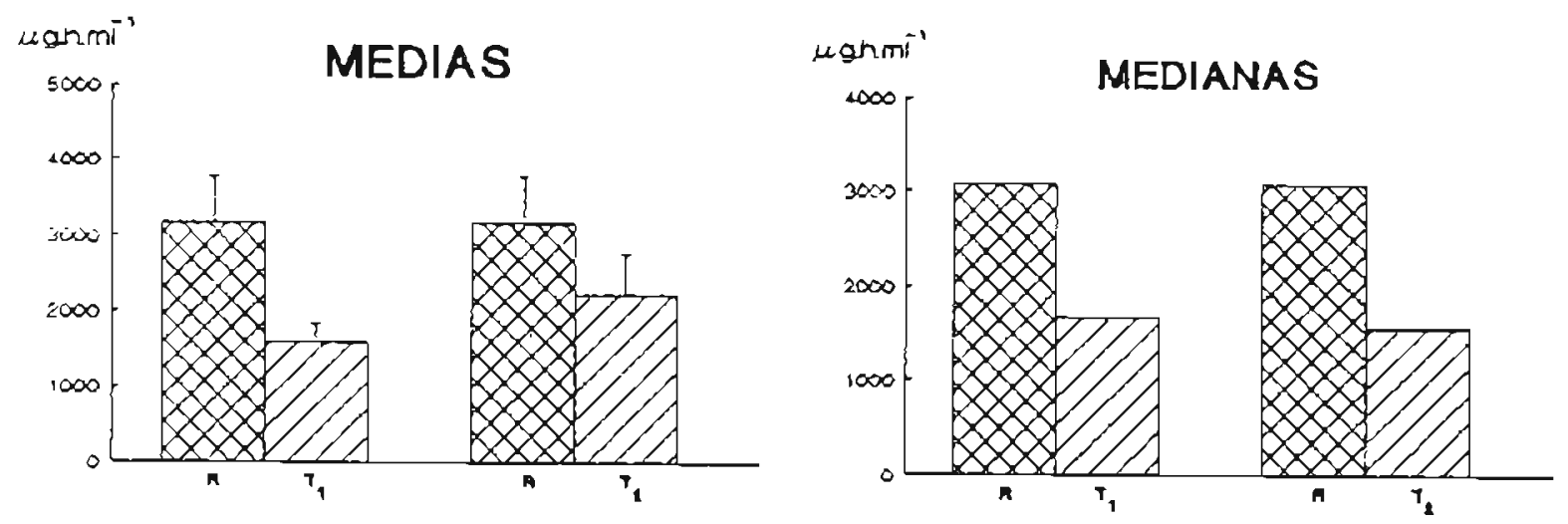

Figura 13: Comparação enure os valores médios de $A U C_{T}$ e respectivos erros padrōes da média após administraçào das formulaçōes $T_{1}$ (Voltaren $\left.{ }^{(B)} 50\right), T_{2}$ (Arten $\left.{ }^{\circledR} 100\right)$ e R (Voltaren Retard $\left.{ }^{\circledR} 100\right)$ a voluntários sadios $(n=8)$. 
Os resultados indicam ainda que a população estudada foi bastante homogênea, uma vez que só se observou "efeito individuo" na análise de variância (ANOVA) para o parâmetro $t_{\max }$, mas não para $C_{\max }$ ou $A U C_{T}$, apesar do número de voluntários ser apenas oito (Apêndice).

O produto referência (Voltaren Retard ${ }^{\circledR} 100$ ) é indicado como formulação de liberação prolongada. Em vista disso, e com base em estudos anteriores, era esperado que o Voltaren Retard ${ }^{\circledR}$ fosse bioinequivalente quando comparado ao Voltaren 80 , o que não aconteceu (Tabelas 1 e 2 ). Além disso era esperado que a curva "concentração plasmática vs tempo" do diclofenaco após administração de Voltaren Retard ${ }^{\circledR} 100$ apresentasse um decaimento mais lento que a mesma curva após administração de Voltaren ${ }^{8}$, o que também não foi observado (Figura 3). A extensão da biodisponibilidade (EBA) do diclofenaco no produto Voltaren ${ }^{\circledR} 50$ foi (em $\bar{X} \pm E P M) 138 \pm 35 \%$, com mediana de $123 \%$ (Tabela 3 ). 
Tabela 3: Extensāo da biodisponibilidade da formulação $T_{1}$ (Voitaren ${ }^{\circledR} 50$ ) em relação à formulação R (Voltaren Retard $\left.{ }^{\circledR} 100\right)$.

\begin{tabular}{|c|c|c|c|}
\hline Voluntário & $\begin{array}{l}\mathrm{AUC}_{\text {rT1 }} \\
(\mathrm{ng} \cdot \mathrm{b} / \mathbf{m l})\end{array}$ & $\underset{(\mathrm{ng}-\mathrm{h} / \mathrm{ml})}{\mathbf{A U C}_{\mathbf{T}}}$ & $\begin{array}{l}\text { EBA } \\
(\%)\end{array}$ \\
\hline 1 & 1918 & 1550 & 247 \\
\hline 2 & 938 & 1424 & 132 \\
\hline 3 & 2108 & 1425 & 296 \\
\hline 4 & 1080 & 6051 & 36 \\
\hline 5 & 533 & 3602 & 30 \\
\hline 6 & 2358 & 2560 & 184 \\
\hline 7 & 2475 & 4385 & 113 \\
\hline 8 & 1414 & 4418 & 64 \\
\hline$\overline{\mathrm{X}}{ }^{*}$ & 1603 & 3177 & 138 \\
\hline$M E D^{* *}$ & 1666 & 3081 & 123 \\
\hline DP† & 715 & 1716 & 98 \\
\hline EPM+ & 253 & 607 & 35 \\
\hline
\end{tabular}

* $\overline{\mathrm{X}}=$ média

**MED = mediana

$\dagger \mathrm{DP}=$ desvio padrão da média

${ }_{\ddagger} E \mathrm{P} M=$ erro padrão da média 
Considerando-se agora o estudo de bioequivalência entre as formulações C (Artren ${ }^{\circledR} 100$ ou $T_{2}$ ) e B (Voltaren Retard ${ }^{\circledR}$ ou R) ilustrado nas Tabelas 4 e 5 , nas Figuras 11, 12 e 13 e no Apêndice observa-se que não houve diferença significativa entre as duas formulaçōes para $O$ parâmetro $t_{\max }$, que apresentou valores, em $\bar{X} \pm E P M$ (mediana), de $2,4 \pm 0,2(2,0)$ h para $R$ e de $2,3 \pm 0,2(2,0) \mathrm{h}$ para $T_{2}$ (Tabela 4, Figura 11). Em relação ao parâmetro $A U C_{T}$ obtiveram-se valores, em $\bar{X} \pm \mathrm{EPM}$ (mediana), de $3177 \pm 607$ (3081) $\mathrm{ng} \cdot \mathrm{h} / \mathrm{ml}$ para $\mathrm{R}$ e de $2237 \pm$ 529 (1559) para $T_{2}$ (Tabela 4, Figura 11), sem diferença significativa. Finalmente, quando se avaliou o parâmetro $C_{\max }$, obtiveram-se valores, em $\overline{\mathrm{X}} \pm$ EPM (mediana) de $1399 \pm 326(1215) \mathrm{ng} / \mathrm{ml}$ para R e del $92 \pm 70(124) \mathrm{ng} / \mathrm{ml}$ para $\mathrm{T}_{2}$ (Tabela 4, Figura 12), evidenciando diferença significativa entre as formulaçōes $\mathrm{C}$ e B para esse parâmetro. A análise de variância (ANOVA) das transformaçōes logarítmicas dos valores de $\mathrm{C}_{\max }$ e de $A U \mathrm{C}_{\mathrm{T}}$ tambérn nào revelou diferença estatística entre as formulações para o parâmetro $\mathrm{AUC}_{\Upsilon}$ enquanto que comprovou a existência de differença estatística para $C_{\max }$ (Tabela 5) 
Tabela 4 Estudo de bioequivalêncıa entre as formulaçōes $T_{2}$ (Arren ${ }^{\circledR}$ 100) e $R$ (Voltaren

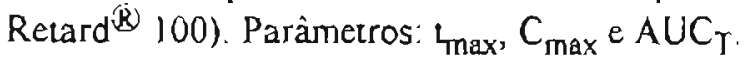

\begin{tabular}{|c|c|c|c|c|}
\hline & & (max & $\underset{(n g / m l)}{C \max }$ & $\begin{array}{c}\mathrm{AUC}_{\mathrm{T}} \\
(\mathrm{ng} \cdot \mathrm{h} / \mathrm{ml})\end{array}$ \\
\hline Formulação R & & $\begin{array}{c}2.4 \pm 0,2 \\
(2,0)\end{array}$ & $\begin{array}{c}1399 \pm 326 \\
(1215)\end{array}$ & $\begin{array}{c}3177 \pm 607 \\
(3081)\end{array}$ \\
\hline Formulaçð̄o $T_{2}$ & & $\begin{array}{c}2,3 \pm 0,2 \\
(2,0)\end{array}$ & $\begin{array}{c}192 \pm 70 \\
(124)\end{array}$ & $\begin{array}{c}2237 \pm 529 \\
(1559)\end{array}$ \\
\hline Testes paramétricos: & $\begin{array}{l}\text { ANOVA } \\
\text { Friedman }\end{array}$ & $\begin{array}{l}p>0,05 \\
p>0,05\end{array}$ & $\begin{array}{l}p=0,012 \\
p=0,039\end{array}$ & $\begin{array}{l}p>0,05 \\
p>0,05\end{array}$ \\
\hline Teste nāo-paramétrico: & Wilcoxon & $p>0,05$ & $p=0.021$ & $p>0,05$ \\
\hline Significância & & NS* & $S^{* *}$ & NS \\
\hline
\end{tabular}

*NS = diferença não significauva.

* $\mathrm{S}=$ diferença signıficativa.

Tabela 5: Estudo de bioequivalência entre as formulaçōes $T_{2}$ (Artren ${ }^{(B)} 100$ ) e R (Voltaren Retard@ 100). Parâmetros: $\ln C_{\max }$ e lnAUC $C_{\mathrm{T}}$.

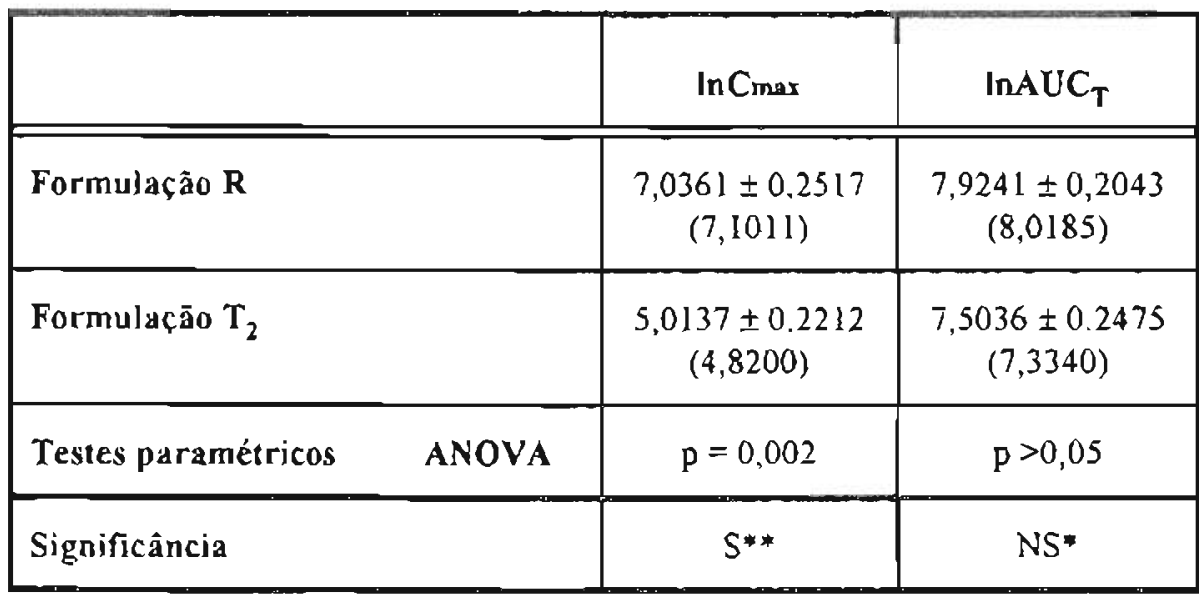

*NS = diferença não signuficativa

* $S$ = diferença significauva 
Nesta fase do estudo a análise de variância (ANOVA) revelou que năo ocorreu o "efeito indivíduo" (Apêndice).

Os testes estatísticos paramétricos e não-paramétricos aplicados à análise dos dados obtidos não evidenciaram diferença significativa entre as formulações $C$ (Artren ${ }^{\circledR} 100, T_{2}$ ) e $B\left(\right.$ Voltaren Retard ${ }^{\circledR} 100, R$ ) para os parâmetros $t_{\max } e$ $\mathrm{AUC}_{\mathrm{T}}$. Entretanto, houve diferença significativa entre as duas formulações para o parâmetro $C_{\max }$, comprovada por três testes estatisticos, evidenciando bioinequivalência entre as formulações $\mathrm{C}$ e B.

O produto Artren ${ }^{\circledR} 100$, também indicado como de liberação prolongada, apresentou usna curva "concentração plasmática vs tempo" com decaimento lento e com um patamar onde a concentração de diclofenaco se manteve mais ou menos constante, conforme era esperado (Figuras 5 e 6). O Artren ${ }^{\circledR} 100$ foi bioinequivalente ao produto referência (Voltaren Retard ${ }^{(100)}$ ), apresentando valores de $C_{\max }$ significativamente menores que os deste último (Tabelas 4 e 5 ). A extensão da biodisponibilidade (EBA) do diciofenaco no produto Artren ${ }^{\circledR} 100$ foi (em X $\pm E P M) 102 \pm 35 \%$, com mediana de $68 \%$ (Tabela 6). 
Tabela 6: Extensão da biodisponibilidade da formulação $T_{2}$ (Artren ${ }^{\circledR} 100$ ) em relação à formulação R (Voltaren Retard ${ }^{\circledR} 100$ ).

\begin{tabular}{|c|c|c|c|}
\hline Voluntário & $\begin{array}{l}\mathrm{AUC}_{\mathrm{TT2}} \\
(\mathrm{ng} \cdot \mathbf{h} / \mathrm{ml})\end{array}$ & $\begin{array}{c}{ }_{(\mathbf{A U C}} \\
(\mathbf{n g} \cdot \mathbf{h} / \mathbf{m l})\end{array}$ & $\begin{array}{l}\text { EBA } \\
(\%)\end{array}$ \\
\hline 1 & 3438 & 1550 & 222 \\
\hline 2 & 4050 & 1424 & 284 \\
\hline 3 & 913 & 1425 & 64 \\
\hline 4 & 1222 & 6051 & 20 \\
\hline 5 & 729 & 3602 & 20 \\
\hline 6 & 1848 & 2560 & 72 \\
\hline 7 & 2475 & 4385 & 101 \\
\hline 8 & 4424 & 4418 & 29 \\
\hline$\overline{\mathbf{X}}^{\star}$ & 2237 & 3177 & 102 \\
\hline$M E D^{* *}$ & 1559 & 3081 & 68 \\
\hline DP† & 1496 & 1716 & 99 \\
\hline EPM $\ddagger$ & 529 & 607 & 35 \\
\hline
\end{tabular}

* $\overline{\mathrm{X}}$ = média

** $\mathrm{MED}=$ mediana

$\dagger D P=$ desvio padrão da média

$\ddagger E P M=$ erro padrão da média 


\section{Discussão}

As formas farmcêuticas de liberação prolongada contendo diclofenaco de sódio têm, como objetivo, minimizar os efeitos colaterais no trato gastrointestinal causados por picos de concentração além de aumentar o intervalo de tempo entre as doses, baseando-se numa liberaçăo mais lenta e prolongada do fármaco no organismo, o que permite que a concentração plasmática se mantenha dentro dos niveis terapêuticos por um intervalo de tempo mais longo que o obtido com os produtos comuns de liberação rápida [1].

Devido à importância do diclofenaco de sódio na terapia de doenças inflamatórias, várias formulações de liberação prolongada contendo este fármaco têm sido pesquisadas, principalmente comprimidos $[1,2,19]$ e supositórios [20]. Diversas formulações de liberação prolongada contendo diclofenaco de sódio encontram-se disponiveis no mercado e, devido ao seu amplo uso, torna-se importante avaliar até que ponto essas formulações são eficazes em evitar picos de concentraçào e em manter niveis plasmáticos adequados de diclofenaco durante um longo periodo de tempo Möller e colaboradores avaliaram em voluntários três formulações contendo diclofenaco de sódio, sendo uma de liberação rápida e duas de liberação prolongada (comprimidos e cápsulas contendo microgrânulos) [17]. A administração das formulações de liberação prolongada originou valores de concentração plasmática máxima de diclofenaco ao redor de $450 \mathrm{ng} / \mathrm{ml}$ enquanto que, após administração da formulação de liberação rápida, obtiveram-se valores de concentração plasmática máxima de aproximadamente $1400 \mathrm{ng} / \mathrm{ml}$. Além disso, o 
periodo de tempo em que a concentração plasmática de diclofenaco manteve-se dentro dos niveis terapêuticos foi bem maior após a administração das formulações de liberação prolongada (cerca de 12 horas) do que após a administração da formulação de liberação rápida (cerca de 4 horas). Outra formulação de liberação prolongada foi avaliada por Fowler e colaboradores e também esta mostrou-se eficiente em evitar picos muito elevados de concentração plasmática de diclofenaco e em manter os niveis plasmáticos de diclofenaco dentro da faixa terapêutica por um longo intervalo de tempo [8]. Neste caso, o diclofenaco atingiu sua concentraçāo plasmática máxima cerca de quatro horas após a administração, com valores de aproximadamente $220 \mathrm{ng} / \mathrm{ml}$, e manteve-se na faixa terapêutica por 10 horas.

Com base nos resultados aqui obtidos sugere-se que o produto escolhido como referência (Voltaren Retard ${ }^{\circledR} 100$ ) apresentou um comportamento semelhante ao produto de liberação rápida (Voltaren ${ }^{50}$ ) quanto à desintegração do comprimido e liberação do fármaco no organismo, já que ambos apresentaram picos de concentração cerca de duas horas após a administração seguidos de decaimento plasmático rápido do diclofenaco. Este comportamento era esperado para o Voltaren ${ }^{\circledR} 50$, mas não para o Voltaren Retard ${ }^{\circledR} 100$, indicado pelo fabricante como produto de liberação prolongada e que, portanto, deveria apresentar não um pico, mas um patamar de concentração, seguido de decaimento lento do diclofenaco plasmático.

Neste caso considerou-se o comportamento inesperado como decorrente de um problema de produção do lote de Voltaren Retard ${ }^{\circledR} 100$ usado neste estudo, uma vez que em outros estudos realizados no Centro Avançado de Estudos em 
Farmacologia Clínica, utilizando comprimidos de Voltaren Retaro ${ }^{\circledR} 300$ provenientes de outros lotes, este último comportou-se como formulação de liberação prolongada. Também Gross e colaboradores, em estudo com Voltaren Retard ${ }^{\circledR} 100$, descrevem-no como formulação de liberação prolongada originando picos de concentração plasmática de diclofenaco entre duas e oito horas após a administração mais baixos que os originados pelo Voltaren ${ }^{\circledR} 50[10]$.

Esse fato evidencia a necessidade de se realizarem estudos periódicos para avaliação da biodisponibilidade dos produtos de liberação prolongada. Considerando que este tipo de formulação tem como principal objetivo aumentar o intervalo de tempo entre as doses por prolongamento do tempo de ação e diminuir os efeitos colaterais é fácil notar que falhas de produção como as evidenciadas por este estudo comprometem seriamente a eficácia terapêutica deste tipo de formulação e que a realizaçào periódica de estudos de biodisponibilidade e bioequivalência é extremamente importante para detectar este tipo de falha e permitir sua correçào industrial.

Com relação ao Artren ${ }^{\circledR} 100$, os resultados obtidos indicam que este produto se comporou como forma de liberação prolongada, apresentando niveis baixos de concentração plasmática, mas que se mantiveram constantes durante um intervalo de tempo prolongado. Os baixos niveis obtidos se devem, provavelmente, a uma liberação ultra-lenta do fármaco no organismo, com maior degradaçăo por eliminação pré-sistêmica durante o processo absortivo. Entretanto, estes baixos niveis de concentração plasmática não devem comprometer a aficácia clínica do produto. uma vez que a concentração minima eficaz do diclofenaco é cerca de 50 $\mathrm{ng} / \mathrm{ml}[20]$ 
Este estudo mostra a existência de diferenças importantes entre três formulações comerciais contendo diciofenaco de sódio quanto à biodisponibilidade do fármaco. Assim, a substituição de uma formulação por outra no tratamento crônico de pacientes deve ser precedida por análise cuidadosa das caracteristicas de cada uma delas e das necessidades do paciente, com o objetivo de evitar diminuição na eficácia clínica da terapia ou aumento de efeitos colaterais.

\section{Conclusões:}

Com base no trabalho desenvolvido conclui-se que:

- o produto Voitaren ${ }^{\circledR} 50$ se comportou como formulação de liberação rápida com $\mathrm{EBA}(\mathrm{em} \mathrm{X} \pm \mathrm{EPM})=138 \pm 35 \%$ (mediana $=123 \%)$ do produto referência (Voltaren Retard ${ }^{\circledR} 100$ ).

- o produto Arren ${ }^{\circledR} 100$ se comportou como formulação de liberação prolongada com EBA (em X $\pm \mathrm{EPM})=102 \pm 35 \%$ (mediana $=68 \%$ ) do produto referência (Voltaren Retard ${ }^{\circledR} 100$ );

- o produto referência (Voltaren Retard $\left.{ }^{\circledR} 100\right)$ se comportou como formulação de liberação rápida, devido a provável falha de impermeabilização do núcleo central do comprimido no processamento industrial deste lote $\mathrm{e}$; 
- os produtos Voltaren ${ }^{\circledR} 50$ e Voltaren Retard ${ }^{\circledR} 100$ se mostraram bioequivalentes neste estudo enquanto Arren ${ }^{\circledR} 100$ e Voltaren Retard ${ }^{\circledR} 100$ se mostraram bioinequivalentes.

\section{Referências bibliográficas}

I ACARTÜRK, F Preparation of a prolonged-release tablet formulation of diclofenac sodium. Pan 1: using chitosan. Pharmazie, Berlin, v. 44, n. 8, p. $547-549,1989$.

2. ACARTÜRK, F. Preparation of a prolonged-release tablet formulation of diclofenac sodium. Part 2: using chitin. Pharmazie, Berlin, v. 44, n. 9, p. $621-622,1989$

3. BIJLSMA, A. The long-term efficacy and tolerability of Voltaren (diclofenac sodium) and indomethacin in rheumatoid arthritis. Scand. J. Rheumatol. Suppl., Stockholm, v. 22, p. 74-80, 1978.

4. BIJLSMA, A, TEN PAS, J.G. A study of the anti-inflammatory effect of Voltaren in patients with rheumatoid arthritis. Scand. J. Rheumatol. Suppl., Stockholm, v. 22, p. 46-50, 1978.

5. CAR, A., JAJIC, I, KRAMPAC, I., VITAUS, M, ZENIC, N, ZIVKOVIC, M. A double-blind multicentre comparison of diclofenac sodium and naproxen 
in osteoanhrosis of the hip. Scand. J. Rheumatol. Suppl., Stockholm, v. 22, p. $63-68,1978$.

6. CHAN, K.K.H., VYAS, K.H., BRANDT, K.H In vitro protein binding of diclofenac sodium in plasma and synovial fluid. J. Pharm. Sci., Washington, v. 76, n. 2, p. 105-108, 1987.

7. CICCOLUNGHI, S.N., CHAUDRI, H.A., SCHUBIGER, B.I., REDDROP, R. Report on a long-term tolerability study of up to two years with diclofenac sodium (Voltaren). Scand. J. Rheumatol. Suppl., Stockholm, v. 22, p. $86-96,1978$

8. FOWLER, P.D., DAWES, P.T., JOHN, V.A., SHOTTON, P.A. Plasma and synovial fluid concentration of diclofenac sodium and its hydroxylated metabolites during once-daily administration of a $100 \mathrm{mg}$ slow-release formulation. Eur. J. Clin. Pharmacol., Berlin, v. 31, p. 469-472, 1986.

9 GIBALDl, M. Biopharmaceutics and clinical pharmacokinetics. $4^{\mathrm{a}} \mathrm{ed}$ Philadelphia: Lea \& Febiger, 1991. p. 146-175.

10. GROSS, W., KROH, J., KREBS, A., ZÖLLER, H. Diclofenac sodium; blood concentration of the slow-release form and influence on the metabolism of kallikrein. Arzneim.-Forsch., Aulendorf, v. 34, n. 10, p. 1327-1329, 1984.

11. HERZFELDT, C.D, BREHM, R. Drug release - Test USP XXI. Pharm. Ztg., Frankfun, v. 132, n. 7. p. 360-364, 1987. 
12. HULTIN, M., OLANDER, K.J. A clinical trial of the analgesic properties of Voltaren (diclofenac sodium). Scand. J. Rheumatol. Suppl., Stockholm, v. 22, p. $42-45,1978$.

13. KAJANDER, A, MARTIO, J. Diclofenac sodium (Voltaren) and naproxen in the treatmentm of rheumatoid arthritis: a comparative double-blind study. Scand. J. Rheumatol. Suppl., Stockholm, v. 22, p. 57-62, 1978.

14. LAMY, P.P. Generic equivalents: issues and concerns. J. Clin. Pharmacol., New York, v. 26, n. S. p. 309-316, 1986

15. MÖLLER, H. Biopharmaceutical assessment of modified release oral dosage forms. Pharm. Ind., Aulendorf, v. 48, n. 5, p. 514-519, 1986

16. MÖLLER, H., STÜBER, W., CZECHANOWSKI, B., GUNDERT-REMY, U. Bioverfügbarkeit von Diclofenac-Fertigarzneimitteln für die orale, rektale un intramuskuläre Applikation. 2. Mitteilung. Pharm. Ztg., Frankfurt, v. 129. n 46, p 2841-2844, 1984

17. MÖLLER, H., STÜBER, W, RENNHARD, D. Bioverfügbarkeit, in vivo- und in vitro-Freisetzung von oralen Diclofenac-Retardformen-1. Mitteilung. Pharm. Ztg, Frankfur, v. 129, n. 41, p. 2387-2392, 1984.

18. MUTRU, O., PENTTLÄ, M., PESONEN, J., SALMELA, P., SUHONEN, O., SONCK, T. Diclofenac sodium (Voltaren) and indomethacinin the ambulatory treatment of rheumatoid arthritis: a double-blind multicentre study. Scand. J. Rheumatol., Suppl., Stockholm, v. 22, p. 51-56, 1978. 
19. NISHIHATA, T. Simple formulation of sustained-release tablets of sodium diclofenac and examination in humans. Int. J. Pharm., Amsterdam, v. 40, p. $125-128,1987$

20. NISHIHATA、T, SUDHO, M., KAMADA, A., KEIGAMI, M., FUJIMOTO, T., KAMIDE, S, TATSUMI, N. Investigation of sustained-release suppository of sodium diclofenac in humans. Int. J. of Pharm., Amsterdam, v. 33, p. 181-186, 1986.

21. RITSCHEL, W.A. Handbook of basic pharmacokinetics. $3^{a}$ ed., Bethesda: Drug Intelligence Publications, 1986

22. SACHS, L Applied statistics $2^{\mathrm{a}}$ ed., New York: Springer, 1984.

23. SANTOS, S.R.C.J., DONZELLA, H., BERTOLINE, M.A, PEREIRA, M.D., OMOSAKO, C.E., PORTA, V. Simplified micromethod for the HPLC measurement of diclofenac in plasma. Braz. J. Med. Biol. Res., Ribeirão Preto, v. 25, p. 125-128, 1992.

24 SHAMS, M.A., MOHAMED, H.F. Binding study of diclofenac sodium to serum albumin. Pharm. Ind., Aulendorf, v. 46, n. 12, p. 1289-1291, 1984.

25. SMALL, R. Diclofenac sodium. Clin. Pharm., Bethesda, v. 8, p. 545-558, 1989

26 SORENSEN, K. A long-term investigation of a new antirheumatic drug, diclofenac sodium (Voltaren), Scand. J. Rheumatol. Suppl., Stockhoim, $\vee 22$, p. $81-85,1978$. 
27 TERHAAG, B., LE PETIT, G., RICHTER, K., ROGNER, M Zur Beziehung von in-vitro- und in-vivo- Untersuchungen beim Menschen am Beispiel von Diclofenac Suppositorien. Pharmazie, Berlin, v. 40, n. 11, p. 784-786, 1985

28. TODD, A.P., SORKIN, E.M. Diclofenac sodium. A reappraisal of its pharmacokinetic properties, and therapeutic efficacy. Drugs, Auckland, v.35, p. $244-285,1988$.

29. VALTONEN, E.J. A comparative short-term trial with Voltaren (diclofenac sodium) and naproxen in soft tissue rheumatism. Scand. J. Rheumatol. Suppl., Stockhoim, v. 22, p. 69-73, 1978.

30 VENTAFRIDDA, V., TOSCANI, F., TAMBURNI, M., CORLI, O., GAlluCCI, M., GOTTliEB, A., SPERANZA, R, CONNO, F. Sodium naproxen versus sodium diclofenac in cancer pain control. Arzneim.-Forsch., Aulendorf, v. 40, n. 10, p. 1132-1134, 1990.

31. WILLIS, J.V., KENDALL, M.J., JACK, D.B. The influence of food on the absorption of diclofenac after single and multiple oral doses. Eur. J. Clin. Pharmacol., Berlin, v. 19, p. 33-37, 1981. 


\begin{abstract}
Bioavailability of diclofenac in two test formulations was compared to a reference after single oral dose to healthy adult volunteers of both sex. Formulations were administered after a fasting night following a randomized study protocol. Blood samples were collected at $1,2,3,4,6,8,10,12$ and 24 hours after dose administration. Diclofenac plasma levels were measured by HPLC technique using a reversed phase system after single extraction with organic solvent in acidic medium. Peaks were monitored at UV-282 nm. Based on "plasma concentration vs time" curves, parameters were determined, expressed as $\overline{\mathrm{X}} \pm \mathrm{SEM}: \mathrm{C}_{\max }=741 \pm$ $137 \mathrm{ng} / \mathrm{ml}$ and $t_{\max }=2,6 \pm 0,4 \mathrm{~h}$, product $A, C_{\max }=1399 \pm 326 \mathrm{ng} / \mathrm{ml}$ and $\mathrm{t}_{\max }=2,4 \pm 0,2 \mathrm{~h}$, product $\mathrm{B}$ and $C_{\max }=192 \pm 70 \mathrm{ng} / \mathrm{ml}$ and $t_{\max }=2,3 \pm 0,2 \mathrm{~h}$, product $C \mathrm{AUC}_{\mathrm{T}}$ values, determined by trapezoidal rule and integration to infinity, were, expressed as $\bar{X} \pm$ SEM: $1603 \pm 253 \mathrm{ng} \cdot \mathrm{h} / \mathrm{m}$, product $A, 3177 \pm 606 \mathrm{ng} \cdot \mathrm{h} / \mathrm{m}$, product B and $2237 \pm 529 \mathrm{ng} \cdot \mathrm{h} / \mathrm{ml}$, product C. Bioavailability (EBA) of diclofenac in test products $(A, B)$ was calculated against reference $(B)$. EBA, expressed as $\bar{X}$ $\pm \operatorname{SEM}$ (median), were: $138 \pm 35$ (123) \%, product A and $102 \pm 35(68) \%$, product C. Based on this data formulation $A$ and $B$ are bioequivalents while $C$ and $B$ are not bioequivalents. There is a strong evidence that product $B$, slow-release formulations, as described by the manufacturer, presented fast-release properties.
\end{abstract}


Apêndice 
Quadro a.1: Características dos voluntários.

\begin{tabular}{|c|c|c|c|c|c|c|c|}
\hline Voluntário & & sero & $\begin{array}{l}\text { idade } \\
\text { (anos) }\end{array}$ & $\begin{array}{l}\text { altura } \\
(\mathrm{cm})\end{array}$ & $\begin{array}{c}\text { peso real } \\
(\mathrm{kg})\end{array}$ & $\begin{array}{c}\text { peso ideal* } \\
(\mathrm{kg})\end{array}$ & $\begin{array}{c}\text { DPI** } \\
(\%)\end{array}$ \\
\hline I (SS) & NFt & $F$ & 41 & 172 & 56 & 65 & -14 \\
\hline $2(O P)$ & $F \ddagger$ & F & 32 & 168 & 55 & 61 & -10 \\
\hline $3(\mathrm{HD})$ & $\mathrm{F}$ & $F$ & 24 & 170 & 72 & 63 & 14 \\
\hline $4(\mathrm{CB})$ & $\mathrm{F}$ & $F$ & 23 & 165 & 58 & 0 & 0 \\
\hline $5(\mathrm{~PB})$ & $F$ & $M$ & 24 & 175 & 65 & 68 & -4 \\
\hline $6(\mathrm{ll})$ & $N F$ & $M$ & 22 & 167 & 55 & 60 & -8 \\
\hline 7 (RF) & NF & $M$ & 19 & 169 & 55 & 62 & -11 \\
\hline $8(\mathrm{MA})$ & NF & $M$ & 28 & 173 & 80 & 66 & 21 \\
\hline
\end{tabular}

${ }^{*}$ peso ideal $=($ altura $(\mathrm{cm})-100) \times 0,9$

**DPI = desvio porcentual do peso ideal

DPI $=[$ (peso real - peso ideal $) /$ peso ideal $\} \times 100$

$\nmid N F=$ não fumante

$\ddagger F=$ fumante 


\section{Termo de Consentimento Pós-informaçāo}

Nome do voluntário / Jdade.

Registro e / ou documento de identificaça 1

Título do projeto: Bioequivalència de formulaçðes contendo díclofenaco de sódio.

Declaro que em _l' ${ }^{\prime}$ _ concordei voluntariamente em participar, como voluntario, do projeto de pesquisa acima referido. Fui devidamente informado em detalhes que:

1. O estudo implica em que eu me submeta a procedimentos, exames complementares e tratamentos devidamente planejados, cujos eventuais riscos me foram explicados:

2. Os procedimentos não incluem, necessariamente, os já reconhecidos como aplicáveis e podem visar à avaliação de tratamentos novos ou a compará-los com os tradicionais;

3. Nào sou obrigado a conunuar participando do projeto e posso. a qualquer momento, sair do mesmo,

4. Meu consentimento aplica-se, igualmente, a paricipar da pesquisa como componente do grupo controle, podendo receber substâncias inócuas ou inativas, com a finalidade de dimensionar o "efeilo placebo":

5. A pesquisa não será feita se houver, relacionados à mesma, grandes riscos para mim. Da mesma forma. caso algurn risco proibitivo venha a se revelar no decurso do estudo. o pesquisador se compromete a me alenar sobre o fato e a suspender de imediato minha participação como voluntário.

Observaçōes complementares:

assinanua do voluntário

São Paulo. de de 
Quadro a.2: Protocolo de administração das formulaçōes aos voluntários.

\begin{tabular}{|c|c|c|c|}
\hline Voluntário & Fase I & Fase II & Fase III \\
\hline \hline 1 & Produto A & Produto B & Produto C \\
2 & Produto B & Produto C & Produto A \\
3 & Produto C & Produto A & Produto B \\
4 & Produto A & Produto B & Produto C \\
5 & Produto B & Produto C & Produto A \\
6 & Produto C & Produto A & Produto B \\
7 & Produto A & Produto B & Produto C \\
8 & Produlo B & Produto C & Produto A \\
\hline
\end{tabular}




\section{VOLUNTARIO 1 - S.S.}

$\mu \mathrm{g} / \mathrm{m} \mathrm{I}$

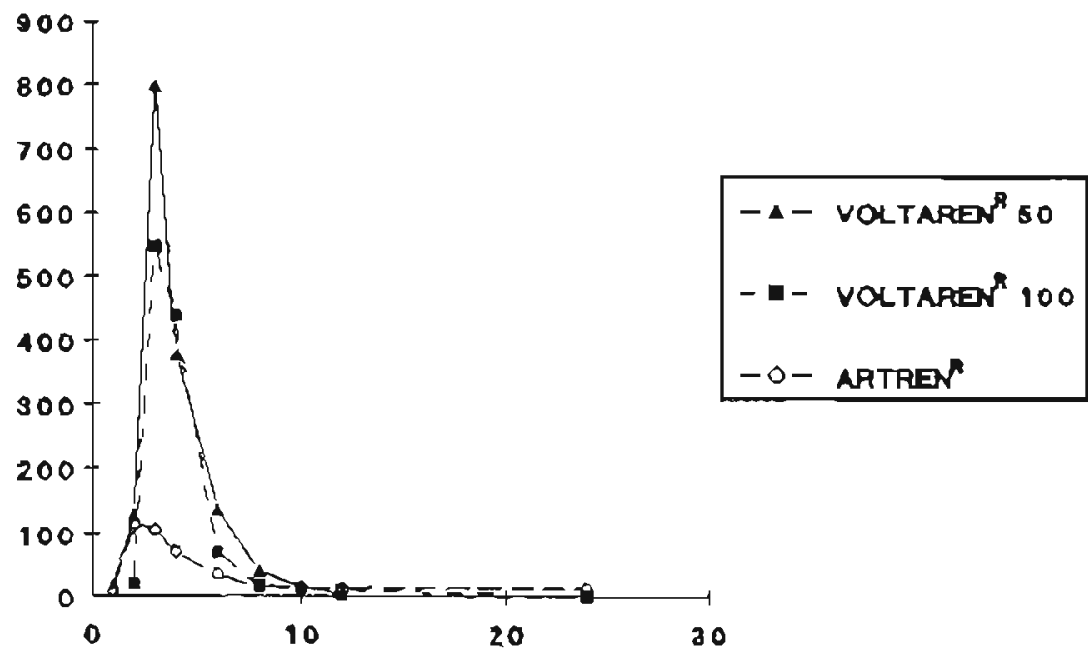

Tempo $\langle h\rangle$

$\begin{array}{ccc}t_{n} & C_{\max } & \begin{array}{r}\text { AUC } \\ \mu g / m l\end{array} \\ 3,0 & 800 & 1918 \\ 3,0 & 547 & 1550 \\ 2,0 & 115 & 3438\end{array}$

Figura a.1: Curvas de decaimento plasmático do díclofenaco após administração de três formulaçōes contendo diclofenaco de sódio - Voluntário l. 


\section{VOLUNTARIO 2 - O.P.}

$\mu g / m$



\begin{tabular}{|c|c|c|c|}
\hline & $t_{n}$ & $\mathbf{C}_{\max }$ & $\begin{array}{l}\mathbf{A U C}_{\mathbf{T}} \\
\mu \mathrm{g} \cdot \mathrm{h} / \mathrm{ml}\end{array}$ \\
\hline VOLTAREN ${ }^{8} 50$ & 4,0 & 938 & 938 \\
\hline VOLTAREN ${ }^{A} 100$ & 3,0 & 403 & 1424 \\
\hline ARTREN $\mathbf{R}$ & 2,0 & 681 & 405 \\
\hline
\end{tabular}

Figura a.2. Curvas de decaimento plasmático do diclofenaco após administração de três formulaçōes contendo diclofenaco de sódio - Voluntário 2. 


\section{VOLUNTARIO 3 - H.D.}

$\mu g / m 1$

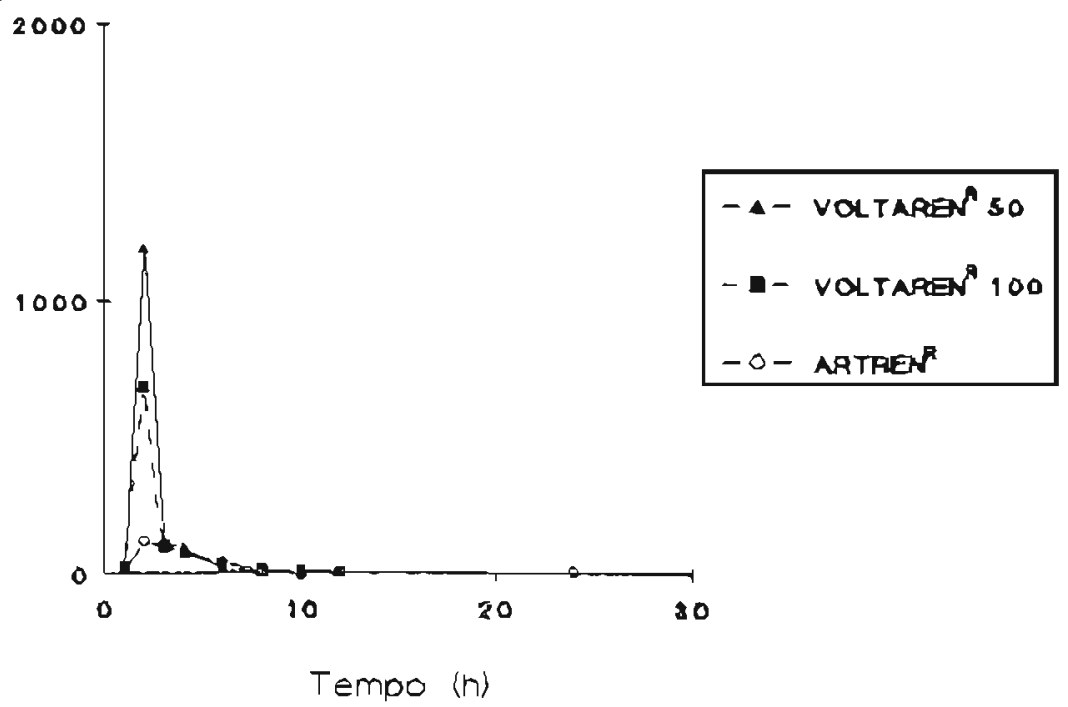

\begin{tabular}{|c|c|c|}
\hline$t_{h}$ & $C_{\mu g / m l}$ & $\begin{array}{l}\mathbf{A U C}_{\boldsymbol{T}} \\
\mathrm{g} \cdot \mathrm{n} / \mathrm{m}\end{array}$ \\
\hline 2,0 & 1190 & 2108 \\
\hline 2.0 & 682 & 1425 \\
\hline 2,0 & 121 & 913 \\
\hline
\end{tabular}

Figura a.3: Curvas de decaimento plasmático do diclofenaco após administração de três formulações contendo diclofenaco de sódio - Voluntário 3. 
VOLUNTARIO 4 - C.B.

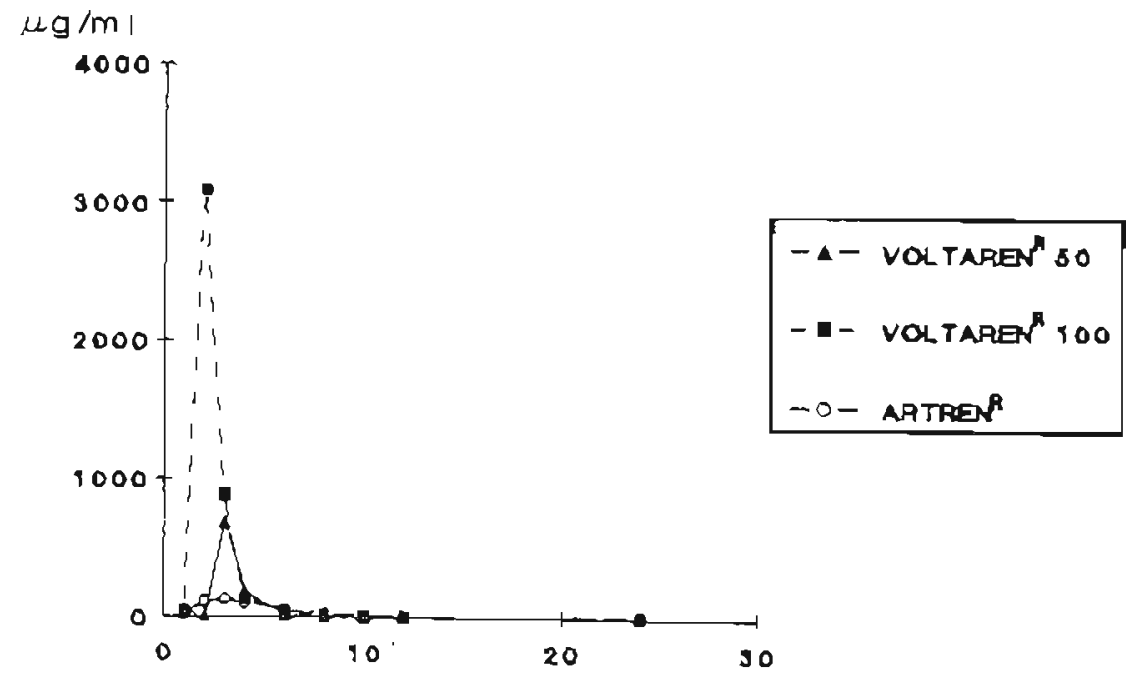

Tempo \{h\}

\begin{tabular}{|c|c|c|c|}
\hline & $t_{t}$ & $\mathbf{C}_{\max }$ & $\underset{\mu g . h / m l}{\text { AUC }^{\top}}$ \\
\hline VOLTAREN & 3,0 & 588 & 1080 \\
\hline VOLTAREN ${ }^{R} 100$ & 2,0 & 3088 & 6051 \\
\hline ARTREN ${ }^{R}$ & 3.0 & 130 & 1222 \\
\hline
\end{tabular}

Figura a.4: Curvas de decaimento plasmático do diclofenaco após admunistração de três formulaçães contendo diclofenaco de sódio - Voluntáno 4. 
VOLUNTARIO 5 - P.B.

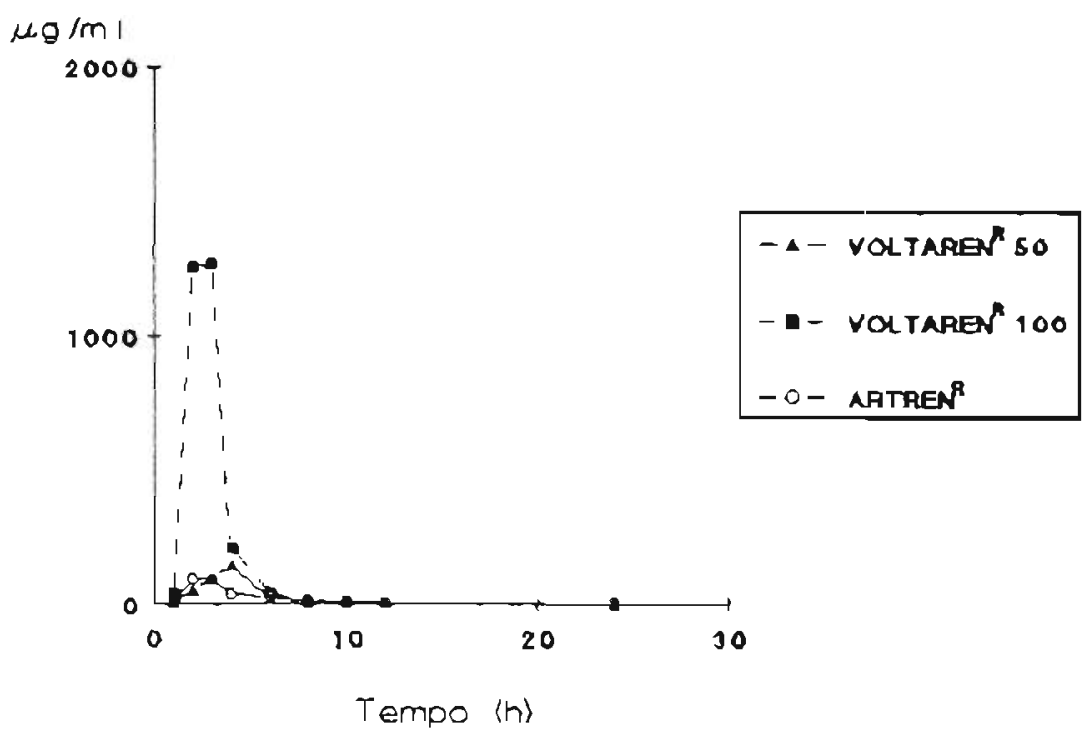

\begin{tabular}{|c|c|c|c|}
\hline & $t_{n}$ & $\underset{\mu g / m i}{C_{\text {max }}}$ & $\underset{\mu \mathrm{g} . \mathrm{n} / \mathrm{m} \mid}{\mathrm{AUS}}$ \\
\hline VOLTAREN ${ }^{R_{50}}$ & 4,0 & 145 & 533 \\
\hline VOLTAREN ${ }^{R} 100$ & 3,0 & 1268 & 3602 \\
\hline ARTREN ${ }^{\mathrm{P}}$ & 2,0 & 95 & 729 \\
\hline
\end{tabular}

Figura a.5: Curvas de decaimento plasmático do diclofenaco apos administração de três formulaçòes contendo diclofenaco de sodı - Voluntário 5 


\section{VOLUNTARIO 6 - I.L.}

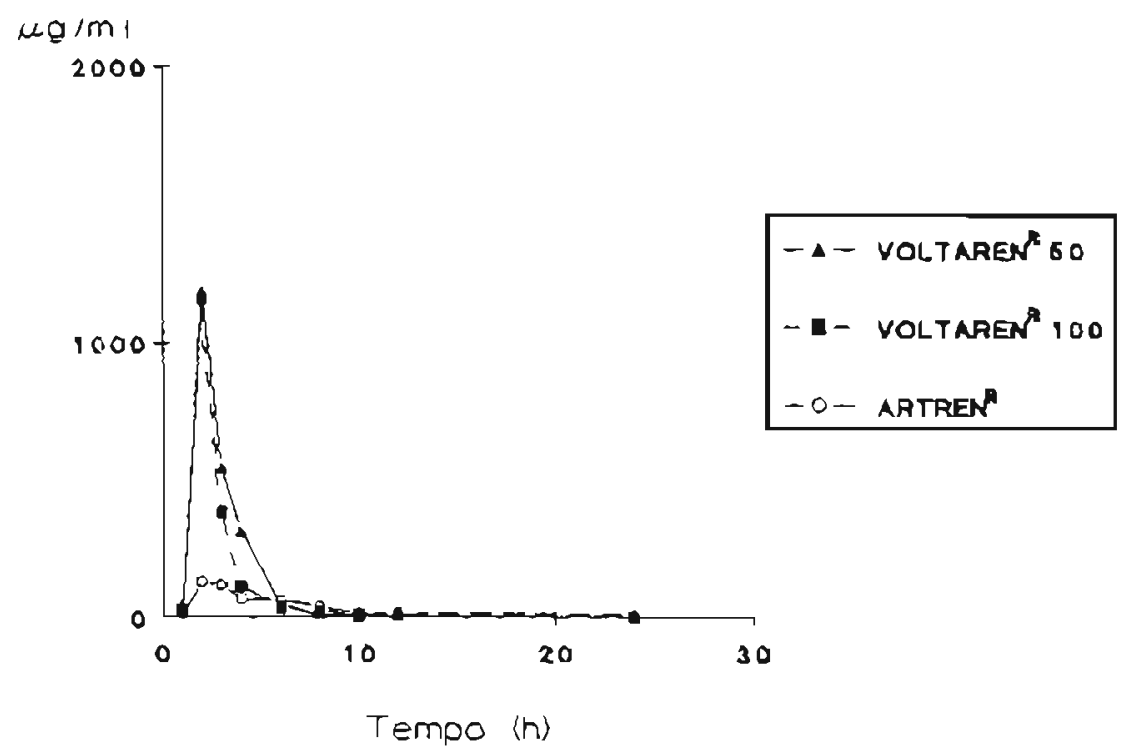

\begin{tabular}{|c|c|c|c|}
\hline & $t_{n}$ & $\mathbf{C}_{\max }$ & $\underset{\mu g h / m}{\text { AU }}$ \\
\hline VOLTAREN 50 & 2,0 & 1190 & 2359 \\
\hline VOL TAREN ${ }^{q} 100$ & 2,0 & 1161 & 2560 \\
\hline ARTREN ${ }^{R}$ & 2,0 & 127 & 1848 \\
\hline
\end{tabular}

Figura a.6: Curvas de decaimento plasmático do diclofenaco após administração de três formulaçōes contendo diclofenaco de sódio - Voluntário 6. 


\section{VOLUNTARIO 7 - R.F.}

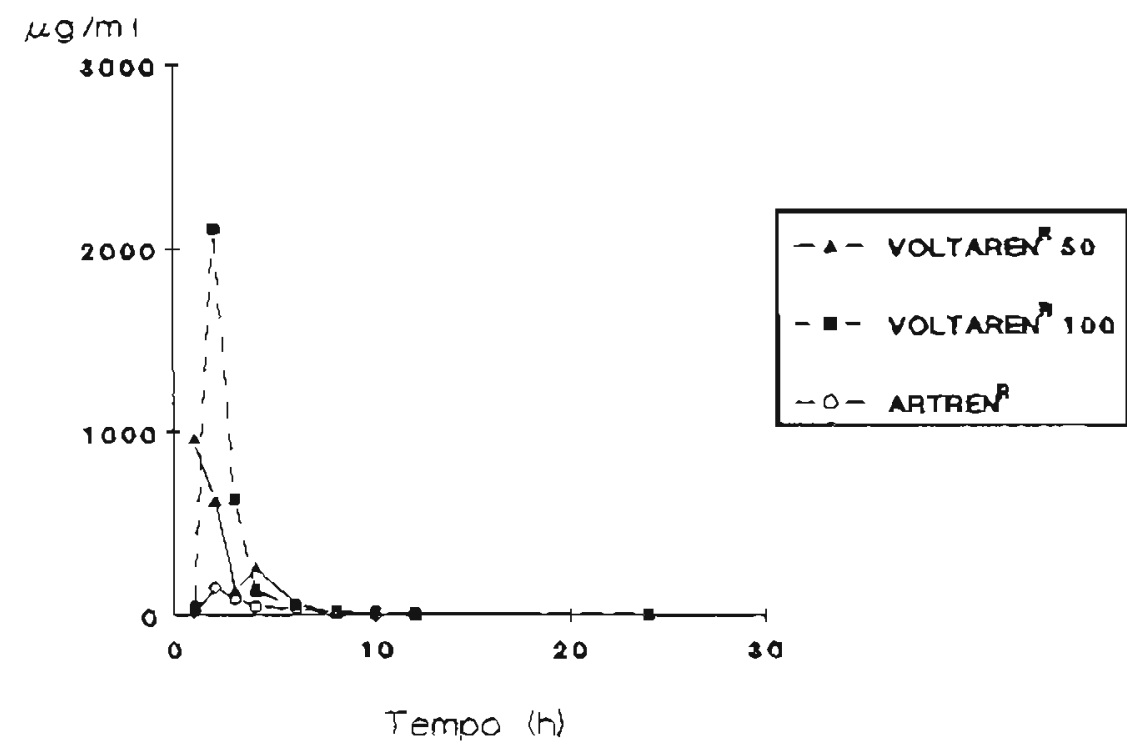

\begin{tabular}{|c|c|c|}
\hline$t_{n}^{\max }$ & $C_{m a}$ & $\underset{\mu \mathrm{g} \cdot n / \mathrm{m}}{\mathbf{A}} \mathbf{C}_{r}$ \\
\hline 1,0 & 966 & 2475 \\
\hline 2.0 & 2110 & 4385 \\
\hline 2,0 & 155 & 4424 \\
\hline
\end{tabular}

Figura a.7: Curvas de decaimento plasmático do diclofenaco após administração de três formulaçóes contendo diclofenaco de sódio - Voluntário? 


\section{VOLUNTARIO 8 - M.A.}

$\mu \mathrm{g} / \mathrm{m} /$



Figura a.8: Curvas de decaimento plasmático do diclofenaco após administraçào de três formulaçōes contendo diclofenaco de sodio - Voluntário 8. 


\section{Estudo de Bioequivalência}

Voltaren ${ }^{\circledR} 50\left(\mathrm{~T}_{1}\right) \times$ Voltaren Retard ${ }^{\circledR} 100(\mathrm{R})$ 
Tabela a.1: Principais parâmetros farmacocinéticos após adminustração peroral de Voltaren ${ }^{\circledR} 50\left(T_{1}\right)$ e Voltaren Retard $100(R)$ em dose única a voluntários sadios.

\begin{tabular}{|c|c|c|c|c|c|c|}
\hline \multirow[t]{2}{*}{ Voluntário } & \multicolumn{3}{|c|}{ Voltaren Retard ${ }^{(100}$} & \multicolumn{3}{|c|}{ Voltaren ${ }^{(8)} 50$} \\
\hline & $\begin{array}{l}t_{\max } \\
(\mathbf{h})\end{array}$ & $\underset{(\mathrm{ng} / \mathrm{ml})}{\mathrm{C}_{\max }}$ & $\underset{(\mathrm{ng} \cdot \mathrm{h} / \mathrm{ml})}{\mathrm{AUC}_{\mathbf{T}}}$ & $\frac{t_{\max }}{(h)}$ & $\underset{(\mathrm{og} / \mathrm{ml})}{\mathrm{C}_{\max }}$ & $\underset{(\mathrm{ng}-\mathrm{h} / \mathrm{ml})}{\mathrm{AUC}_{\mathrm{T}}}$ \\
\hline 1 & 3.0 & 547 & 1550 & 3.0 & 800 & 1918 \\
\hline 2 & 3.0 & 403 & 1424 & 4.0 & 265 & 938 \\
\hline 3 & 2.0 & 682 & 1425 & 2.0 & 1190 & 2108 \\
\hline 4 & 2.0 & 3088 & 6051 & 3.0 & 683 & 1080 \\
\hline 5 & 3,0 & 1268 & 3602 & 4.0 & 145 & 533 \\
\hline 6 & 2.0 & 1161 & 2560 & 2.0 & 1190 & 2358 \\
\hline 7 & 2,0 & 2110 & 4385 & 1.0 & 966 & 2475 \\
\hline 8 & 2.0 & 1936 & 4418 & 2.0 & 691 & 1414 \\
\hline$\overline{\mathrm{X}}^{*}$ & 2.4 & 1399 & 3177 & 2.6 & 741 & 1603 \\
\hline $\mathrm{MED}^{\star *}$ & 2.0 & 1215 & 3081 & 2,5 & 746 & 1666 \\
\hline $\mathrm{DP} \uparrow$ & 0.5 & 922 & 1716 & 1.1 & 386 & 715 \\
\hline EPM $\ddagger$ & 0.2 & 326 & 607 & 0.4 & 137 & 253 \\
\hline
\end{tabular}

$* \bar{X}=$ medra

**MED $=$ medsana

† DP = desvio padrào da média

${ }_{+}^{+} E \mathrm{PM}=$ erro padrão da média 
Tabela a.2: Principais parâmetros farmacocinéticos após administração peroral de Voltaren $^{\&} 50\left(T_{1}\right)$ e Voltaren Retard $\$ 100(R)$ em dose única a voluntários sadios - transformação logaritmica.

\begin{tabular}{|c|c|c|c|c|}
\hline \multirow[t]{2}{*}{ Voluntário } & \multicolumn{2}{|c|}{ Voltaren Retard 100} & \multicolumn{2}{|c|}{ Voltaren $^{(8)} 50$} \\
\hline & $\mathrm{In}_{\mathrm{max}}$ & $\ln A U C_{T}$ & $\ln C_{\max }$ & $\ln A \cup C_{T}$ \\
\hline 1 & 6.3044 & 7,3460 & 6,6846 & 7,5590 \\
\hline 2 & 5.9989 & 7,2612 & 5.5797 & 6,8437 \\
\hline 3 & 6.5250 & 7,2619 & 7,0817 & 7,6535 \\
\hline 4 & 8.0353 & 8,7080 & 6.5265 & 6.9847 \\
\hline 5 & 7.1452 & 8,1892 & 4.9767 & 6.2785 \\
\hline 6 & 7,0570 & 7,8478 & 7,0817 & 7,7656 \\
\hline 7 & 7.6544 & 8,3859 & 6.8732 & 7,8140 \\
\hline 8 & 7.5684 & 8,3934 & 6.5381 & 7,2542 \\
\hline$\overline{\mathrm{X}}^{\star}$ & 7,0361 & 7,9241 & 6,4178 & 7,2692 \\
\hline MED** & 7,1011 & 8,0185 & 6,6114 & 7,4066 \\
\hline $\mathrm{DP} \dagger$ & 0,7120 & 0,5777 & 0,7527 & 0,5370 \\
\hline EPM & 0.2517 & 0,2043 & 0,2661 & 0.1899 \\
\hline
\end{tabular}

* $\overline{\mathrm{X}}=$ média

**MED = mediana

$+D P=$ desvıo padrão da média

†EPM = erro padrão da média 
Tabela a.3: Análise de variância - Voltaren ${ }^{\otimes} 50 \quad\left(T_{1}\right) \times$ Voltaren Retard ${ }^{\circledR} \quad 100 \quad(R)$
Parâmetro: $t_{\max }$

\begin{tabular}{|c|c|c|c|}
\hline fonte de variação & $\begin{array}{l}\text { graus de } \\
\text { liberdade }\end{array}$ & $\begin{array}{c}\text { soma de } \\
\text { quadrados }\end{array}$ & $\begin{array}{l}\text { desvio padrāo } \\
\text { da variância }\end{array}$ \\
\hline $\begin{array}{l}\text { indivíduo } \\
\text { formulaçāo } \\
\text { erro } \\
\text { total }\end{array}$ & $\begin{array}{l}7 \\
1 \\
6 \\
15\end{array}$ & $\begin{array}{l}8,00 \\
0,25 \\
1,75 \\
10,00\end{array}$ & $\begin{array}{l}0,88 \\
0,25 \\
0.28\end{array}$ \\
\hline & $t_{\max T}$ & & $\frac{\mathbf{t}_{\max R}}{(\mathrm{~h})}$ \\
\hline $\begin{array}{l}\text { média } \\
\text { variância }\end{array}$ & $\begin{array}{l}2,6 \\
1,1\end{array}$ & & $\begin{array}{l}2,4 \\
0.3\end{array}$ \\
\hline $\begin{array}{l}\text { efeito individuo } \\
\text { efeito formulaçāo }\end{array}$ & \multicolumn{3}{|c|}{$\begin{array}{l}p=0,031\left(p<0,05, S^{* *}\right) \\
p=0,351\left(p>0,05, N S^{*}\right)\end{array}$} \\
\hline
\end{tabular}

*NS = diferença não significativa.

${ }^{* *} S$ = diferença significatuva 
Tabela a.4: Análise de variância - Voltaren ${ }^{\circledR} 50 \quad\left(\mathrm{~T}_{1}\right) \times$ Voltaren Retard ${ }^{\circledR} 100 \quad(\mathrm{R})$ Parâmetro: $\mathrm{C}_{\max }$

\begin{tabular}{|c|c|c|c|}
\hline fonte de variação & $\begin{array}{l}\text { graus de } \\
\text { liberdade }\end{array}$ & $\begin{array}{c}\text { soma de } \\
\text { quadrados }\end{array}$ & $\begin{array}{l}\text { desvio padrão } \\
\text { da variância }\end{array}$ \\
\hline $\begin{array}{l}\text { individuo } \\
\text { formulaçāo } \\
\text { erro } \\
\text { total }\end{array}$ & $\begin{array}{l}7 \\
1 \\
6 \\
15\end{array}$ & $\begin{array}{l}3606964 \\
1732514 \\
3390426 \\
8729904\end{array}$ & $\begin{array}{l}515281 \\
1732514 \\
565071\end{array}$ \\
\hline & $\begin{array}{l}\mathrm{C}_{\max T} \\
(\mathrm{ng} / \mathrm{ml}\end{array}$ & & $\begin{array}{c}\mathrm{C}_{\mathrm{marr}} \\
(\mathrm{ng} / \mathrm{ml})\end{array}$ \\
\hline $\begin{array}{l}\text { média } \\
\text { variância }\end{array}$ & $\begin{array}{r}741 \\
14928\end{array}$ & & $\begin{array}{c}1399 \\
850347\end{array}$ \\
\hline $\begin{array}{l}\text { efeito individuo } \\
\text { efeito formulação }\end{array}$ & \multicolumn{3}{|c|}{$p=0,469\left(p>0.05, N^{*}\right)$} \\
\hline
\end{tabular}

*NS = diferença não significativa. 
Tabela a.5: Análise de variâncıa-Voltaren ${ }^{(\circledR)} 50 \quad\left(\mathrm{~T}_{1}\right) \times$ Voltaren Retard ${ }^{(\circledR)} 100 \quad(\mathrm{R})$ Parâmetro: $C_{\max }$ - transformação logaritmica.

\begin{tabular}{|c|c|c|c|}
\hline fonte de variaçāo & $\begin{array}{l}\text { graus de } \\
\text { liberdade }\end{array}$ & $\begin{array}{l}\text { soma de } \\
\text { quadrados }\end{array}$ & $\begin{array}{l}\text { desvio padrāo } \\
\text { da variância }\end{array}$ \\
\hline $\begin{array}{l}\text { indivíduo } \\
\text { formulaçāo } \\
\text { erro } \\
\text { total }\end{array}$ & $\begin{array}{l}7 \\
1 \\
6 \\
15\end{array}$ & $\begin{array}{l}4,402771 \\
1,529175 \\
3,111633 \\
9,043579\end{array}$ & $\begin{array}{l}0,628967 \\
1.529175 \\
0,518606\end{array}$ \\
\hline & $\ln C_{\max T}$ & & $\ln C_{\max R}$ \\
\hline $\begin{array}{l}\text { média } \\
\text { variância }\end{array}$ & $\begin{array}{r}6,4178 \\
0,566515\end{array}$ & & $\begin{array}{r}7,0361 \\
0.506971\end{array}$ \\
\hline $\begin{array}{l}\text { efeito individuo } \\
\text { efeito formulação }\end{array}$ & \multicolumn{3}{|c|}{$\begin{array}{l}p=0.329\left(p>0.05, N S^{*}\right) \\
p=0,106(p>0.05, N S)\end{array}$} \\
\hline
\end{tabular}

*NS = diferença não significativa. 
Tabela a.6: Análise de variâncı - Voltaren ${ }^{(\mathbb{B})} 50 \quad\left(\mathrm{~T}_{1}\right) \times$ Voltaren Retard $^{(\overline{\mathrm{B}})} 100 \quad(\mathrm{R})$ Parâmetro. AUC $\mathrm{T}$.

\begin{tabular}{|c|c|c|c|}
\hline fonte de variação & $\begin{array}{l}\text { graus de } \\
\text { liberdade }\end{array}$ & $\begin{array}{l}\text { soma de } \\
\text { quadrados }\end{array}$ & $\begin{array}{l}\text { desvio padrāo } \\
\text { da variância }\end{array}$ \\
\hline $\begin{array}{l}\text { indivíduo } \\
\text { formulaçāo } \\
\text { erro } \\
\text { total }\end{array}$ & $\begin{array}{l}7 \\
1 \\
6 \\
15\end{array}$ & $\begin{array}{l}10259220 \\
9908336 \\
13932040 \\
34099600\end{array}$ & $\begin{array}{l}1465602 \\
9908336 \\
2322006\end{array}$ \\
\hline & $\begin{array}{l}\mathrm{AUC}_{7} \\
(\mathrm{ng} \cdot \mathrm{h} / \mathrm{s}\end{array}$ & & $\underset{(n g \cdot h / m l)}{\mathrm{AUC}_{\mathrm{rR}}}$ \\
\hline $\begin{array}{l}\text { média } \\
\text { variância }\end{array}$ & $\begin{array}{l}160 \\
5115\end{array}$ & & $\begin{array}{c}3177 \\
2944320\end{array}$ \\
\hline $\begin{array}{l}\text { efeito indivíduo } \\
\text { efeito formulação }\end{array}$ & \multicolumn{3}{|c|}{$p=0.652\left(p>0,05 . N S^{*}\right)$} \\
\hline
\end{tabular}

*NS = diferença não significativa. 
Tabela a.7: Análıse de variância - Voltaren ${ }^{\circledR} 50 \quad\left(T_{1}\right) \times$ Voltaren Retard ${ }^{(} 100 \quad$ (R) Parâmetro: $\mathrm{AUC}_{\mathrm{T}}$ - transformação logaritmica.

\begin{tabular}{|c|c|c|c|}
\hline fonte de variaçào & $\begin{array}{l}\text { graus de } \\
\text { liberdade }\end{array}$ & $\begin{array}{l}\text { soma de } \\
\text { quadrados }\end{array}$ & $\begin{array}{l}\text { desvio padrăo } \\
\text { da variância }\end{array}$ \\
\hline $\begin{array}{l}\text { indivíduo } \\
\text { formulação } \\
\text { erro } \\
\text { total }\end{array}$ & $\begin{array}{l}7 \\
1 \\
6 \\
15\end{array}$ & $\begin{array}{l}1.758057 \\
1.715637 \\
2,595947 \\
6,069641\end{array}$ & $\begin{array}{l}0,251151 \\
1.715637 \\
0.432658\end{array}$ \\
\hline & $\ln A U C_{T T 1}$ & & $\ln A U C_{T R}$ \\
\hline $\begin{array}{l}\text { média } \\
\text { variância }\end{array}$ & $\begin{array}{r}7,2691 \\
0.288369\end{array}$ & & $\begin{array}{l}7,9241 \\
0.333631\end{array}$ \\
\hline $\begin{array}{l}\text { efeito individuo } \\
\text { efeito formulaçào }\end{array}$ & \multicolumn{3}{|c|}{$\begin{array}{l}p=0,690\left(p>0,05, N S^{*}\right) \\
p=0.069(p>0.05, N S)\end{array}$} \\
\hline
\end{tabular}

*NS = diferença não significativa. 
Estudo de Bioequivalência

Artren ${ }^{\circledR} 100\left(T_{2}\right) \times$ Voltaren Retard ${ }^{\circledR} 100(R)$ 
Tabela a.8: Principais parâmetros farmacocinéticos após administração peroral de Artren $^{(\mathbb{R})} 100\left(T_{2}\right)$ e Voltaren Retard ${ }^{(\circledR)} 100(\mathrm{R})$ em dose única a voluntários sadios.

\begin{tabular}{|c|c|c|c|c|c|c|}
\hline \multirow[t]{2}{*}{ Voluntário } & \multicolumn{3}{|c|}{ Voltaren Retard ${ }^{(8)} 100$} & \multicolumn{3}{|c|}{$\operatorname{Artren}^{\mathbb{Q}} 100$} \\
\hline & (hax & $\underset{(\mathrm{ng} / \mathrm{ml})}{\mathrm{C}_{\max }}$ & $\underset{(\mathrm{ng} \cdot \mathrm{h} / \mathrm{ml})}{\mathrm{AUC}_{\mathrm{T}}}$ & $t_{\text {(hax }}^{t_{\max }}$ & $\underset{(\mathrm{ng} / \mathrm{ml})}{\mathrm{C}_{\max }}$ & $\underset{(n g \cdot h / m l)}{\mathbf{A U C}_{\mathbf{T}}}$ \\
\hline 1 & 3,0 & 547 & 1550 & 2.0 & 115 & 3438 \\
\hline 2 & 3,0 & 403 & 1424 & 2.0 & 681 & 4050 \\
\hline 3 & 2,0 & 682 & 1425 & 2.0 & 121 & 913 \\
\hline 4 & 2,0 & 3088 & 6051 & 3.0 & 130 & 1222 \\
\hline 5 & 3,0 & 1268 & 3602 & $2 ; 0$ & 95 & 729 \\
\hline 6 & 2,0 & 1161 & 2560 & 2.0 & 127 & 1848 \\
\hline 7 & 2,0 & 2110 & 4385 & 2.0 & 155 & 4424 \\
\hline 8 & 2,0 & 1936 & 4418 & 3.0 & 114 & 1269 \\
\hline $\mathbf{X}^{*}$ & 2.4 & 1399 & 3177 & 2.3 & 192 & 2237 \\
\hline$M E D^{\star \star *}$ & 2.0 & 1215 & 3081 & 2.0 & 124 & 1559 \\
\hline $\mathrm{DP} \dagger$ & 0.5 & 922 & 1716 & 0.5 & 198 & 1496 \\
\hline EPM & 0.2 & 326 & 607 & 0,2 & 70 & 529 \\
\hline \multicolumn{7}{|l|}{${ }^{*} X=$ médıa } \\
\hline \multicolumn{7}{|c|}{ **MED = mediara } \\
\hline \multicolumn{7}{|c|}{ †DP = desvıo padrão da média } \\
\hline \multicolumn{7}{|c|}{${ }_{\ddagger}^{\ddagger} E P M=$ erTo padrão da média } \\
\hline
\end{tabular}


Tabela a.9: Principais paràmetros farmacocinéticos após administração peroral de Artren ${ }^{\circledR} 100\left(T_{2}\right)$ e Voltaren Retard ${ }^{\circledR} 100(R)$ en dose única a voluntários sadios - transformação logaritmica.

\begin{tabular}{|c|c|c|c|c|}
\hline \multirow[t]{2}{*}{ Voluntário } & \multicolumn{2}{|c|}{ Voltaren Retard ${ }^{(1)} 100$} & \multicolumn{2}{|c|}{ Artren 50} \\
\hline & $\ln C_{\max }$ & $\operatorname{InAUC} \mathrm{T}_{\mathrm{T}}$ & $\ln C_{\max }$ & $\ln A U C_{T}$ \\
\hline 1 & 6,3044 & 7.3460 & 4,7449 & 8,1426 \\
\hline 2 & 5,9989 & 7,2612 & 6,5236 & 8.3065 \\
\hline 3 & 6.5250 & 7,2619 & 4.7958 & 6,8167 \\
\hline 4 & 8,0353 & 8,7080 & 4.8675 & 7,1082 \\
\hline 5 & 7,1452 & 8,1892 & 4.5539 & 6.5917 \\
\hline 6 & 7,0570 & 7,8478 & 4,8442 & 7,5219 \\
\hline 7 & 7,6544 & 8,3859 & 5,0434 & 8,3948 \\
\hline 8 & 7,5684 & 8,3934 & 4.7362 & 7,1460 \\
\hline$\overline{\mathrm{X}}^{*}$ & 7,0361 & 7,9241 & 5,0137 & 7,5036 \\
\hline$M E D^{* *}$ & 7.1011 & 8,0185 & 4,8200 & 7,3340 \\
\hline DPt & 0,7120 & 0,5777 & 0,6255 & 0,7005 \\
\hline EPM & 0.2517 & 0.2043 & 0,2212 & 0.2475 \\
\hline \multicolumn{5}{|l|}{$* \bar{X}=$ media } \\
\hline \multicolumn{5}{|c|}{ **MED = mediana } \\
\hline \multicolumn{5}{|c|}{$\uparrow \mathrm{DP}=$ desvio padrāo da média } \\
\hline \multicolumn{5}{|c|}{$\ddagger E P M=$ erro padrão da média } \\
\hline
\end{tabular}


Tabela a.10: Análise de variância - Artren ${ }^{\circledR} 100 \quad\left(\mathrm{~T}_{2}\right) \times$ Voltaren Retard ${ }^{\circledR} 100 \quad(\mathrm{R})$ Parâmetro: tmax.

\begin{tabular}{|l|c|c|c|}
\hline fonte de variação & $\begin{array}{c}\text { graus de } \\
\text { liberdade }\end{array}$ & $\begin{array}{c}\text { soma de } \\
\text { quadrados }\end{array}$ & $\begin{array}{c}\text { desvio padrão } \\
\text { da variância }\end{array}$ \\
\hline \hline indivíduo & 7 & 0,94 & 0,13 \\
formulação & 1 & 0,06 & 0,06 \\
erro & 6 & 2,44 & 0,41 \\
\hline total & 15 & 3,44 & $t_{\text {maxr }}$ \\
\hline (h)
\end{tabular}

*NS = diferença não significativa. 
Tabela a.11: Análıse de variâncıa - Artren ${ }^{\circledR} 100 \quad\left(T_{2}\right) \times$ Voltaren Retard ${ }^{\circledR} 100 \quad(\mathrm{R})$ Parâmetro. $C_{\max }$.

\begin{tabular}{|c|c|c|c|}
\hline fonte de variação & $\begin{array}{l}\text { graus de } \\
\text { liberdade }\end{array}$ & $\begin{array}{l}\text { soma de } \\
\text { quadrados }\end{array}$ & $\begin{array}{l}\text { desvio padrāo } \\
\text { da variância }\end{array}$ \\
\hline $\begin{array}{l}\text { individuo } \\
\text { formulação } \\
\text { erro } \\
\text { total }\end{array}$ & $\begin{array}{l}7 \\
1 \\
6 \\
15\end{array}$ & $\begin{array}{l}2598456 \\
5828604 \\
3628992 \\
12056050\end{array}$ & $\begin{array}{l}371208 \\
5828604 \\
604832\end{array}$ \\
\hline & $\begin{array}{l}\mathrm{C}_{\max \mathrm{T}_{2}} \\
(\mathrm{ng} / \mathrm{ml})\end{array}$ & & $\begin{array}{c}\mathrm{C}_{\max R} \\
(\mathrm{ng} / \mathrm{ml})\end{array}$ \\
\hline $\begin{array}{l}\text { média } \\
\text { variância }\end{array}$ & $\begin{array}{r}192 \\
39289\end{array}$ & & $\begin{array}{c}1399 \\
850347\end{array}$ \\
\hline $\begin{array}{l}\text { efeito individuo } \\
\text { efeito formulaçào }\end{array}$ & \multicolumn{3}{|c|}{$p=0,665\left(p>0.05 . N^{*}\right)$} \\
\hline
\end{tabular}

*NS = diferença não significativa.

**S = diferença significativa. 
Tabela a.12: Análise de variância - Artren ${ }^{\circledR} 100 \quad\left(\mathrm{~T}_{2}\right) \times$ Voltaren Retard ${ }^{\circledR} 100 \quad(\mathrm{R})$ Parâmetro: $C_{\max }$ - transformação logarítmica.



*NS = diferença não significativa.

**S = diferença significativa. 
Tabela a.13: Análise de variância - Artren ${ }^{\circledR} 100 \quad\left(\mathrm{~T}_{2}\right) \times$ Voltaren Retard ${ }^{\mathbb{B}} 100 \quad$ (R) Parâmetro: $\mathrm{AUC}_{\mathrm{T}}$.

\begin{tabular}{|c|c|c|c|}
\hline fonte de variação & $\begin{array}{l}\text { graus de } \\
\text { liberdade }\end{array}$ & $\begin{array}{c}\text { soma de } \\
\text { quadrados }\end{array}$ & $\begin{array}{l}\text { desvio padrão } \\
\text { da variância }\end{array}$ \\
\hline $\begin{array}{l}\text { indivíduo } \\
\text { formulação } \\
\text { erro } \\
\text { total }\end{array}$ & $\begin{array}{l}7 \\
1 \\
6 \\
15\end{array}$ & $\begin{array}{l}13444100 \\
3536280 \\
22824070 \\
39804460\end{array}$ & $\begin{array}{l}1920586 \\
3536280 \\
3804012\end{array}$ \\
\hline & $\begin{array}{l}\mathbf{A U C}_{\mathrm{TT}} \\
(\mathrm{ng} \cdot \mathrm{h} / \mathrm{m})\end{array}$ & & $\begin{array}{c}\mathrm{AUC}_{\mathrm{TR}} \\
(\mathrm{ng} \cdot \mathrm{h} / \mathrm{ml})\end{array}$ \\
\hline $\begin{array}{l}\text { média } \\
\text { variância }\end{array}$ & $\begin{array}{r}2237 \\
2236849\end{array}$ & & $\begin{array}{c}3177 \\
2944320\end{array}$ \\
\hline $\begin{array}{l}\text { efeito individuo } \\
\text { efeito formulação }\end{array}$ & \multicolumn{3}{|c|}{$\begin{array}{l}p=0,749\left(p>0,05, N^{*}\right) \\
p=0,332(p>0,05, N S)\end{array}$} \\
\hline
\end{tabular}

*NS = diferença não significativa. 
Tabela a.14: Análise de variância-Arren ${ }^{\circledR} 100 \quad\left(\mathrm{~T}_{2}\right) \times$ Voltaren Retard ${ }^{\circledR} \quad 100 \quad(\mathrm{R})$ Paràmetro: $\mathrm{AUC}_{\mathrm{T}}$ - transformação logaritmica.

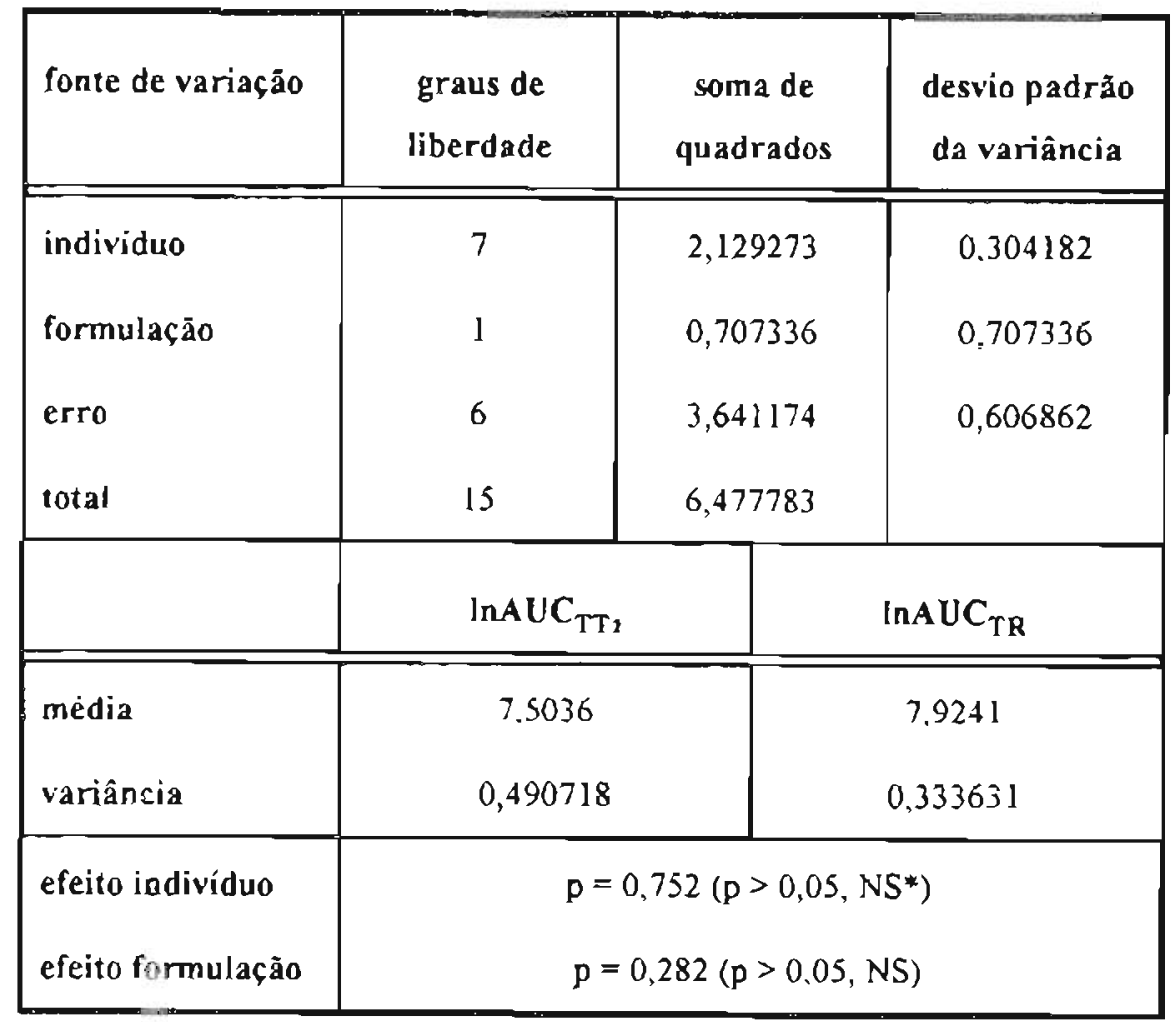

*NS = diferença não significativa. 


\section{Método para determinação simultânea de diclofenaco e seus produtos de biotransformação hidroxilados em urina por cromatografia líquida de alta eficiência}

Capítulo III 


\section{Índice}

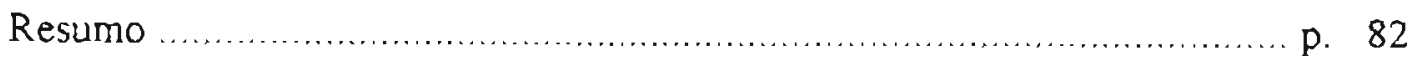

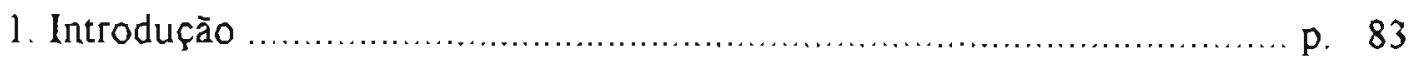

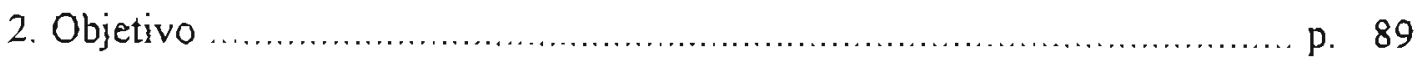

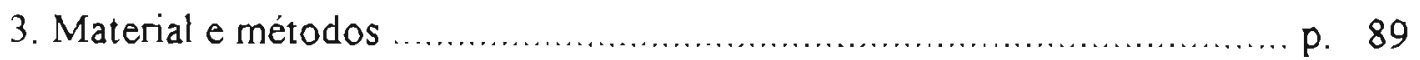



32 Preparação de padrões …................................................... p. 92

3.3. Determinação de diclofenaco e seus produtos de biotransformaçāo hidroxilados em urina .................................. P. 93

3.4. Limites de confiança do método de determinação de diclofenaco e seus produtos de biotransformação hidroxilados em urina .............. p 97

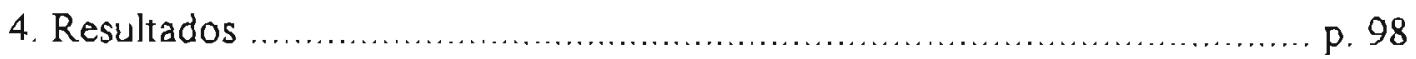

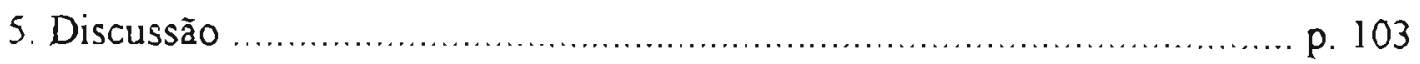

6. Referências bibliográficas ................................................... p. 108






\section{Resumo}

O diclofenaco é um antiinflamatório não-esteroidal indicado para o tratamento de pacientes portadores de inflamações dolorosas de ongem reumática ou não. É brotransformado por reaçōes de oxidação seguidas de conjugação glicurônica. Uma pequena porcentagem do fármaco original sofre glicuronização direta. Vários métodos têm sıdo propostos para a determınaçào de diclofenaco e seus produtos de biotransformação em fluidos biológicos, incluindo cromatografia a gás com detecção por captura de elétrons e cromatografia liquida de alta eficiência (CLAE) com detecçāo eletroquínica ou no ultravioleta. Entretanto, nenhum dos mérodos utilizando CLAE mostrou-se suficientemente seletivo para o uso em estudos de disposição cinética. Descreve-se aqui um método sensível e específico para a determinação de diclofenaco e seus produtos de biotransformação hidroxilados em urina por CLAE com deteç̧ào no ultravioleta precedida de hidrólise enzimática nas amostras e extração com solvente orgânico em meio ácido. Adicionaram-se $500 \mu$ de urina a tubos contendo $10 \mathrm{mg}$ de mistura de $\beta$-glicuronidase e aril-sulfatase e 500 $\mu \mathrm{l}$ de tampāo acetato $0,75 \mathrm{M}$. A mistura foi incubada a $37^{\circ} \mathrm{C}$ por uma hora e, em seguida, transferiram-se $800 \mu \mathrm{l}$ do hidrolisado para tubos contendo $3,3 \mu \mathrm{g}$ de padrão intemo para diclofenaco (ácido 2-(p-ciclo-hexen-l'-fenil)propiônico) e 1,0 $\mu \mathrm{g}$ de padrão intemo para produtos de biotransformação (fenacetina). Procedeu-se à extração com $2 \mathrm{ml}$ de mistura de diclorometano e álcool isopropilico $(9: 1, \mathrm{v} / \mathrm{v})$ e agitação seguida por centrifugação a 3000 rom durante 30 minutos. Desprezou-se a fase aquosa e filtrou-se a fase orgânica em

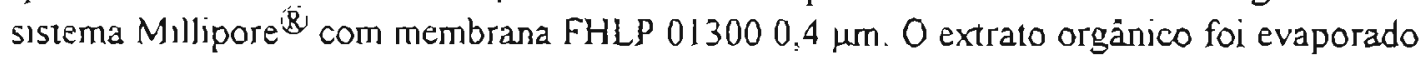
em corrente de nutrogênio a $37^{\circ} \mathrm{C}$ e o residuo, dissolvido em volumes de $500-2000 \mu \mathrm{l}$ de fase móvel e injetado em CLAE. Usaram-se dois sistemas cromatográficos independentes e consecutivos para a separaçào do diclofenaco e seus metabólitos hidroxilados. Inicialmente unlizou-se coluna de fase reversa ODS-Shimadzu, $150 \times 6,0 \mathrm{~mm}, 5 \mu \mathrm{m}$ e fase móvel

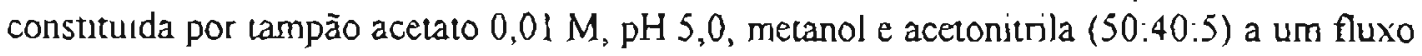
de $1,0 \mathrm{ml} / \mathrm{min}$ para eluição do padrão interno (fenacetína) a 10 minutos, 4',5-du-hidroxidíclofenaco a 12 minutos, 3'-hidroxidiclofenaco a 34 minutos, 4'-hidroxidiclofenaco a 40 minutos e 5-hidroxidiclofenaco a 44 minutos. Em seguida urilizou-se a colına Novapak ${ }^{\circledR} C_{18}, 150 \times 3,9 \mathrm{~mm}, 4 \mu \mathrm{m}$ e fase móvel constituida por tampão acetato $0,75 \mathrm{M}, \mathrm{pH} 5,0$ e acetonitrila $(55: 45$, v/v) e um fluxo de $0,9 \mathrm{ml} / \mathrm{min}$ para eluição do diclofenaco a 3,3 minutos e padrão interno (ácido 2-(p-ciclo-hexen-l'-il-fenil)propiônico, a 6,5 minutos. Os limites de confiança do método foram: $0,4-10,0 \mu \mathrm{g} / \mathrm{ml}$, linearidade; $0,1 \mu \mathrm{g} / \mathrm{ml}$, sensibilidade. $75 \%$, recuperação relativa média da extração e precssão intra e interdias variando de 1,3 a $2,2 \%$ e de 3,3 a $5,7 \%$, respectivamente. O método mostrou-se suficientemente sensível, preciso, exato e especifico para o uso em estudos de excreção urinária de diclofenaco e seus produtos de biotransformação hidroxilados. 


\section{Introdução}

O diclofenaco de sódio, ou sal sódico do àcido [o-[(2,6-diclorofenil)amino]fenil]acético (Figura 1) é um potente antiinflamatório não-esteroidal administrado em doses de 75 a $200 \mathrm{mg} / \mathrm{dia}$ em regime de dose única ou múltipla no tratamento de pacientes com osteoarrite, artrite reumatóide, gota e outras condições reumáticas $[12,13]$. Além da ação antiinflamatória apresenta também ação analgésica, sendo usado para o alivio da dor em pacientes com cólica renal ou biliar e no periodo pós-operatório imediato [13].

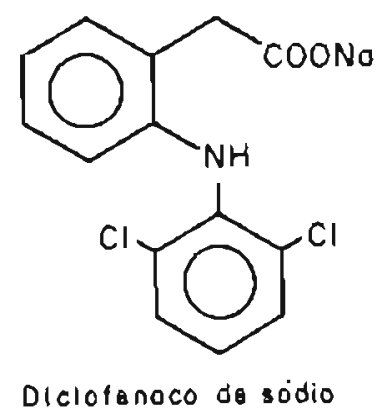

Figura 1: Diclofenaco de sódio. 
O diclofenaco é bem absorvido após administração peroral e rapidamente distribuido, apesar de altamente ligado às proteínas plasmáticas. Apresenta uma elevada taxa de depuração plasmática, em função da biotransformação hepática e posterior excreção renal e biliar de seus produtos de metabolismo [13]. No homem o diclofenaco è biotransformado através de reações oxidativas da fase 1 , fornecendo os derivados mono-hidroxilados 3'-hidroxidiclofenaco (3'-OH-D), 4'-hidroxidiclofenaco (4'-OH-D) e 5-hidroxidiclofenaco (5-OH-D) e o derivado di-hidroxilado 4',5-di-hidroxidiclofenaco (4',5-OH-D). O derivado 3'-OH-D pode ainda sofrer metilação originando o 3'-hidroxi-4'-metoxidiciofenaco (3'-OH-4'-MeO-D) (Figura 2). Estes produtos sofrem conjugação, através das reações da fase II do metabolismo, fornecendo sulfatos ou glicuronatos. Apenas pequena porcentagem da dose administrada é encontrada na urina sob forma de diclofenaco inalterado [6]. 


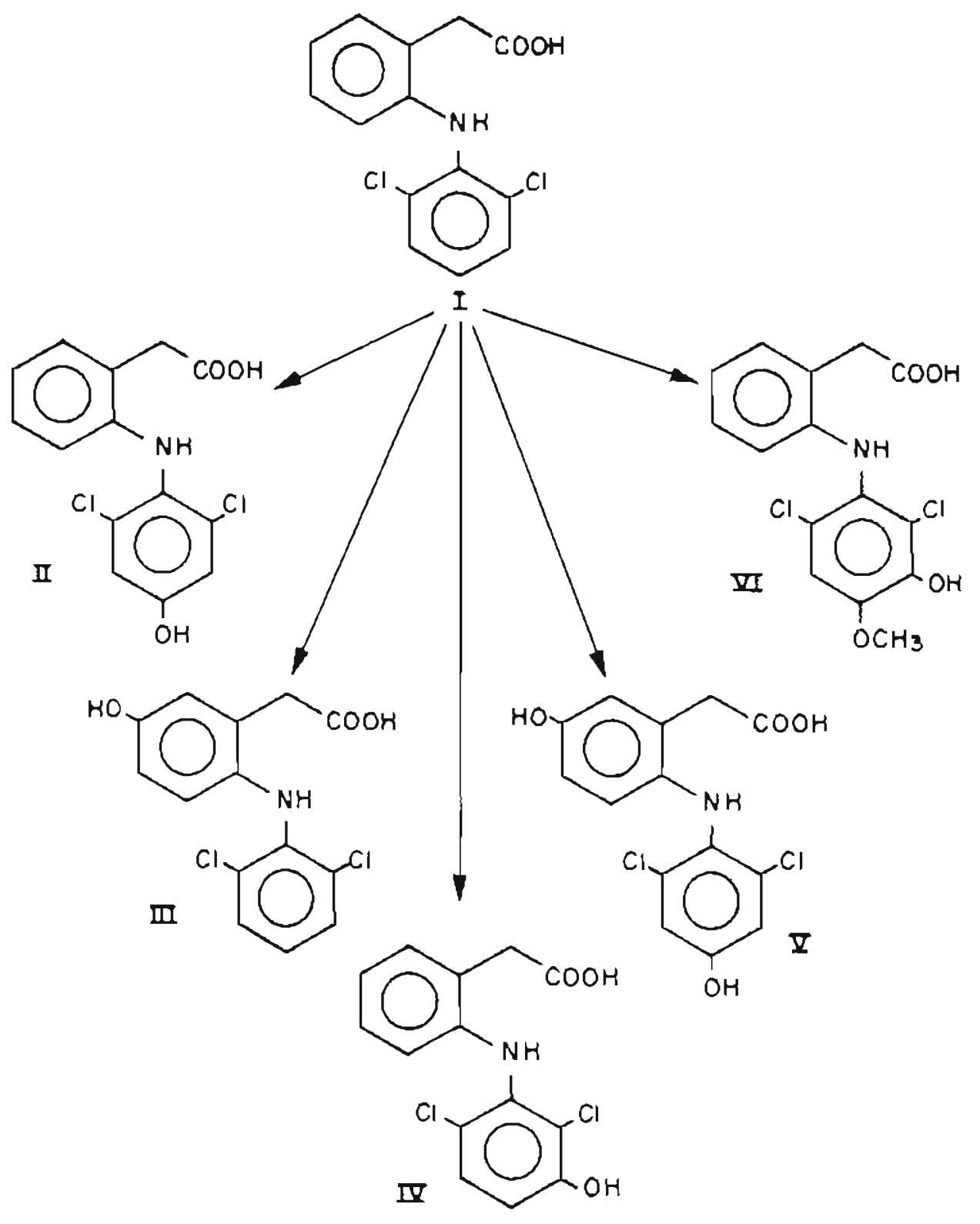

Figura 2: Dielofenaco e seus produtos de biotransformação. I: diclofenaco; II: 4'-OH.D; III: 5.OH.D; IV: 3'-OH.D; V: 4', 5-OH-D; IV: 3'-OH-4'MeO-D. 
Dentre os métodos de quantificação de diclofenaco em urina, aqueles utilizando a cromatografia gás-liquido com detecção por captura de elétrons (CG-DCE ${ }^{63} \mathrm{Ni}$ ) destacaram-se inicialmente como os mais adequados, em funçāo da presença de dois átomos de cloro na molécula deste fármaco [2]. Entretanto, a determinação de diclofenaco por CG só foi possivel após derivatização do grupo carboxila. Para a quantificação de diclofenaco urinário os derivados foram obtidos através de ciclização, originando indolinonas $[3,9,11]$.

Os produtos de biotransformação do diclofenaco podem também ser quantificados em urina $[9,11]$ ou plasma [10] simultaneamente ao diclofenaco, por métodos utilizando a técnica de cromatografia gás-liquido com detecção por captura de elétrons e derivatização por ciclízação.

Devido às estruturas análogas, è dificil obter boa separação entre os produtos de biotransformação do diclofenaco. Schweizer e colaboradores [1]] propuseram a determinação simultânea de diclofenaco e seus produtos de biotransformação mono-hidroxilados, mas não conseguiram diferenciação entre 3'-OH-D, 4'-OH-D e 5-OH-D, expressando sua excreção urinária sob forma de derivados mono-hidroxilados totais.

Em seguida, Schneider e Degen repontaram a determinação simultânea de diclofenaco e seus produtos de biotransformação hidroxilados também por CG-DCE ${ }^{63} \mathrm{Ni}$ após ciclização [9]. Os derivados foram eluídos no sistema cromatográfico em cerca de 15 minutos. Estes mesmos autores [10], posteriormente, propuseram modificações no método acrescentando uma etapa de extraçāo e aumentando o tempo de eluição para 30 minutos e conseguindo, desta 
forma, quantificar em plasma o diclofenaco, seus produtos de biotransformação hidroxilados e, ainda, o produto de biotransformação metoxilado, com ótima sensibilidade e seletividade.

Devido ao procedimento laborioso de extração e derivatização, os métodos de quantificação de diclofenaco e seus produtos de biotransformação em urina utilizando CG-DCE ${ }^{63} \mathrm{Ni}$ vêm sendo substituidos por outros utilizando a cromatografia líquida de alta eficiência (CLAE), sem necessidade de derivatização pré-coluna.

No inicio da década de 80 propôs-se um método para determinação de diclofenaco na urina utilizando a cromatografia líquida de alta eficiência (CLAE) com deteç̧ão por absorbância no ultravioleta $(\lambda=254 \mathrm{~nm})$ precedida de extração com solvente orgànico em meio ácido [7]. Este método apresenta boa precisão e exatidão, além de uma ótima recuperação relativa da extração, mas não é suficientemente sensivel para estudos farmacocinéticos. Outro método para determinação de diclofenaco em urina juntamente com outros antiinflamatórios, utilizando a cromatografia líquida de alta eficiência, é descrito na literatura. Este método visa a realização de "screening" toxicológico, não sendo indicado para estudos farmacocinéticos [1].

A determinação simultânea de diclofenaco e seus produtos de biotransformação na urina por métodos utilizando cromatografia líquida de alta eficiência foi proposta inicialmente por Godbillon e colaboradores [4]. Este método apresentou boa sensibilidade, mas não se mostrou seletivo, já que o produto de biotransformação di-hidroxilado (4',5-OH-D) não pôde ser determinado devido a 
interferência de compostos endógenos; além disso, os produtos mono-hidroxilados 3'-OH-D e 4'-OH-D foram eluídos como um único pico não sendo, portanto, possivel a sua quantificação. Uma melhoria da seletividade foi obtida por Landsorp e colaboradores [5], que conseguiram uma separação razoável entre 3'-OH-D e 4'-OH-D, além da elirninação da interferência dos compostos endógenos na análise de 4,5-OH-D. Estes dois métodos utilizaram detecção por absorbância no ultravioleta em comprimento de onda de $282 \mathrm{~nm}$. Um método para determinação de diclofenaco e seus produtos de biotransformação em plasma e fluido cerebrospinhal utilizando cromatografia líquida de alta eficiência e desector eletroquimico encontra-se descrito na literatura. Estes autores conseguiram uma separação razoável entre o diclofenaco e seus cinco produtos de biotransformação conhecidos [14].

Para a quantificação de diclofenaco em plasma propuseram-se inicialmente métodos analiticos utilizando a cromatografia gás-liquido. Estes métodos foram posteriormente substituidos por outros utilizando a cromatografia líquida de alta eficiência mantendo-se, ou até melhorando-se, a sensibilidade e a seletividade. Da mesma forma, os primeiros métodos analíticos propostos para a quantificação de diclofenaco e seus produtos de biotransformação em fluidos biológicos empregaram a cromatografia gás-líquido e a tendência foi substituir estes métodos por outros que empregassem a cromatografia líquida de alta eficiência. Entretanto, apesar de todas as tentativas que têm sido feitas, nenhum dos métodos propostos até a presente data para análise simultânea e quantificação de diclofenaco e seus produtos de biotransformação utilizando cromatografia liquida de alta eficiência 
apresentou seletividade equivalente à dos métodos que utilizam cromatografia liquido-gás.

\section{Objetivo}

O objetivo deste trabalho é estabelecer um método analitico para quantificação do diclofenaco e seus metabólitos hidroxilados em unina através de técnica de cromatografia líquida de alta eficjência para uso em estudo farmacocinético.

\section{Material e métodos}

\subsection{Material}

Todos os solventes utilizados para extração (diclorometano, àlcool isopropilico), cromatografia (metanol, acetonitrila) ou preparo de padrões (metanol) foram de grau espectroscópico ou cromatográfico (E. Merck, Carlo Erba, Grupo Química) Para evaporação dos exiratos orgânicos usou-se nitrogênio de pureza 99,99\% (White Martins). As soluções ácidas, básicas, iônicas ou tampōes foram preparadas a partir de reagentes pró-análise (grau p.a.). A água 
destinada tanto à limpeza do cromatografo quanto ao preparo de soluçōes foi filtrada em membrana Millipore ${ }^{\circledR}$, tipo $\mathrm{HA}$, de $0,4 \mu \mathrm{m}$

Para a análise cromatográfica utilizaram-se as colunas Novapak ${ }^{\circledR} C_{18}$, Waters - Millipore, de $150 \times 3,9 \mathrm{~mm}$ e parículas de $4 \mu \mathrm{m}$ e ODS Shimadzu de $150 \times 6,0 \mu \mathrm{m}$ e pariculas de $5 \mu \mathrm{m}$.

O material de vidro usado foi cuidadosamente lavado com detergente e solução sulfocrômica e enxaguado com água destilada. A secagem foi feita em estufa. Todo o material foi enxaguado com diclorometano imediatamente antes do uso.

Padrões e enzimas

Usaram-se os seguintes compostos:

- diclofenaco de sódio - doado pela Biogalênica - utilizado como padrão para doseamento de diclofenaco em urina;

- 3'-hidroxidiclofenaco, 4'-hidroxidiclofenaco, 5-hidroxidiclofenaco e 4',5-di-hidroxidiclofenaco-doados pela Ciba-Geigy (Suica)-utilizados como padrões para doseamento destes produtos de biotransformação em urina;

- ácido 2-(p-ciclo-hexen-1'-il-fenil)propiônico-doado pela Biogalênica - utilizado como padrão intemo para doseamento de diclofenaco em urina; 
- fenacetina-doada pelo Setor de Quimica Farmacêutica dâ FCF-USP - utilizada como padrão interno para doseamento de produtos de biotransformação hidroxilados do diclofenaco em urina e;

- mistura de enzimas ( $\beta$-glicuronidase e aril-sulfatase-Limpet Acetone Powder, tipo I, L-1251) - adquirida da Sigma Chemical Company (EUA) - utilizada para hidrólise dos conjugados de diclofenaco, 3'-OH-D, 4'-OH-D, 5-OH-D e 4', 5-OH-D em urina.

\section{Equipamento}

Para a cromatografia utilizou-se equipamento Shimadzu constituido por bomba modelo LC-6A controlada por microprocessador modelo SCL-6B, injetor automático modelo SIL-6B, detector de absorbância variável modelo SPD $6 \mathrm{AV}$ $(\lambda=282 \mathrm{~nm})$ e integrador automático modelo CR-6A.

Para as hidrólises e extrações utilizaram-se banho-maria Fanem ${ }^{\circledR}$ Ltda., tipo Dubnoff, modelo 145, agitador de tubos Phoenix, modelo AT 56 e centrifuga refrigerada Du Pont, modelo Sorvall ${ }^{\circledR}$ RC-5B. Para a evaporação dos extratos utilizou-se banho-maria Fanem ${ }^{\circledR}$ Ltda. equipado com sistema de evaporação.

No preparo da fase móvel usaram-se banho de ultrassom Mini-Som Thornton para a desgaseificação e medidor de pH Tacussel, modelo PHN 75, equipado com eletrodo específico para mistura de soluções aquosas e solventes orgânicos, para o ajuste de $\mathrm{pH}$. 


\subsection{Preparação de padrões}

Os padrōes de diclofenaco e de seus produtos de biotransformação hidroxilados em urina foram preparados a partir de soluçōes metanólicas contendo exatamente cerca de $1 \mathrm{mg} / \mathrm{ml}$ de diclofenaco ou de cada produto de biotransformação hidroxilado. Essas soluçōes foram diluidas inicialmente com água e em seguida com branco de urina previamente testado, obtendo-se: padrões em très concentrações diferentes contendo exatamente cerca de 6,0,3,0 e 0,6 $\mathrm{\mu g} / \mathrm{ml}$ de diclofenaco e $10,0,5,0$ e $1,0 \mu \mathrm{g} / \mathrm{ml}$ de cada produto de biotransformação hidroxilado (3'-OH-D, 4'-OH-D, 5-OH-D e 4',5-OH-D).

O padrão interno para doseamento de diclofenaco em urina foi preparado por dissolução de ácido 2-(p-ciclo-hexen-l'-fenil)propiônico em metanol obtendo-se uma solução com concentração de $66 \mathrm{\mu g} / \mathrm{m}$, enquanto que o padrão interno para doseamento de produtos de biotransformação hidroxilados do diclofenaco em urina foi preparado por dissolução de fenacetina em metanol obtendo-se uma solução com concentração de $10 \mu \mathrm{g} / \mathrm{ml}$.

Tanto os padrões em urina quanto os padrões internos foram armazenados em congelador a $-20^{\circ} \mathrm{C}$. 


\subsection{Determinação de diclofenaco e seus produtos de biotransformação hidroxilados em urina}

O diclofenaco é excretado na urina sob forma livre e de conjugados, tanto glicuronatos quanto sulfatos, enquanto que os seus produtos de biotransformaçào hidroxilados (3'-OH-D, 4'-OH-D, 5-OH-D e 4',5-OH-D) são excretados na urina sob forma conjugada [13]. As concentraçōes de diclofenaco e seus produtos de biotransformação hidroxilados em amostras de urina humana foram determinadas através de cromatografia liquida de alta eficiência em fase reversa precedida de hidrólise enzimática nas amostras e extraçăo do hidrolisado com solvente orgânico em meio àcido.

A integração dos picos do cromatograma foi realizada pelo método da padronização interna utilizando-se como padrào interno ( $\mathrm{Pi}$ ) para o diclofenaco um análogo estrutural, o ácido 2-(p-cicio-hexen-1'-il-fenil)propiônico e para os produtos de biotransformação, a fenacetina.

\section{Procedimento de extração}

Efetuou-se a hidrólise enzimática das amostras biológicas utilizando-se uma mistura comercial contendo $\beta$-glicuronidase e aril-sulfatase. As amostras hidrolisadas foram purificadas por extração do diclofenaco e seus produtos de biotransformação hidroxilados com solvente orgânico em meio ácido. Adicionaram-se volumes de $500 \mu \mathrm{l}$ de urina a tubos contendo $10 \mathrm{mg}$ da mistura de enzimas. A 
seguir acidificou-se a urina com $500 \mu$ de tampão acetato $0,75 \mathrm{M}, \mathrm{pH} 5,0$ contendo $4 \mathrm{mg} / \mathrm{ml}$ do antioxidante metabissulfito de sódio e incubou-se esta mistura em banho-maria a $37^{\circ} \mathrm{C}$ por uma hora. Transferiram-se, então, $800 \mu l$ do hidrolisado para tubos contendo $50 \mu$ de Pi para diclofenaco (solução metanólica de ácido 2-(p-cicio-hexen-l'-il-fenil)propiônico a $66 \mu \mathrm{g} / \mathrm{ml})$ e $100 \mu \mathrm{l}$ de Pi para produtos de biotransformação hidroxilados do diclofenaco (solução metanólica de fenacetina a $10 \mu \mathrm{g} / \mathrm{ml}$ ) previamente evaporados em cortente de nitrogênio a $37^{\circ} \mathrm{C}$. Procedeu-se à extração com $2 \mathrm{ml}$ de mistura diclorometano:álcool isopropilico $(9: 1, \mathrm{v} / \mathrm{v})$ durante 90 segundos. Após centrifugação a $3000 \mathrm{rpm}$ por 30 minutos para quebra da emulsão aspirou-se a fase aquosa e imergiu-se o extrato orgânico remanescente em banho de gelo seco e acetona para congelamento da fase aquosa restante. Decantou-se cuidadosamente o extrato orgânico que, em seguida, foi filtrado em sistema Millipore ${ }^{\circledR}$ com membrana FHLP 01300, transferido para tubo cônico e evaporado em corrente de nitrogênio a $37^{\circ} \mathrm{C}$. Dissolveu-se o resíduo em volumes de 500 a $2000 \mu l$ de fase móvel para injeção em CLAE.

Para a purificaçāo do branco e dos padrōes utilizou-se o mesmo procedimento, omitindo-se apenas a incubação por uma hora em banho-maria a $37^{\circ} \mathrm{C}$, uma vez que, no caso dos padrões, tanto o diclofenaco quanto os produtos de biotransformaçăo encontram-se na forma não-conjugada (Esquema analítico). 


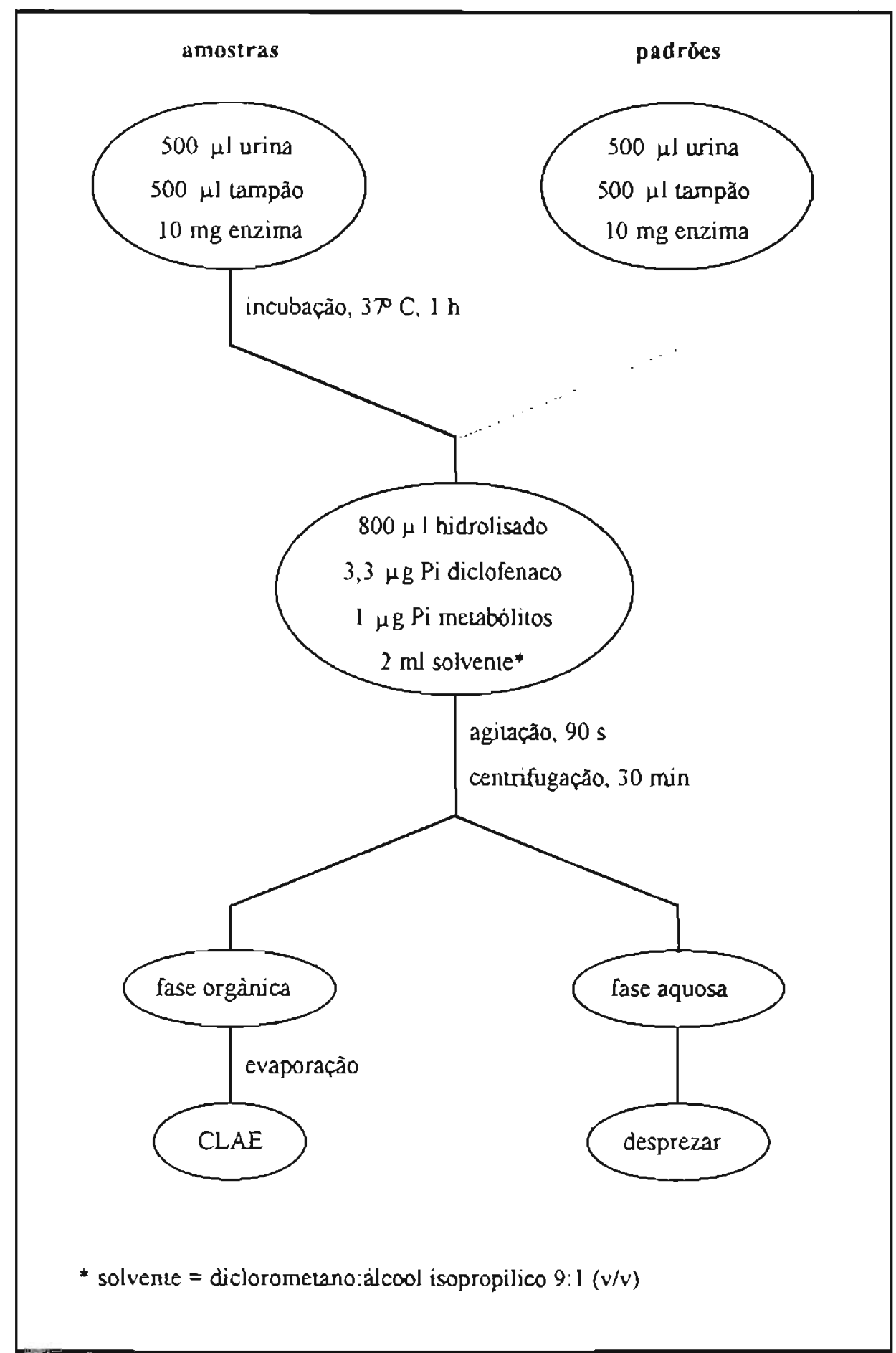

Esquema analítico: Procedimento de extração para deteminaçāo de diclofenaco e seus produtos de biotransformação hidroxilados em urina. 


\section{Condições instrumentais para cromatografia líquida de alta eficiência}

Foram realizadas duas análises por amostra através de cromatografia liquida de alta eficiência: a primeira para quantificaçăo de produtos de biotransformação hidroxilados do diclofenaco e a segunda para a quantificação de diclofenaco inalterado.

$\mathrm{Na}$ análise de produtos de biotransformação hidroxilados do diclofenaco empregou-se coluna ODS Shimadzu de $150 \mathrm{~mm}$ de comprimento e $6,0 \mathrm{~mm}$ de diâmetro interno contendo partículas de $5 \mu \mathrm{m}$, enquanto que, na análise de diclofenaco inalterado empregou-se coluna Novapak ${ }^{\circledR} C_{18}$ de $150 \mathrm{~mm}$ de comprimento e $3,9 \mathrm{~mm}$ de diâmetro interno contendo partículas de $4 \mu \mathrm{m}$. Diariamente, antes do uso, as colunas mantida em metanol e água $(75: 25 \mathrm{v} / \mathrm{v})$ foram condicionadas com acetonitrila seguida de água ultrapura durante 30 minutos

Para a quantificação de produtos de biotransformação hidroxilados do diclofenaco a fase móvel foi constituida por mistura de tampão acetato $0,01 \mathrm{M}$, pH 5,0, metanol e acetonitrila na proporção de 50:40:5 (v/v) e teve seu pH ajustado com ácido acético glacial para 5,40. A fase móvel foi desgaseificada a vácuo em ultrassom e, em seguida, bombeada para o sistema cromatográfico com fluxo de $1,0 \mathrm{ml} / \mathrm{min}$. A estabilização do sistema exigiu cerca de 30 minutos.

Para a quantificação de diclofenaco a fase móvel foi constituída por mistura de tampão acetato $0,75 \mathrm{M}, \mathrm{pH} 5,0$ e acetonitrila na proporção de $55: 45$ $(v / v)$, desgaseificada a vácuo em ultrassom antes do uso e bombeada para o sistema 
cromatográfico com fluxo de $0,9 \mathrm{ml} / \mathrm{min}$. A estabilização do sistema exigiu cerca de 30 minutos.

\subsection{Limites de confiança do método de determinação de diclofenaco e seus produtos de biotransformação bidroxilados em urina}

As curvas de calibração foram construidas a partir de padrões obtidos pela adição de diferentes quantidades de diclofenaco e de seus produros de biotransformação hidroxilados a brancos de urina. A linearidade foi avaliada utilizando-se ajuste pelo método dos mínimos quadrados e regressão linear. $\mathrm{O}$ limite de quantificação do método foi estabelecido após purificação por extração dos padrões utilizados na construção das curvas de calibração. A reprodutibilidade foi determinada a partir da precisão intra e interdias. Para a determinação da recuperação relativa da extração, padrões de diclofenaco e de seus produtos de biotransformação hidroxilados em unina foram extraidos e analisados por CLAE contra injeção direta da mistura de diclofenaco e de seus produtos de biotransformação hidroxilados com os respectivos padrões internos. Finalmente, a estabilidade dos extratos orgânicos foi avaliada reinjetando-se em CLAE extratos submetidos a diferentes condições de armazenamento (temperatura ambiente e congelador a $-20^{\circ} \mathrm{C}$ ). 


\section{Resultados}

O diclofenaco e seu padrão interno lácido

2-(p-ciclo-hexen-l'-fenil)propiônico) apresentaram boa separação entre si e também dos componentes da urina. Os tempos de retenção foram de 3,3 e 6,5 minutos respectivamente para o diclofenaco e o padrão intemo, correspondendo a volumes de retenção de 3,0 e 5,9 ml (Figura 3). 


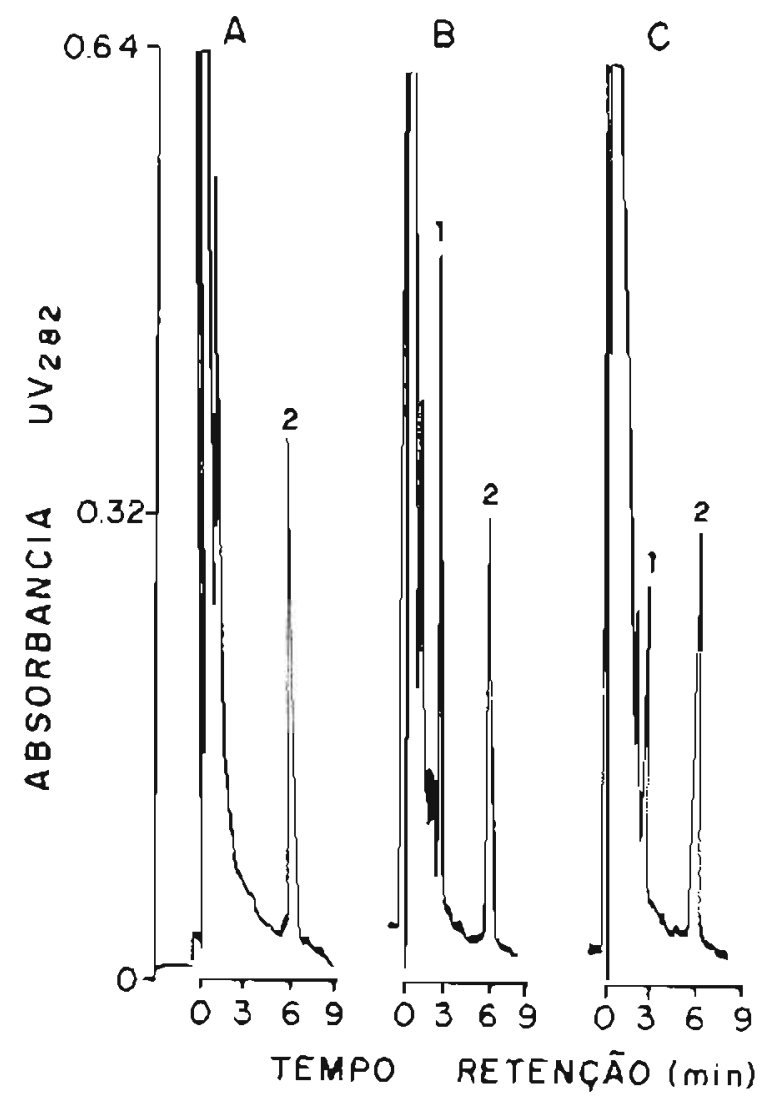

Figura 3: Perfil cromatográfico do diclofenaco e seu padrão interno (ácido 2-(p-ciclo-hexen-l'-il-fenil)propiônico). A: branco de urina + padrão interno; B: padrão (branco de unina $+6,0 \mu \mathrm{g}$ diclofenaco/ml) + padrão interno; $\mathrm{C}$ : urina de voluntário após administração peroral de diclofenaco de sódio + padrão interno. 1: diclofenaco; 2: padrão interno.

Também os quatro produtos de biotransformação hidroxilados do diclofenaco e seu padrão interno (fenacetina) apresentaram boa separação entre si e dos componentes da urina. Os tempos de retenção foram de 10,12, 34, 40 e 44 minutos respectivamente para o padrão interno, o 4',5-OH-D, o 3'-OH-D, o 
4'-OH-D e o 5-OH-D correspondendo a volumes de retenção de $10,12,34,40$ e $44 \mathrm{ml}$ (Figura 4).
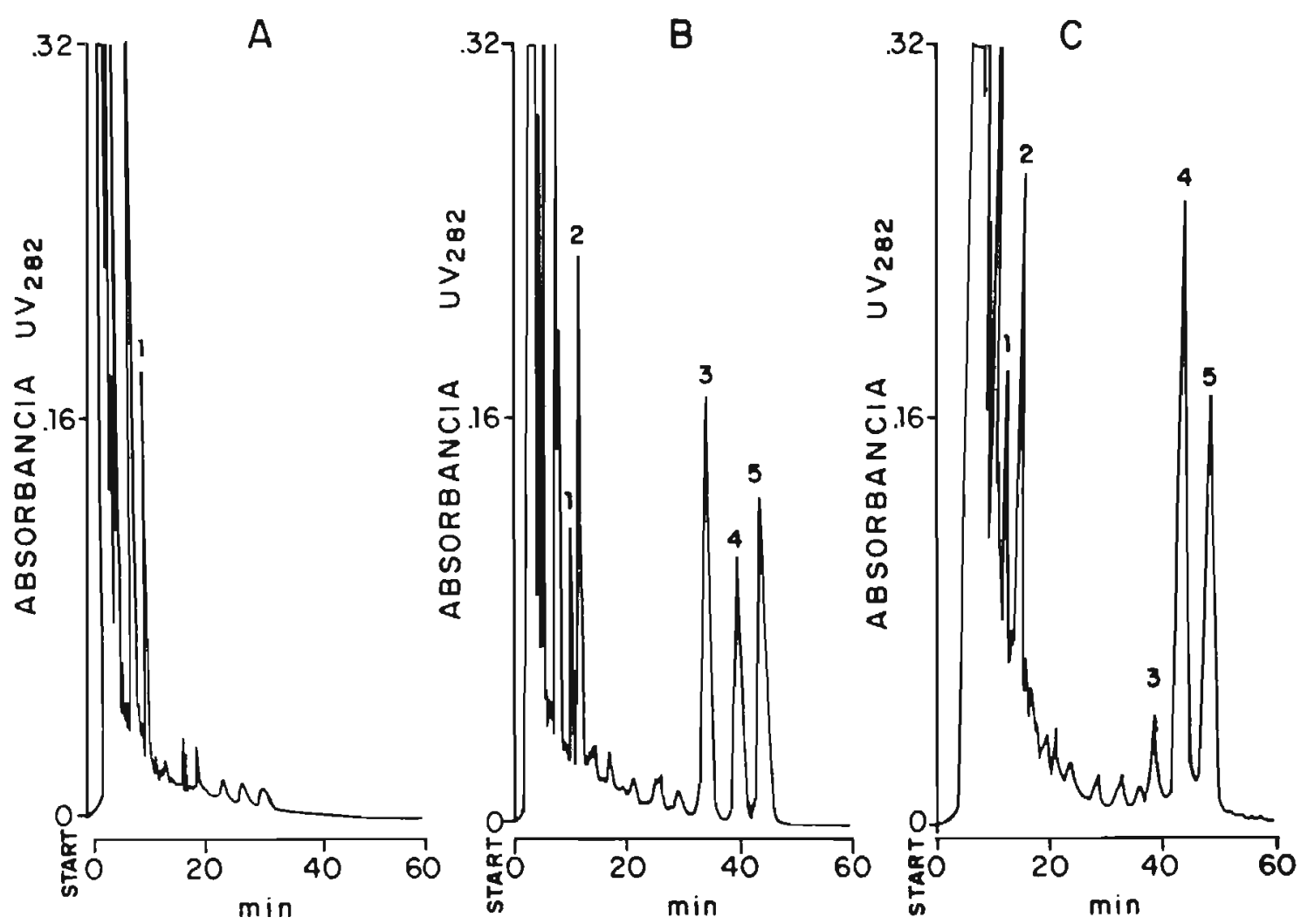

Figura 4: Perfil cromatográfico dos produtos de biotransformac,ão hidroxilados do diclofenaco e seu padrão interno (fenacetina). A: branco de urina + padrão interno; B: padrão (branco de urina $+5,0 \mu \mathrm{g}$ de cada metabólito/ml) + padrão interno; C: urina de voluntário após administração peroral de diclofenaco de sódio + padrão interno. 1: padrão interno; 2: 4',5-OH-D; 3: 3'-OH-D; 4: 4'-OH-D; 5: 5-OH-D. 
O limite de quantificação do método foi de $0,1 \mu \mathrm{g} / \mathrm{ml}$ tanto para o diclofenaco inalterado quanto para todos os produtos de biotransformação hidroxilados. Obteve-se uma relação linear entre as concentrações de 0,4 e 10,0 $\mu \mathrm{g} / \mathrm{ml}$ para o diclofenaco e para os produtos de biotransformação hidroxilados (Figura 5). O coeficiente de variação foi de 1,3 a 2,2\% para amostras analisada no mesmo dia e de 3,3 a 5,7\% para amostras analisadas em dias diferentes. A recuperação relativa da extração foi de $70 \%$ em média para todos os compostos investigados (Tabela 1)

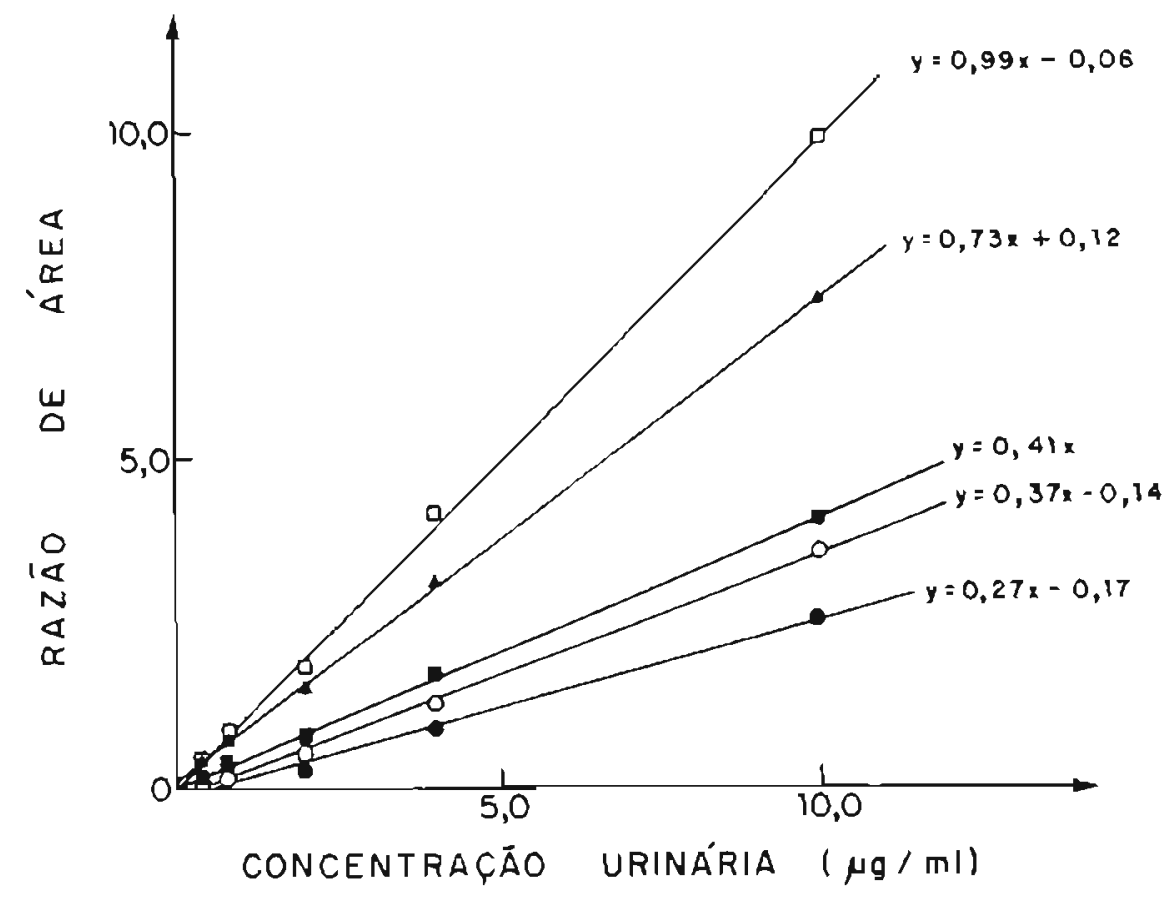

Figura 5. Curvas de calibraçào do diciofenaco e seus produtos de biotransformação hudroxilados em urina. : 4',5-OH-D; $4: 3^{\prime}-\mathrm{OH}-\mathrm{D}$; $=4{ }^{\prime}-\mathrm{OH}-\mathrm{D} ; \mathrm{O}: 5-\mathrm{OH}-\mathrm{D}$; $\square$ diclofenaco. $r^{2}=0,99$. 
Os extratos orgânicos não reconstituidos com fase móvel mantém-se estáveis por quatro dias quando conservados em congelador a $-20^{\circ} \mathrm{C}$; os extratos reconstituidos mantém-se estáveis por dois dias quando conservados a $-20^{\circ} \mathrm{C}$ e por 24 horas quando conservados à temperatura ambjente. Em vista disso, foi possivel a automatização das análises por cromatografia liquida de alta eficiência, além da realização de dois perfis, conforme proposto neste trabalho.

Tabela 1: Limites de confiança do método de determinação de diclofenaco e seus produtos de biotransformação hidroxilados em urina.

\begin{tabular}{|c|c|c|c|c|c|c|}
\hline Parâmetro & Unidade & \multicolumn{5}{|c|}{ Vajor } \\
\hline & & $4^{\prime} .5-\mathrm{OH}-\mathrm{D}$ & 3'-OH-D & $4^{\prime}-\mathrm{OH}-\mathrm{D}$ & 5-OH-D & D \\
\hline $\begin{array}{l}\text { lımite de } \\
\text { quantificaçāo }\end{array}$ & $\mu \mathrm{g} / \mathrm{ml}$ & 0.1 & 0,1 & 0.1 & 0.1 & 0.1 \\
\hline linearidade & $\mu \mathrm{g} / \mathrm{ml}$ & $0.4-10.0$ & $0,4-10,0$ & $0.4-10,0$ & $0.4-10,0$ & $0.4 \cdot 10,0$ \\
\hline $\begin{array}{l}\text { recuperaçāo da } \\
\text { exıração }\end{array}$ & $\%$ & $57 \pm 1$ & $68 \pm 4$ & $63 \pm 3$ & $63 \pm 4$ & $92 \pm 8$ \\
\hline $\begin{array}{l}\text { reprodulibilidade } \\
(1,0-10,0 \mu g / m])\end{array}$ & & & & & & \\
\hline intradia & $\%$ & 1.7 & 2,2 & 2.0 & 1,3 & 1.4 \\
\hline interdias & $\%$ & 3,3 & 3.9 & 4,9 & 4,6 & 5,7 \\
\hline
\end{tabular}




\section{Discussão}

Nos últimos oito anos reportaram-se apenas dois métodos para determinação de diclofenaco e seus produtos de biotransformação hidroxilados em urina através de cromatografia liquida de alta eficiência utilizando detector espectrofotométrico com luz ultravioleta no comprimento de onda de $282 \mathrm{~nm}[4,5]$ após hidrólise quimica básica das amostras seguida de extração em meio ácido com éter di-isopropilico [4] ou éter metil-t-butilico [5]. A hidrólise é necessária pois o diclofenaco e seus produtos de biotransformação hidroxilados são excretados na urina sob forma de conjugados, mas só podem ser quantificados na forma livre, ou nāo-conjugada.

No presente trabalho propõe-se a hidrólise enzimática da urina utilizando uma mistura comercial de $\beta$-glicuronidase e aril-sulfatase (Limpet Acetone Powder, tipo I; $10 \mathrm{mg} / \mathrm{ensaio}$ ) na quebra dos conjugados. A hidrólise enzimática, além de especifica, ocorre em condições mais brandas que a hidrólise química básica, fornecendo um hidrolisado que deve conter apenas o diclofenaco inalterado e seus produtos de biotransformaçāo na forma nāo-conjugada, permanecendo portanto livre de produtos indesejáveis que possam se formar em função da hjdrólise quimica da urina.

Os dois metodos para determinação simultânea de diclofenaco e seus produtos de biotransformação hidroxilados em urina referidos acima propõem, para purificação das amostras, duas extrações em meio ácido intercaladas por uma extração em meio básico utilizando-se, como solvente orgânico, o èter 
di-isopropilico [4] ou o éter metil-t-butílico [5]. Zecca e colaboradores propõem, para a análise simultânea de diclofenaco e seus produtos de biotransformação em plasma ou fluido cerebrospinhal, a extração em coluna tipo $C_{18}$ [14]. No presente método realizou-se extração simples em meio ácido do diclofenaco e seus produtos de biotransformação hidroxilados (3'-OH-D, 4'-OH-D, 5-OH-D e 4', 5-OH-D), após a hidrólise enzimática das amostras de urina, utilizando-se uma mistura de solventes contendo diclorometano e álcool isopropílico $(9: 1, v / v)$. A extração simples proposta no método aqui descrito, precedida de hidrólise enzimática nas amostras de urina, garantiu uma melhor recuperação que a extração tripla proposta por Landsorp e colaboradores além de fornecer extratos mais puros que aqueles obtidos após hidrólise química alcalina. Como consequência, o método aqui apresentado mostrou ser mais sensivel que aquele descrito por Landsorp e colaboradores [5] tanto na determinação de diclofenaco inalterado quanto na determinação de seus produtos de biotransformação hidroxilados.

De forma geral a separação cromatográfica foi obtida utilizando-se coluna de fase reversa tipo $C_{18}[4,5]$ ou $C_{8}[14]$. Godbillon e colaboradores, utilizando coluna Nucleosi ${ }^{\circledR} \mathrm{C}_{18}, 250 \times 4,7 \mathrm{~mm}$, contendo parículas de $10 \mu \mathrm{m}$ e fase móvel constituida por mistura de metanol, acetonitrila e tampão fosfato de pH 7,0 na proprção de 30:17:53 (v/v) não conseguiram separar o produto de biotransformação 4',5-OH-D dos componentes endógenos extraídos da urina; também não obtiveram separação entre 3'-OH-D e 4'-OH-D, que foram eluídos no mesmo tempo de retenção, tomando impossivel a quantificação destes dois compostos no material biológico em questão [4]. Landsorp e colaboradores conseguiram uma melhoria da seletividade em relação ao método anterior 
utilizando coluna Chrompack ${ }^{\circledR}$ Hypersil 5-ODS, $250 \times 4,6 \mathrm{~mm}$, contendo partículas de $5 \mu \mathrm{m}$, acopiada a uma pré-coluna e fase móvel constituida por mistura de acetonitrila, metanol, tetra-hidrofurano e água na proporção de 15:10:3:72 (v/v). Este sistema permitiu uma separação razoável dos produtos de biotransformação hidroxilados do diclofenaco com eluição do 4',5-OH-D aos 5 minutos, seguida pela eluição do 3'-OH-D, 4'-OH-D e 5-OH-D aos 10, 11 e 15 minutos respectivamente. Observa-se que o 4',5-OH-D foi eluído muito próximo aos componentes endógenos presentes no extrato de urina hidrolisada e que a separação entre 3'-OH-D e 4'-OH-D foi incompleta. Após a eluição dos produtos de biotransformação hidroxilados foram necessários cerca de 30 minutos adicionais para a eluição do diclofenaco inalterado [5]. Zecca e colaboradores, analisando amostras de plasma e fluido cerebrospinhal, e utilizando coluna $C_{8}, 80 \times 4,6 \mathrm{~mm}$, contendo particulas de $3 \mu \mathrm{m}$ e fase móvel constituida por acetonitrila e tampão acetato pH 3,0 na proporção 35:65 (v/v) conseguiram separação entre todos os produtos de biotransformação do diclofenaco, embora, também neste caso, a eluição do 4',5-OH-D tenha sido precoce e a separação entre 3'-OH-D, 3'-OH-4'-MeO-D e 4'-OH-D tenha sido incompleta. Após a eluição dos produtos de biotransformação foram necessários cerca de 15 minutos adicionajs para a eluição do diclofenaco inalterado [14].

No presente trabalho, propõe-se a análise do diclofenaco e produtos de biotransformação hidroxilados em dois perfis combinados, ou seja, em dois sistemas cromatográficos independentes, mas consecutivos. No primeiro deles efetuou-se a separação dos produtos de biotransformação hidroxilados utilizando coluna ODS Shimadzu ${ }^{\circledR}, 150 \times 6,0 \mathrm{~mm}$, contendo particulas de $S \mu \mathrm{m}$ e fase móvel 
constituída por mistura de tampão acetato $0,01 \mathrm{M}, \mathrm{pH} \mathrm{5,0,} \mathrm{metanol} \mathrm{e} \mathrm{acetonitrila}$ na proporção de 50:40:5 (v/v). O pH da fase móvel foi ajustado com ácido acético glacial ( $\mathrm{pH}=5,40)$. Este sistema mostrou-se altamente seletivo para os produtos de biotransformação hidroxilados do diclofenaco e seu padrão interno (fenacetina) que foram eluidos na seguinte ordem e com os seguintes tempos de retenção, respectivamente: padrão interno, 10 minutos; 4',5-OH-D, 12 minutos; 3'-OH-D, 34 minutos; 4'-OH-D, 40 minutos e 5-OH-D, 44 minutos. Foram necessários cerca de 45 minutos para a eluição de todos os produtos de biotransformação hidroxilados utilizando fluxo de $1,0 \mathrm{ml} / \mathrm{min}$. É importante ressaltar que o $\mathrm{pH}$ final da fase mostrou-se critico para garantir a seletividade do sistema, devendo ser testado diariamente para garantir a reprodutibilidade dos tempos de retenção dos produtos de biotransformação. No sistema acima descrito, o diclofenaco inalterado exigiria cerca de 300 minutos para ser eluido, equivalendo a um volume de retenção de 300 ml. Portanto, o prejuizo em função do tempo de análise, desgaste do sistema cromatográfico e utilização de volumes altos de fase móvel, bem como problemas na deteç̧ão do pico deste componente pela sua alta interação com a fase estacionária justificam a realização de um segundo perfil de separação para determinação do diclofenaco inalterado na urina.. Assim sendo, propõe-se um segundo sistema cromatográfico utilizando coluna Novapak ${ }^{\circledR} C_{18}, 150 \times 3,9 \mathrm{~mm}$, contendo parículas de $4 \mu \mathrm{m}$ e fase móvel constituida de tampão acetato $0,75 \mathrm{M}$, pH 5,0 e acetonitrila na proporção de $55: 45(\mathrm{v} / \mathrm{v})$ e fluxo de $0,9 \mathrm{ml} / \mathrm{min}$. Este sistema é o mesmo utilizado para a determinação de diclofenaco em plasma descrita no Capitulo I [8]. Neste sistema o diclofenaco foi eluido em 3,3 minutos e o seu padrão interno (ácido 2-(p-ciclo-hexen-l'-fenil)propiônico), em 6,5 minutos. 
Desta forma foi possivel automatizar a análise cromatográfica de diclofenaco e seus produtos de biotransformação hidroxilados. Os extratos secos de urina hidrolisada reconstituídos com fase móvel foram submetidos primeiramente ao sistema cromatográfico para análise simultânea dos produtos de biotransformação hidroxilados do diclofenaco, numa corrida de 45 minutos por amostra. Em seguida, os mesmos extratos foram submetidos ao segundo sistema para determinação do diclofenaco inalterado. Cerca de 15 horas são necessárias para a análise dos extratos de urina (replicata, $n=2$ ) provenientes de amostras de voluntários coletadas nos periodos de $0-4,4-8,8-12,12-24,24-36$ e 36-48 horas e dos extratos de urina provenientes dos padrões (replicata, $n=3$ ) utilizando estes dois sistemas cromatográficos num mesmo equipamento.

O método de determinação de diclofenaco e seus produtos de biotransformaçāo hidroxilados na urina mostrou-se sensivel, linear na faixa de estudo, com boa recuperação na extração e precisão das medidas para todos os componentes investigados. O procedimento analitico mostrou-se também altamente seletivo comparativamente àqueles já reportados, possibilitando estudos de excreção renal e metabolismo do diclofenaco bem como de interação farmacocinética. 


\section{Referências bibliográficas}

1. BATTISTA, H.J., WEHINGER, G., HENN, R. Separation and identification of non-steroidal antirheumatic drugs containing a free carboxyl function using high-performance liquid chromatography. J. Chromatogr., Amsterdam, v. 345, p. $77-89,1985$.

2. DEGEN, P.H. The assay of diclofenac and metabolites: a review. Methodol. Surv. Biochem. Anal., New York, v. 18, p. 107-114, 1988.

3. GEIGER, U.P., DEGEN, P.H., SIOUFI, A. Quantitative assay of diclofenac in biological material by gas-liquid chromatography. J. Chromatogr., Amsterdam, v. 1] l. p. 293-298, 1975.

4. GODBLLLON, J, GAURON, S., METAYER, J.P. High performance liquid chromatographic determination of diclofenac and its monohydroxilated metabolites in biological fluids. J. Chromatogr. Amsterdam, v. 338, p. $151-159,1985$

5. LANDSORP, D., JANSSEN, T.J., GUELEN, P.J.M., VREE, T.B. Highperformance liquid chromatographic method for the determination of diclofenac and its hydroxy metabolites in human plasma and urine. $\mathbf{J}$. Chromatogr., Amsterdam, v.528, p.487-494, 1990.

6. MENASSÉ, R., HEDWALL, P.R., KRAETZ, J., PERICIN, C. RIESTERER, A., SALLMANN, R., ZIEL, R., JAQUES, R. Pharmacological properties 
of diclofenac sodium and its metabolites. Scand. J. Rheumatol. Suppl,, Stockholm, v. 22, p. 5-16, 1978.

7. SAID, S.A., SHARAF, A.A Pharmacokinetics of diclofenac using a developed HPLC method. Arzneim. Forsch., v.31, p. 2089-2092, 1981

8. SANTOS, S.R.C.J.S., DONZELLA, H, BERTOLINE, M.A., PERERA, M.D., OMOSAKO, C.E., PORTA, V. Simplified micromethod for the HPLC measurement of diclofenac in plasma. Braz. J. Med. Biol. Res., Ribeirão Preto, v.25, p. 124-128, 1992.

9. SCHNEIDER, W. \& DEGEN, P.H. Simultaneous determination of diclofenac sodium and its hydroxy metabolites by capillary column gas chromatography with electron-capture detection. J. Chromatogr., Amsterdam, v. 217, p. 263-271, 1981

10. SCHNEIDER. W., DEGEN. P.H. Simultaneous determination of diclofenac sodium and its metabolites in plasma by capillary column gas chromatography with electron-capture detection. J. of Chromatogr., Amsterdam, v.383, p. 412-418, 1986.

11. SCHWEIZER, A., WILLIS, J.V., JACK, D.B, KENDALL, M.J. Determination of total monohydroxylated metabolites of diclofenac in urine by electron-capture gas-liquid chromatography. J. Chromatogr., Amsterdam, v. 195, p. $421-424,1980$.

12. SMALL, R.E. Diclofenac sodium. Clin. Pharm., Bethesda, v. 8, p.545-558, 1989 
13. TODD, P.A. \& SORKN, E.M. Diclofenac sodium. A reappraisal of its pharmacodynamic and pharmacokinetic properies, and theurapetic efficacy. Drugs, Auckland, v.35, p.244-285, 1988 ..

14. ZECCA, L., FERRARIO, P. \& COSTI, P. Determination of diclofenac and its metabolites in plasma and cerebrospinal fluid by high-performance liquis chromatography with electrochemical detection. J. Chromatogr., Amsterdam, v.567, p.425-432, 1991. 


\begin{abstract}
Diclofenac is a non-steroidal anti-inflammatory drug (NSAID) advocated for use in painful and inflammatory rheurnatic diseases and certain non-rheumatic conditions. Diclofenac is extensively metabolized mainly by oxidative pathways followed by glucuronide conjugation. A small percentage of the original drug is glucuronidated directly. Many methods have been described for the determination of diclofenac and its metabolites in biological fluids, including gas-chromatography with electron-capture detection and high-performance liquid chromatography (HPLC) with UV or electrochemical detection. However, none of the HPLC methods was sufficiently specific for use in kinetic disposition studies. We describe a sensixive and specific procedure for the determination of diclofenac and its hydroxy metabolites in urine, involving single extraction after enzymic hydrolysis of the glucuronic conjugates and HPLC with UV detection. The enzymic hydrolysis was performed by adding $500 \mu \mathrm{l}$ of urine to test tubes containing $10 \mathrm{mg}$ of a mixture of $\beta$-glucuronidase and anil-sulphatase and $500 \mu \mathrm{l}$ of acetate buffer $0,75 \mathrm{M}, \mathrm{pH} 5,0$. This mixture was incubated at $37^{\circ} \mathrm{C}$ for one hour. Then, $800 \mu$ of the mixture were transferted 10 test tubes containing $3,3 \mu \mathrm{\mu g}$ intemal standard for diclofenac (2-(p-ciclohexen-l'-il-phenyl)propionic acid) and $1 \mu \mathrm{g}$ intemal standard for metabolites (phenacetıne). Dichlormethane and isopropyl alcohol $(9: 1, \mathrm{v} / \mathrm{v})(2 \mathrm{ml})$ was added and the mixture was agitated with a vortex mixer and centrifuged at $3000 \mathrm{rpm}$ for 30 minutes. The aqueous phase was discarded and the organic phase filtered through a $0,4 \mu \mathrm{m}$ FHLP 01300 Millspore ${ }^{\circledR}$ filter and evaporated in a stream of nitrogen at $37^{\circ} \mathrm{C}$. The residue was dissolved in 500-2000 $\mu \mathrm{l}$ mobile phase and injected in the liquid chromatograph. Analytical separation was performed in two independent consecutives isocratic systems on reverse-phase column. In the first HPLC profile an ODS-Shumadru column, $150 \times 6,0 \mathrm{~mm}$, $5 \mu \mathrm{m}$ and a mobile phase constituted of acetate buffer $0,01 \mathrm{M}, \mathrm{pH} 5,0$, methanol and acetonitrile $(50: 40: 5, \mathrm{v} / \mathrm{v})$ at a flow rate of $1,0 \mathrm{ml} / \mathrm{min}$ were used for the elution of intemal standard (phenacetine) at 10 minutes, 4',5-dihydroxydiclofenac at 12 minutes, 3'-hydroxydiclofenac at 34 minutes, 4'-hydroxydiclofenac at 40 minutes and 5-hydroxydiclofenac at 44 minutes. In the second one a Novapak ${ }^{\circledR} C_{18}$ column, $150 \times 3,9$ $\mathrm{mm}, 4 \mu \mathrm{m}$ and a mobile phase constituted of acetate buffer $0,75 \mathrm{M}, \mathrm{pH} 5,0$ and acetonitrile $(55: 45, \mathrm{v} / \mathrm{v})$ at a flow rate of $0,9 \mathrm{ml} / \mathrm{min}$ were used for the elution of diclofenac at 3,3 minutes and intemal standard (2-(p-cyclohexen-l'-phenyl)propionic acid) at 6,5 minutes. Confidence limuts for diclofenac an its hydroxy metabolites were: $0,4-10,0 \mu \mathrm{g} / \mathrm{ml}$, linearity; $0.1 \mu \mathrm{g} / \mathrm{ml}$, sensitivity. $75 \%$, mean extraction recovery, and intra and interassay precision ranging from 1,3 to $2,2 \%$ and 3,3 to $5,7 \%$, respectively. This method proved to be sufficiendy sensitive, precise, accurate and specific for urinary excretin studies involving diclofenac and its hydroxy metabolites.
\end{abstract}




\section{Estudo de interação entre a ranitidina e o diclofenaco em voluntários sadios após administração peroral de Voltaren ${ }^{\circledR} \mathbf{5 0}$}

Capítulo IV 


\section{Índice}

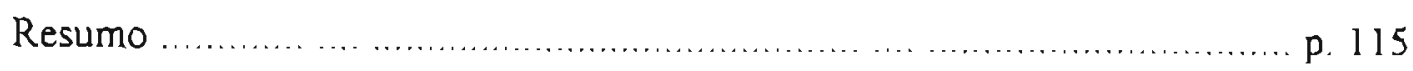

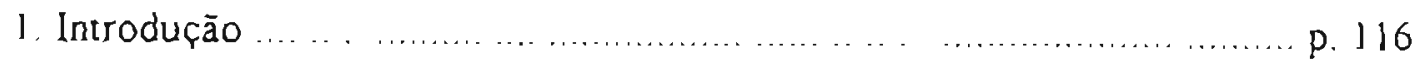



3 Material e metodos .................................................................... 122

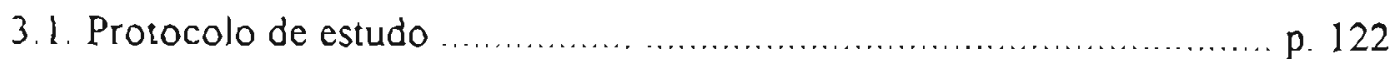

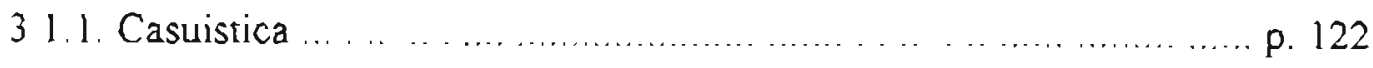

3.1.2. Administração dos färmacos ................................................... 123

3. 1.3. Coleta e armazenamento de amostras ..................................... p. 124

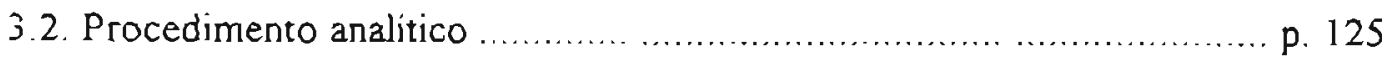

3.2.1. Análise das amostras de plasma ............................................. p. 125

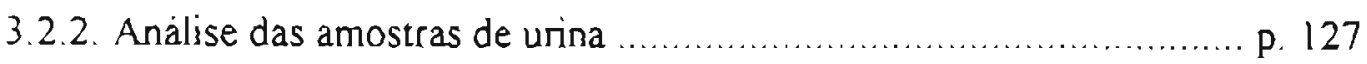

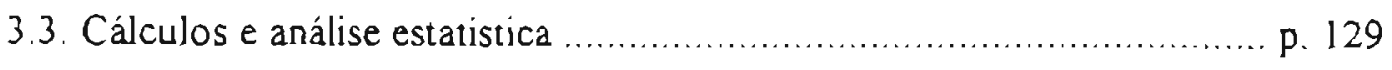





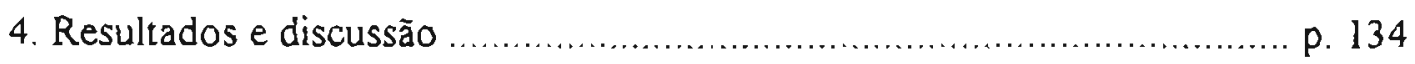




\section{Resumo}

Avaliou-se a existència ou não de interação farmacocinética entre a ranitidina e o diclofenaco em voluntários sadios após administração de dose peroral de Volzaren ${ }^{\circledR} 50$. Selecionaram-se 15 e avaliaram-se oito voluntários adulsos, de ambos os sexos, sadios, em estudo constituido por duas fases. Dos oito voluntários, um foi excluido do estudo. Na Fase I o diciofenaco foi administrado isoladamente aos voluntários em jejum pela manhã. Na Fase II, os voluntários foram submetidos a um tratamento de sete dias com ranitidina, depois do qual receberam nova dose de diclofenaco. A administração de ranitidina continuou por mais três dias. Foram colhidas amostras de sangue e urina no intervalo de 0-72 horas após a administração de diclofenaco nas duas fases do estudo. Determinou-se a concentração plasmática e urinária de dicloferaco e a concentração urinária de seus produtos de biotransformaçāo hidroxilados por técnica de cromatografia liquida de alta eficiência, em dois perfis independentes e consecutivos para diciofenaco e produtos de biotransformação, precedida por extração com solvente orgânico em meio ácido $e$, no caso das amostras de urina, precedida também por hidrólise enzimática. Os valores de "clearance" de formação $\left(\mathrm{Cl}_{f}\right)$ dos produtos de biotransformaçào hidroxilados foram, em X \pm EPM (mediana): $15,9 \pm 2,9(15,2)$ $\mathrm{ml} / \mathrm{min}$ para $\circ 4^{\prime}, 5$-hidroxidiclofenaco, $3,3 \pm 0,9 \quad(2,6) \mathrm{ml} / \mathrm{min}$ para 0 3'-hidroxidiclofenaco, $22,1 \pm 5,9(23,5) \mathrm{ml} / \mathrm{min}$ para 0 4'-hidroxidiclofenaco e $8,74 \pm 1,43(7,4) \mathrm{m} / \mathrm{min}$ para $\circ$ 5-hidroxidiclofenaco quando se administrou diclofenaco isoladamente. Não houve alteração significativa destes valores pela associação com a ranitidina. Da mesma forma, o "clearance" renal $\left(\mathrm{Cl}_{\mathrm{r}}\right)$ do diclofenaco, de $7,1 \pm 2,8(5,1) \mathrm{m} / \mathrm{min}$ após administração de diclofenaco isolado, não sofreu alteração significativa pela associação com a ranitidina. A associação com a ranitidina provocou um aumento significativo de cerca de $43 \%$ na meia-vida de eliminação do diclofenaco em plasma, que passou de $1,01 \pm 0,13 \mathrm{~h}(\mathrm{X} \pm \mathrm{EPM})$ na Fase I (fármaco isolado) para $1,44 \pm 0,34$ h na Fase II (fármaco associado), além de causar redução da excreção urinária do produto de biotransformaçāo 4'-hidroxidiclofenaco, que teve sua fração eliminada total $\left(\mathrm{Fel}_{\mathrm{T}}\right)$ reduzida de $5,85 \pm 1,12(5,06) \%$ (X \pm EPM (med)) na Fase I para $4.39 \pm 0,75(3,73) \%$ na Fase II. Com base nestes resultados sugere-se que a ranitidina reduza a biotransformação do diclofenaco pela diminuição da excreção renal de seu principal produto de biotransformação hidroxilado (4'-hidroxidiclofenaco) com conseqüente aumento da meia-vida de eliminação plasmática do diclofenaco. Apesar da interação farmacocinética aqui registrada, a associação diclofenaco-ranitidina é vantajosa para pacientes com história de úlcera péptica, suscetiveis a ulceração recorrente. 


\section{Introdução}

O diclofenaco e um antiinflamatório não-esteroidal capaz de suprimir inflamação aguda e crònica dor e hipertermia em modelos animais [16,29] Seus efeitos farmacológicos estão relacionados à inibiçăo da enzima cicloxigenase com conseqüente inibição da sintese de prostaglandinas [29].

O diclofenaco é indicado no tratamento de pacientes portadores de doenças reumáticas acompanhadas de dor e inflamação e também em algumas condiçōes nāo-reumáticas $[27,29]$.

Este färmaco é eliminado do organismo fundamentalmente através de biotransformação, sofrendo principalmente reações de oxidação em várias posições dos anéis aromáticos que originam quatro produtos de biotransformaçāo hidroxilados: 3'-hidroxidiclofenaco (3'-OH-D), 4'-hidroxidiclofenaco (4'-OH-D), 5-hidroxidiclofenaco (5-OH-D) e 4',5-di-hidroxidiclofenaco (4',5-OH-D) $[17,26,28]$. Em 1988, Faigle e colaboradores identificaram um quinto produto de biotransformaçāo do diclofenaco, $\quad 0$ 3'-hidroxi-4'-metoxidiclofenaco (3'-OH-4'-MeO-D). A formação deste produto envolve reaçōes de oxidação e metilação e é provável que os produtos de biotransformação $3^{\prime}-\mathrm{OH}-\mathrm{D}$ e $4^{\prime}-\mathrm{OH}-\mathrm{D}$ atuem como intermediairios destas reações [5] (Figura 1). 


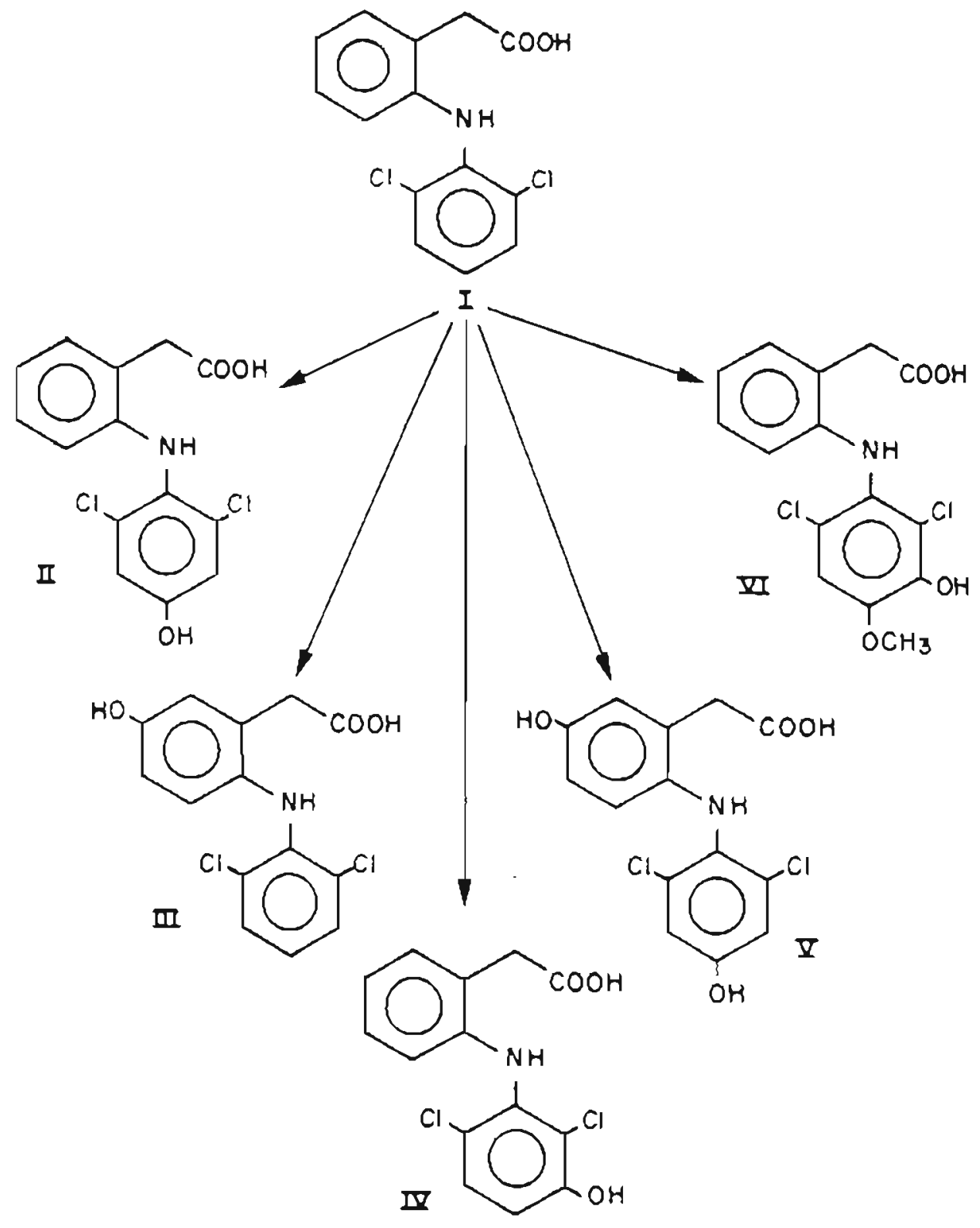

Figura 1: Diclofenaco e seus produtos de biotransformação.

I: diclofenaco; II: 4'.OH-D; III : 5-OH-D; IV : 3'-OH.D;

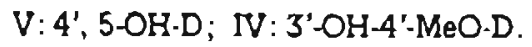


Os produlos de biotransformaçăo hidroxilados (4'-OH-D. 3'-OH-D. S-OH-D e 4',5-OH-D) apresentam uma cinética em plasma semelhante à do diclofenaco, atingindo concentração plasmática máxima cerca de 40 minutos após administração de solução peroral de diclofenaco de sódio. A meia-vida de decaimento plasmático dos produtos de biotransformaçāo hidroxilados varia entre 1 e 3 horas, sendo, portanto, semelhante à do diclofenaco. Decorridas 36 horas da administração já não é possivel detectar o diclofenaco ou seus produtos de biorransformaçāo hidroxilados no plasma. O produto de biotransformaçāo metoxilado (3'-OH-4'-MeO-D), por sua vez, alcança concentração plasmática máxima 12 horas após a administração e permanece no plasma por mais de 96 horas, apresentando meia-vida de eliminação de cerca de 80 horas [2].

Tanto o diclofenaco quanıo seus produtos de biotransformaçāo sofrem conjugaçào originando no homem glicuronatos e sulfatos que são excretados na bile e na urina $[17,26,28,29]$. No cào e no rato o diclofenaco sofre circulação entero-hepática [17]. Schneider e colaboradores, em estudo realizado em pacientes portadores de doença hepática ou càncer de pâncreas, determinaram que cerca de $5 \%$ da dose administrada por via oral foi excretada por via biliar na forma de diclofenaco inalterado e produtos de biotransformaçāo, mas este valor pode chegar a $10 \%$ em individuos com função hepática normai [23]

Entre os produtos de biotransformação hidroxilados, o de maior excreção urinária é o 4'-OH-D, seguido pelos produtos 4',5-OH-D, 5-OH-D e 3'-OH-D, em ordem decrescente de excreção urinária $[2,17]$. 
0 produto de biotransformaçāo 4'-OH-D apresenta atividade antiedematosa em ratos. sendo seis vezes mais potente neste caso que o ácido acetilsalicilico, mas 30 vezes menos ativo que o diclofenaco inaiterado. Também é ativo na redução do inchaço de artrite induzida em ratos, sendo, neste caso, 40 vezes menos eficiente que o diclofenaco. Apresenta atividade antipirética cerca de 30 vezes menor que a do diclofenaco. A atividade antiinflamatória deste produto de biotransformaçào deve-se à sua capacidade de inibir a sintese de prostaglandinas $m$ viro. Os outros produtos de biotransformação hidroxilados do diclofenaco não apresentam atividade antiinflamatoria e só são capazes de inibir a sintese de prostaglandinas $m$ vitro em altas doses. Nenhum dos produtos de biotransformaçào hidroxilados apresentou toxicidade superior à do díclofenaco: a $\mathrm{DL}_{50}$ do 4'-OH-D é da mesma ordem que a do diclofenaco inalterado. enquanto que a toxicidade dos outros produtos é significativamente menor. Além disso, nenhum destes produtos de biotransformação apresenta efeito deletério na mucosa gastrointestinal de ratos. ao contrário do fármaco inalterado [16]. O produto 3'-OH-4'-MeO-D é cerca de 300 vezes menos ativo que o diclofenaco inalterado na inibição da sintese de prostaglandinas in vitro e cerca de 50 vezes menos potente como analgésico [29]

Como a grande maioria dos fármacos antiinflamatórios não-esteroidais. o diclofenaco pode provocar, como efeito colateral. lesões no trato gastrointetinal [29]. Para evitar essas reações adversas alguns autores sugerem a administração de ranitidina, um antagonista de receptores $\mathrm{H}_{2}$ de histamina a pacientes que estejam em tratamento crônico com antiinflamatórios nāo-esteroidais [4]

A ranitidina é um antagonista de receptor $\mathrm{H}_{2}$ de histamina que, juntamente com a famotidina, vêm substituindo a cimetidina no tratamento de pacientes com 
lesōes gástricas, por se mostrar mais potente e por produzir menos efeitos colaterais.

Os fármacos que sofrem reações de biotransformação oxidativas no retículo endoplasmático hepatico, entre os quais inclui-se o diclofenaco, ligam-se ao citocromo P-450 formando um complexo que sofre oxidação pela ação de monoxigenases de função mista. A cimetidina também se liga ao citocromo P-450, produzindo um complexo citocromo-substrato estável. A formação deste complexo impede o acesso de outros fármacos ao sistema enzimático do citocromo P-450. inibindo as monoxigenases de função mista e reduzindo, desta forma, a biotransformação de outros fármacos. [24,25]. A ranitidina nāo forma um complexo tāo estável quanto a cimetidina e, portanto, nāo inibe a biozransformaçāo de outros färmacos na mesma extensão [24]. Alguns autores chegam a considerar a ranitidina e a famotidina livres de interação [19,32], mas, como a cimetidina, a ranitidina tambèm é capaz de inibir a monoxigenase $[9,10,13]$.

Estudos comprovam que a cimetidina e a ranitidina provocam redução do fluxo sanguineo hepático, e foi sugerido que este fato seria responsável pela redução da depuraçāo hepática de alguns fármacos [1]. Novas evidências, no entanto, indicam que os antagonistas de receptores $\mathrm{H}_{2}$ de histamina não têm efeito significativo sobre o fluxo sanguineo hepático $\{3,15,30\}$ e este efeito seria pouco importante na interação.

A cimetidina é capaz de inibir o metabolismo da nifedipina [24] o mesmo ocorrendo, em menor escala, com a ranitidina [13]. Também a nitrendipina sofreu inibiçào por parte da cimetidina [12] e da ranitidina $[9,22]$. A famotidina, um novo 
antagonista de receptores $\mathrm{H}_{2}$ de histamina, não mostrou interferência no metabolismo da nifedipina [11].

Outros fármacos que têm sua cinética alterada por inibiçāo de sua biotransformação quando associados à cimetidina ou à ranitidina são o midazolam [6], a warfarina e o metoprolol. As alterações provocadas pela ranitidina são sempre em menor escala que as provocadas pela cimetidina. Assim, quando é necessário associar um fármaco altamente biotransformado no sistema microssomal hepatico a um antagonista de receptor $\mathrm{H}_{2}$ de histamina opta-se pela ranitidina [24]. Em vista disso, a ranitidina é largamente prescrita em associaçào a antiinflamatórios nāo-esteroidais, como o diclofenaco. Que tipo de interação pode ser esperada, de forma a tornar essa associação vantajosa? Devido à ausência de trabalhos sobre tal assunto é imperativa a realizaçāo desse estudo, para dar suporte farmacológico ao Clínico, visando terapia eficaz e de baixo risco.

\section{Objetivo}

O objetivo deste trabalho é avaliar a existència ou não de interação entre diclofenaco, um fármaco altamente biotransformado, e a ranitidina. um antagonista de receptores $\mathrm{H}_{2}$ de histamina, altamente prescrito em associação. 


\section{Material e métodos}

\subsection{Protocolo de estudo}

\subsubsection{Casuística}

Foram selecionados inicialmente 15 voluntários sadios, de ambos os sexos, para inclusão no estudo. Apenas oito, dos quais um fumante e sete não fumantes, consumidores moderados ou nào-consumidores de álcool, com idade variando de 20 a 44 anos (28 \pm 8 anos, $\bar{X} \pm$ DP $)$, peso de 47 a $97 \mathrm{~kg}(64 \pm 15 \mathrm{~kg}, X \pm D P)$ e altura de 150 a $193 \mathrm{~cm}(17) \pm 14 \mathrm{~cm}, 8 \pm \mathrm{DP})$ concluiram o protocolo de estudo. A identificação e dados pessoais de cada voluntário são indicados no Quadro a.1, A pêndice. Todos os voluntarios foram informados em detalhes sobre o estudo e forneceram o seu consentimento de participação por escrito (Consentimento de Participação Pós-informaçāo, Apêndice). Nenhum deles tomou qualquer medicação que pudesse interferir no estudo nas très semanas que o precederam Um dos voluntários (Voluntário 8) foi retirado do estudo por ter contraido infecção durante o mesmo, necessitando da administração de antibióticos e antivirais 


\subsubsection{Administração dos fármacos}

O estudo foi dividido em duas fases, conforme o esquema:

\begin{tabular}{|c|c|c|}
\hline $\begin{array}{l}\text { Fase I } \\
\text { la semana }\end{array}$ & $\begin{array}{l}\text { Fase } \Pi \\
2^{a} \text { sernana }\end{array}$ & \\
\hline $\begin{array}{l}\text { Io dia } \\
\text { diclofenaco de sódio } \\
50 \mathrm{mg} \\
\text { dose únca }\end{array}$ & $\begin{array}{l}1^{\circ} \text { ao } 10^{\circ} \text { dia } \\
\text { cloridrato de ranicidina } \\
300 \mathrm{mg} / \mathrm{dia}\end{array}$ & $\begin{array}{l}7^{\circ} \text { dia } \\
\text { diclofenaco de sódio } \\
50 \mathrm{mg} \\
\text { dose única }\end{array}$ \\
\hline
\end{tabular}

O diclofenaco foi administrado na forma de comprimidos de revestimento entérico contendo $50 \mathrm{mg}$ de diclofenaco de sodio por comprimido (Voltaren ${ }^{\circledR 50}$ ), enquanto que a ranitidina foi administrada diariamente na dose de $300 \mathrm{mg}$, duas vezes ao dia

Na Fase 1 do estudo o diclofenaco foi administrado pela manhà aos voluntários em jejum em dose única peroral de um comprimido. Os voluntarios receberam desjejum uma hora após a aưministraçăo e, depois disso, seguiram uma dieta normal.

Uma semana após a realização da Fase I iniciou-se a Fase II. Nesta fase os voluntários foram submetidos a um tratamento de dez dias com ranitidina durante o qual receberam $300 \mathrm{mg}$ de cloridrato de ranitidina por dia, divididos em duas doses 
de $150 \mathrm{mg}$ cada, sendo uma dose administrada de manhă e a outra, à noite. No setimo dia do tratamento procedeu-se à administração do diclofenaco conforme descrito anteriormente para a Fase I. A ad́ministraçào de ranitidina continuou por mais três dias, correspondentes ao tempo necessário para as coletas de urina.

\subsubsection{Coleta e armazenamento de amostras}

\section{Plasma}

Foram coletadas amostras de sangue $0,5,1,1,5,2,3,4,6$ e 8 horas após a administração do diclofenaco, tanto na Fase I quanto na Fase II do estudo. Esta coleta foi feita com seringas plásticas descaráveis mantendo-se a veia dos voluntários com Butterfly Abbott heparinizado. O plasma foi separado por centrifugaçāo e mantido em congelador a $-20^{\circ} \mathrm{C}$ até a execução da anàlise.

Urina

A urina dos voluntarios foi coletada nos intervalos de $0-4,4-8,8-12$, $12-24,24-36,36-48,48-60$ e 60-72 horas após a administração do diclofenaco Esta coleta foi realizada em frascos àmbar contendo o antioxidante metabissulfito de sódio (4 mg/mL urina). No periodo de coleta os frascos foram mantidos em refrigerador. Mediram-se o pH e o volume total de urina em cada intervalo de 
coleta Aliquotas de $20 \mathrm{ml}$ em duplicara foram mantidas em congelador a $-20^{\circ} \mathrm{C}$ até a execuçào da análise.

\subsection{Procedimento analítico}

\subsubsection{Análise das amostras de plasma}

As amostras de plasma foram analisadas em duplicata paraleiamente a padrões em três diferentes concentraçōes em triplicata. A concentração plasmática de diclofenaco nas amostras foi determinada através de cromatografia liquida de aha eficiência em fase reversa precedida de extração, conforme descrito no Capitulo I e resumido no Esquerna analítico 1 [21]. 


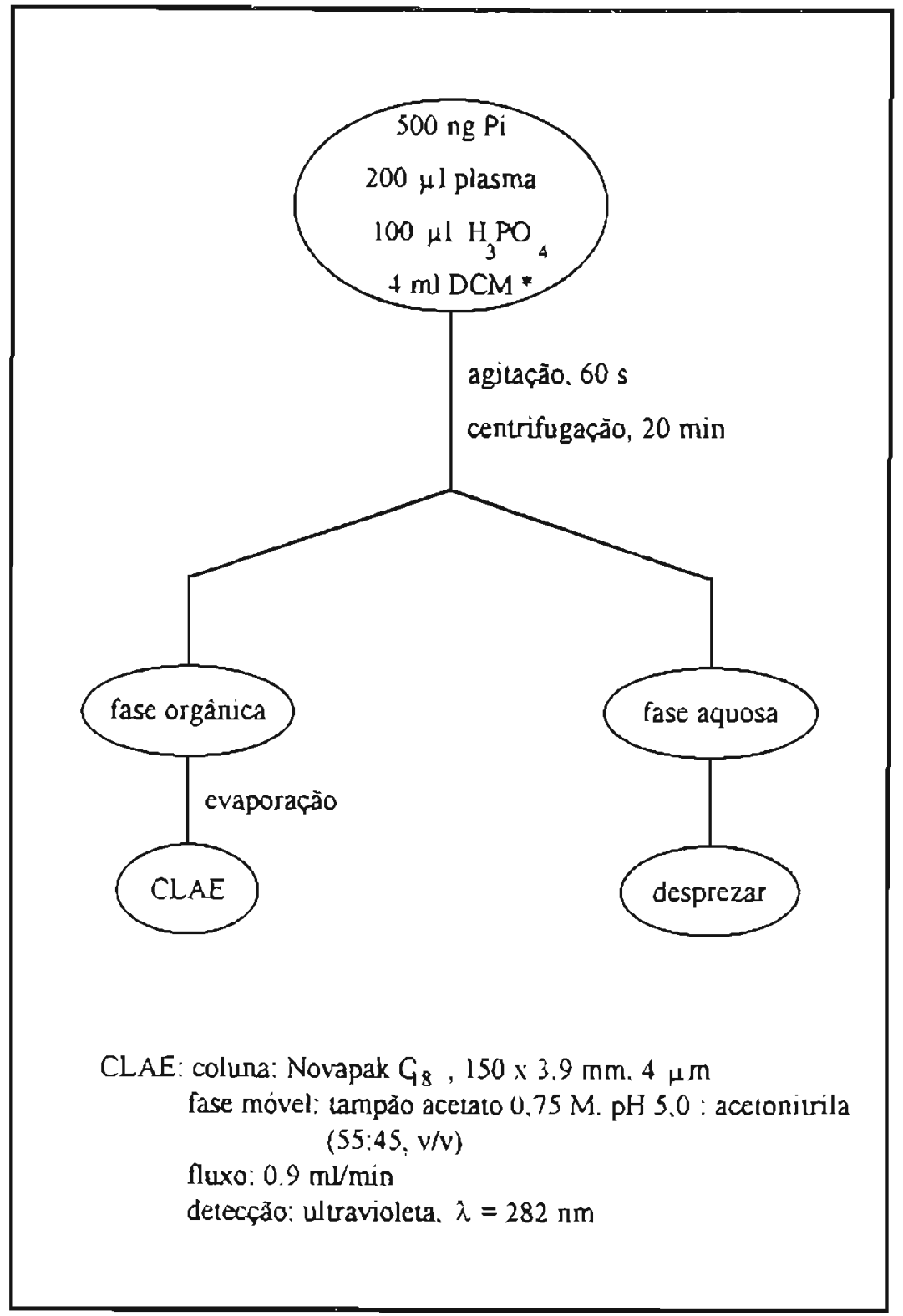

Esquema analítico 1: Micrométodo para determinação de diclofenaco em plasma através de cromatografia líquida de alta eficiência (CLAE). 


\subsubsection{Análise das amostras de urina}

As amostras de urina foram analisadas em duplicata paralelamente a padrōes em três diferentes concentraçōes em triplicata. A concentração urinária de diclofenaco e seus metabólitos hidroxilados nas amostras foi determinada através de cromatografia líquida de alta eficiência precedida de hidrólise enzimática e extração com solvente orgânico em meio ácido conforme descrito no Capitulo III e resumido no Esquema analítico 2 




Esquema analítico 2: Procedimento de extração para determinação de diclofenaco e seus produtos de biotransformação hidroxilados em unina. 


\subsection{Cálculos e análise estatística}

\subsubsection{Cálculos}

\section{Plasma}

A farmacocinérica do diclofenaco em plasma após administração de dose unica peroral de diclofenaco de sódio associado ou não à ranitidina foi avaliada em voluntários sadios com base nas curvas "concentração plasmática vs tempo" $(\mathrm{C} \times \mathrm{t})$ e "transformação logaritmica da concentração plasmática vs tempo" $(\log C \times t)$ Aplicou-se um modelo bicompartimental aberto de administração extravascular, caracterizado por três fases: absorção, distribuição e elíminação [18]

Foram calculados os seguintes parâmetros farmacocinéticos:

- $C_{\max }$. concentração plasmática máxima que o fármaco atinge após a administração peroral. É obtida a partir da curva "concentraçăo plasmática ( $\mathrm{ng} / \mathrm{mL}$ ) vs tempo (h)".

- $\mathrm{t}_{\max }$ tempo necessário para que a concentração plasmática do fármaco atinja o valor de $C_{\max }$. Também é obtido a partir da curva "concentração plasmatica (ng/mL) vs tempo (h)"

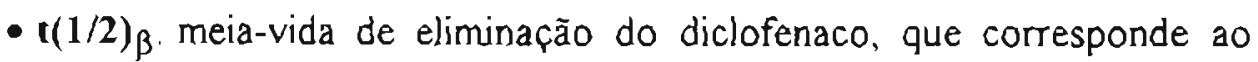
tempo necessário para que a concentração plasmática do f'ármaco se reduza em 
$50 \%$ É obtida graficamente a partir da curva "concentração plasmática $(\mathrm{ng} / \mathrm{mL})$ vs tempo (h)"

- B: constante de velocidade de eliminação. calculada através da equação

$$
\beta=\frac{0,693}{\mathrm{t}(1 / 2)_{\beta}}
$$

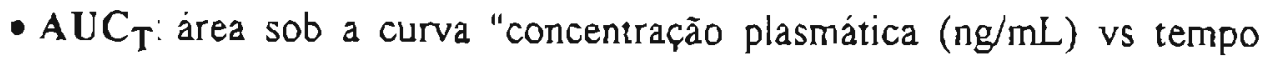
(h)", calculada da seguinte forma:

$$
\begin{aligned}
& \mathrm{AUC}_{\mathrm{T}}=\mathrm{AUC}_{0-8}+\mathrm{AUC}_{8 \cdot-\infty} \quad(\mathrm{ng} \cdot \mathrm{h} / \mathrm{ml}) \\
& \text { onde: }
\end{aligned}
$$

$\mathrm{AUC}_{0-8}$ : área sob a curva "concentração plasmática $(\mathrm{ng} / \mathrm{mL}) \times$ tempo $(h) "$ no intervalo de 0 a 8 horas, calculada pelo método dos trapezóides através da equaçăo
$\mathrm{AUC}_{0.8}=\sum \mathrm{AUC}_{\text {incerato }}$
e
$A U C_{\text {intervato }}=\frac{\left(t_{2}-t_{1}\right)\left(C_{1}+C_{2}\right)}{2} \quad(n g \cdot h / m l)$

$t_{1}$ : instante inicial do intervalo em que se quer determinar AUC;

$t_{2}$ instante final do intervalo em que se quer determinar AUC;

$C_{1}$ : concentração plasmática de diclofenaco em $t_{1}$ e; 
$\mathrm{C}_{2}$ concentração plasmática de diclofenaco em $\mathrm{t}_{2}$.

e:

$\mathrm{AUC}_{8-\infty}$ área sob a curva "concentração plasmática (ng/mL) x tempo (h)" no intervalo de $8 \mathrm{~h}$ a $\propto$, calculada por extrapolação ate infinito através da equação:

$\mathrm{AUC}_{8 . \infty}=\frac{\mathrm{C}_{8}}{\beta} \quad(\mathrm{ng} \cdot \mathrm{h} / \mathrm{ml})$

onde:

$\mathrm{C}_{8}$ : concentração plasmática de diclofenaco em $\mathrm{t}=8 \mathrm{~h}$.

- $\mathrm{Cl}_{\mathrm{T}}$ : taxa de depuração plasmática cotal ("clearance" total) do diclofenaco, calculada pela equação:

$\mathrm{Cl}_{\mathrm{T}}=\frac{\mathrm{D}}{\mathrm{AUC} \mathrm{C}_{\mathrm{T}}} \quad(\mathrm{m} / \mathrm{min})$

onde.

D dose de diclofenaco administrada.

- $V_{d}$ volume aparente de distribuição do fármaco, obtido através da equaçào.

$$
v_{d}=\frac{C l_{T}}{\beta}
$$




\section{Urina}

A excreção urinária do diclofenaco e de seus metabólito hidroxilados em voluntários sadios após administração de dose única de diclofenaco associado ou nào à ranitidina foi avaliada através dos seguintes paràmetros $[7,18]$ :

- Ae $_{\Delta t}$ : quantidade de fármaco ou metabólito excretada na urina num determinado intervalo de tempo. É obtida pela equação:

$$
A e_{\Delta t}=C_{\Delta t} \times V_{\Delta t} \quad(\mathrm{mg})
$$

onde:

$C_{\Delta t}$ concentração urinária de diclofenaco ou produto de biocransformação no intervalo de tempo $\Delta t$ e;

$V_{\Delta t}$ : volume de urina no intervalo de tempo $\Delta t$

- Fel $\mathbf{T}$ fração da dose eliminada na urina sob forma de diclofenaco ou produto de biotransformação durante todo o periodo de duração do estudo. É calculado pela equação:

$$
\begin{aligned}
& \mathrm{Fel}_{\mathrm{T}}=\sum \mathrm{Fel}_{\Delta s} \\
& \mathrm{e}:
\end{aligned}
$$

Fel $\Delta$ t fração da dose administrada eliminada na urina sob forma de diclofenaco ou produto de biotransformação, calculada pela equação: 


$$
\mathrm{Fel}_{\Delta 1}=\frac{A \mathrm{e}_{\Delta 1}}{\mathrm{D}} \times 100
$$

- $\mathrm{Cl}_{\mathbf{r}}$. taxa de depuraçăo renal ("clearance" renal) do diclofenaco, obtida por meio da equação:

$$
\mathrm{Cl}_{\mathrm{r}}=\mathrm{Fel}_{\mathrm{Td}} \times \mathrm{Cl}_{\mathrm{T}} \quad(\mathrm{ml} / \mathrm{min})
$$

onde:

Fel Td. fração da dose eliminada na urina sob forma de diclofenaco durante todo o periodo de duração do estudo.

- $\mathrm{Cl}_{\mathrm{f}}$ taxa de formação ("clearance" de formaçāo) de cada produto de biotransformação do diclofenaco, calculada pela equação:

$$
\mathrm{Cl}_{\mathrm{r}}=\mathrm{Fel}_{\mathrm{Tm}} \times \mathrm{Cl}_{\mathrm{T}} \quad(\mathrm{mL} / \mathrm{min})
$$

onde:

$\mathrm{Fel}_{\text {Tm }}$ : fração da ơose eliminada na urina sob forma de cada produto de biotransformação do diclofenaco durante todo o periodo de duração do estudo.

\subsubsection{Análise estatística}

Sugeriu-se, com base estatística, que a interpretacão dos resultados fosse efetuada utilizando-se teste estatístico não-paramétrico, uma vez que se trata de 
estudo altamente controlado, investigando-se, no entanto, populaçăo reduzida Desta forma os resultados foram submetidos ao teste de Wilcoxon ("Rank Sum Test"). Efetuou-se também um teste estatistico paramétrico (teste "t"de Student) para efeito de comparação [20].

\section{Resultados e discussão}

Os principais paràmetros farmacocinéticos do diclofenaco em voluntários sadios, determinados com base nas curvas de decaimento plasmático do diclofenaco em função do tempo após administração de diclofenaco isolado e associado à ranitidina, estāo descritos na Tabela 1. 
Tabela 1 Disposıção cinética do diclofenaco em voluntanos sadios apos dose única peroral de diclofenaco de sódio.

\begin{tabular}{|c|c|c|c|c|}
\hline Paràmetro & diclofenaco & $\begin{array}{c}\text { diclofenaco } \\
+ \\
\text { ranitidina }\end{array}$ & p & significância \\
\hline$t(1 / 2)_{\beta}(h)$ & $\begin{array}{c}1.01 \pm 0.13 \\
(0.95)\end{array}$ & $\begin{array}{c}1.44 \pm 0.34 \\
(0,95)\end{array}$ & $\begin{array}{l}0.26^{*} \\
0.05^{* *}\end{array}$ & $\begin{array}{l}\mathrm{NS}+ \\
\mathrm{S}_{+}^{+}\end{array}$ \\
\hline$\beta\left(b^{-1}\right)$ & $\begin{array}{c}0.7683 \pm 0.1102 \\
(0,7295)\end{array}$ & $\begin{array}{c}0,5933 \pm 0.0859 \\
(0.7295)\end{array}$ & $\begin{array}{l}0.23 \\
0,09\end{array}$ & $\begin{array}{l}\text { NS } \\
\text { NS }\end{array}$ \\
\hline $\mathrm{Cl}_{\mathrm{T}}(\mathrm{mL} / \mathrm{min})$ & $\begin{array}{c}447 \pm 80 \\
(374)\end{array}$ & $\begin{array}{c}408 \pm 52 \\
(367)\end{array}$ & $\begin{array}{l}0.69 \\
0.35\end{array}$ & $\begin{array}{l}\text { NS } \\
\text { NS }\end{array}$ \\
\hline$V d(I)$ & $\begin{array}{c}37.9 \pm 7.2 \\
(30.7)\end{array}$ & $\begin{array}{c}46.7 \div 6.7 \\
(48.8)\end{array}$ & $\begin{array}{l}0.39 \\
0.45\end{array}$ & $\begin{array}{l}\text { NS } \\
\text { NS }\end{array}$ \\
\hline$A \cup C_{T}(n g \cdot h / m l)$ & $\begin{array}{c}1986 \pm 252 \\
(2075)\end{array}$ & $\begin{array}{c}2022 \pm 209 \\
(2113)\end{array}$ & $\begin{array}{l}0.91 \\
0.93\end{array}$ & $\begin{array}{l}\text { NS } \\
\text { NS }\end{array}$ \\
\hline
\end{tabular}

valores em $X \pm$ EPM (mediana)

" teste " $\mathrm{t}$ ". paramétrico

* teste de Wilcoxon. nào-paramétrico

†NS: dıferença não-signıficatıva

† S:diferença significatıva

As curvas médias de decaimento plasmático do diclofenaco em função do tempo após administração isolada e associado à ranitidina estão iłustradas na Figura 2, enquanto que as curvas das medianas podem ser vistas na Figura 3. 




Figura 2: Curvas médias de decaumento plasmático do diclofenaco após admunistração de Voltaren ${ }^{\sqrt{3}} 50$ isolado (Fase I) ou associado à ranitidina (Fase II) a voluntários sadios $(n=7)$. 




Figura 3: Curvas medianas de decaimento plasmatico do diclofenaco após administraçăo de Vottaren 50 isolado (Fase I) ou associado à ranitidina (Fase II) a voluntários sadios $(n=7)$ 
Observou-se uma diferença significativa, com $p=0,05$, entre os valores de meia-vida de eliminaçăo do diclofenaco nas duas fases do estudo. Após administração de diclofenaco isolado (Fase I), obteve-se meia-vida de, expressa em $X \pm E P M$ (mediana), $1,01 \pm 0,13(0,95) \mathrm{h}$. Quando o diclofenaco foi associado à raniridina (Fase II), a meia-vida aumentou para 1,44 $\pm 0,34(0,95)$ h (Tabela 1). Os demais parâmetros farmacocinéticos, como constante de eliminação $(\beta)$, depuração plasmática total $\left(\mathrm{Cl}_{\mathrm{T}}\right)$, volume aparente de distribuição $(\mathrm{Vd})$ e área sob a curva "concentração plasmática vs tempo" (AUC $C_{T}$ ) não mostraram diferença entre as duas fases do estudo (Tabela 1).

Os valores de meia-vida de eliminaçāo $\left(1(1 / 2)_{\beta}\right)$ e àrea sob a curva "concentração plasmática vs tempo" (AUC ) obtidos para o diclofenaco na Fase I deste estudo são semelhantes aos descritos anteriormente na literatura para voluntários sadios $[2,31]$

A Figura 4 ilustra as curvas média de excreção urinária do diclofenaco inalterado e de seus produtos de biotransformação hidroxilados nas Fases I e II deste estudo. As medianas dos valores de fração da dose administrada eliminada na urina sob forma de fármaco inalterado ou biotransformado em cada periodo de coleta $(0-4,4-8,8-12,12-24,24-36,36-48,48-60$ e 60-72) nas Fases I e II do estudo estão ilustradas nas Figuras $5,6,7,8$ e 9 respectivamente para o 4',5-di-hidroxidiclofenaco, o 3'-hidroxidiclofenaco, o 4'-hidroxidiclofenaco, o 5-hidroxidiclofenaco e o diclofenaco inalterado. 


\section{FRACAO ELIMINADA - MEDIAS}


Figura 4: Curvas médias de excreção urinária de diclofenaco e de seus produtos de biotransformaçào hidroxilados após administraçào de dose única de diclofenaco de sódio isolado ou associado à ranitidina $(n=7)$. 


\section{FRAÇĀO ELIMINADA VS INTERVALO 4'5-DIIDROXIDICLOFENACO}

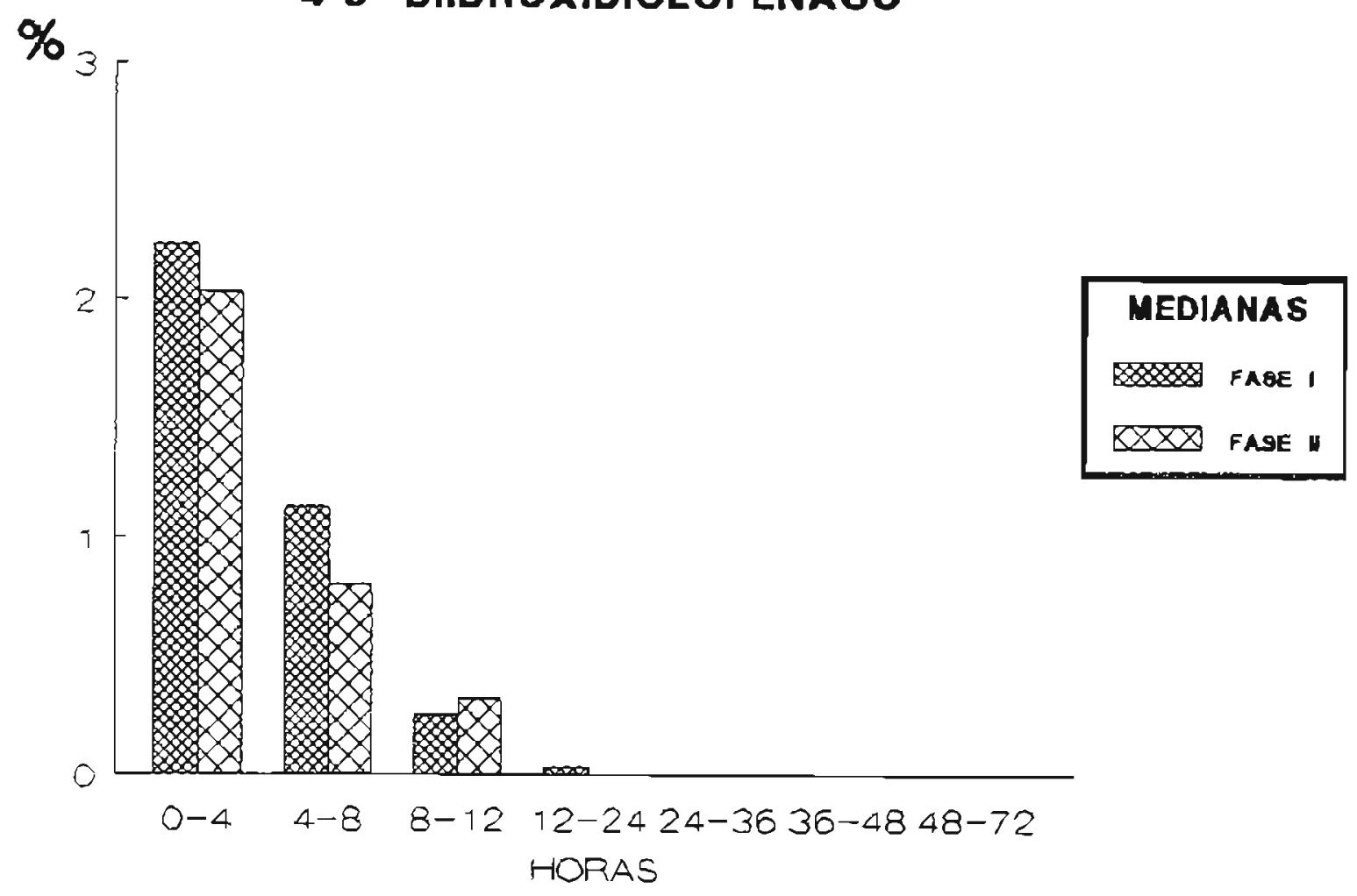

Figura 5: Fraçào da dose administrada eliminada na unina sob forma de 4'.5-di-hidroxudiclofenaco apos admunistração de dose única de diclofenaco de sódio isolado ou associado à rantidina - medianas $(n=7)$. 


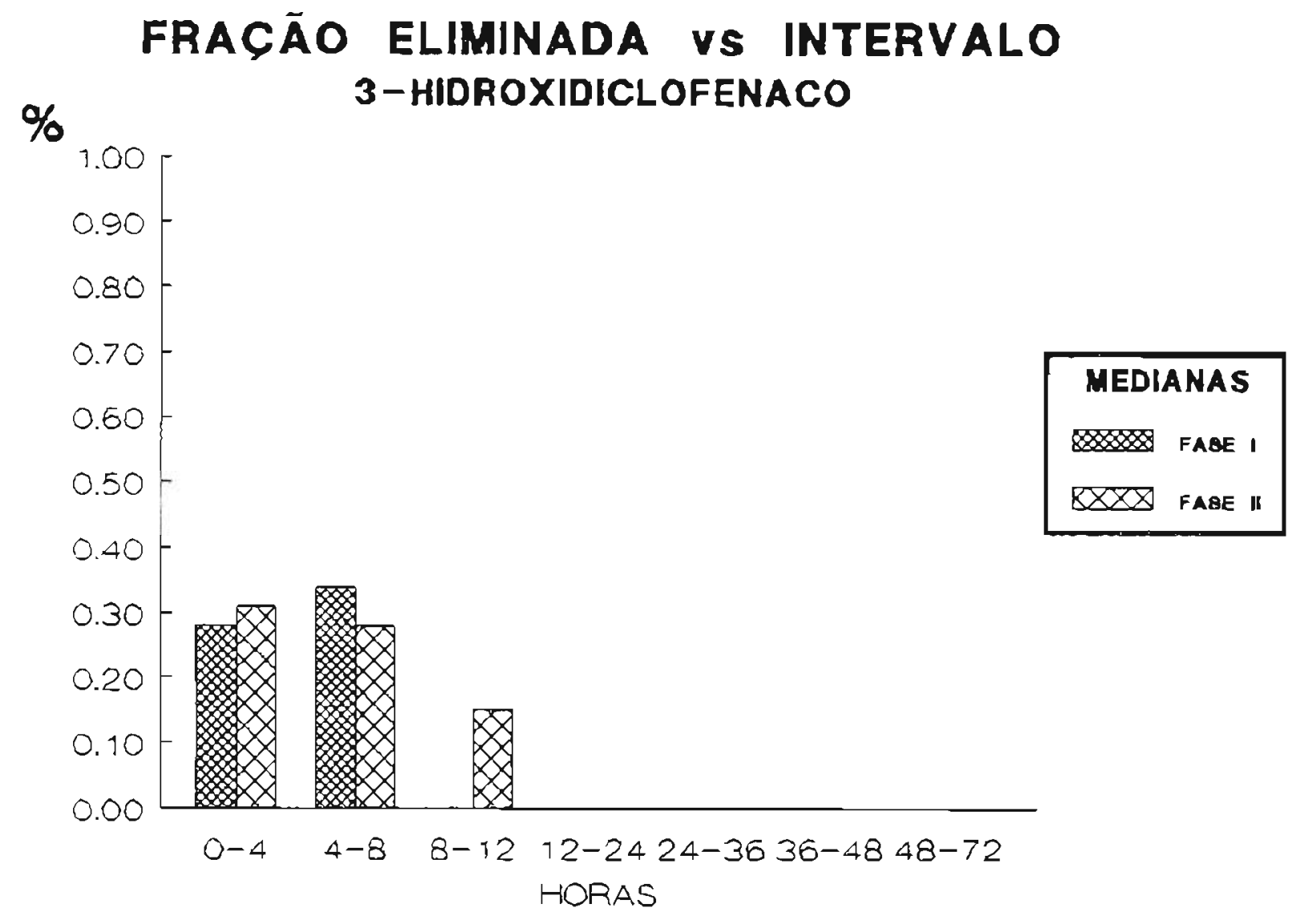

Figura 6: Fraçào da dose ad́ministrada eliminada na unina sob forma de 3'-hidroxidiclofenaco após administração de dose única de diclofenaco de sódio isolado ou associado à ranividina - medianas $(n=7)$. 




Figura 7: Fraçăo da dose administrada eliminada na urina sob forma de 4'-hidroxidiclofenaco após administraçào de dose única de diclofenaco de sódio isolado ou associado à ranitidina - medianas $(n=7)$. 
FRAÇĀO ELIMINADA VS INTERVALO

$\%$ 5-HIDROXIDICLOFENACO



MEDIANAS

FA8E I

QXX FASE W

Figura 8. Fraçào da dose adminıstrada eliminada na urina sob forma de j-hudroxidiclofenaco após ad́munistração de dose única de diciofenaco de sódio ısolado ou assocrado à ranitidina - medianas $(n=7)$ 




Figura 9: Fraçào da dose administrada eliminada na urina sob forma de diclofenaco inalterado apos admunustração de dose única de diclofenaco de sódio isolado ou assocıado à ranutıdina - medianas $(n=7)$. 
Observou-se decaimento exponencial para os principais produtos de biouransformação hidroxilados do diclofenaco, o 4'.5-OH-D (Figuras 4 e 5), o 4'-OH-D (Figuras 4 e 7) e o 5-OH-D (Figuras 4 e 8). O mesmo não ocorreu para o 3'-OH-D (Figuras 4 e 6), o que é explicado pelo fato deste produto ser, entre os produtos de biotransformaçào hidroxilados, o de menor imporància na depuração hepática do diclofenaco e, portanto, de menor excreção urinária $(2,17]$. Assim sendo, no presente trabalho, não se observou decaimento exponencial deste produto em funçào do tempo.

A excreção renal de diclofenaco inalterado e de seus produtos de biotransformação expressa sob forma de fração eliminada no periodo de 0-72 horas é descrita nas Tabela 2 e 3 A e B. A fração da dose administrada eliminada na urina sob forma inalterada e biotransformada no periodo de 0-72 horas foi da ordem de $20 \%$ nas duas fases do estudo. 
Tabela 2. Excreção renal de diclofenaco inalterado e seus pradutos de biotransformaçào hidroxilados em voluntánios sadios após dose única peroral de diclofenaco de sódı expressa por meso da fraçào da dose adminisirada excretada na urına durante o periodo do estudo $\left(\mathrm{Fel}_{\mathrm{T}}\right)$

\begin{tabular}{|c|c|c|c|c|}
\hline \multirow[t]{2}{*}{ Produto } & \multicolumn{2}{|c|}{$\mathrm{Fel}_{\mathrm{T}}(\%)$} & \multirow[t]{2}{*}{$p$} & \multirow[t]{2}{*}{ significância } \\
\hline & diclofenaco & $\begin{array}{c}\text { diclofenaco } \\
+ \\
\text { ranitidina }\end{array}$ & & \\
\hline 4'S-OH-D & $\begin{array}{c}3.81 \pm 0.69 \\
(3,55)\end{array}$ & $\begin{array}{c}3.61 \pm 0.67 \\
(2,99)\end{array}$ & $\begin{array}{l}0.84^{*} \\
0.67^{* *}\end{array}$ & $\begin{array}{l}\text { NSt } \\
\text { NS }\end{array}$ \\
\hline $3-O H-D$ & $\begin{array}{c}0.83 \pm 0,27 \\
(0,69)\end{array}$ & $\begin{array}{c}0,72 \pm 0,20 \\
(0,87)\end{array}$ & $\begin{array}{l}0.76 \\
0.67\end{array}$ & $\begin{array}{l}\text { NS } \\
\text { NS }\end{array}$ \\
\hline $4^{\prime}-O H-D$ & $\begin{array}{c}5.85 \pm 1.12 \\
(5,06)\end{array}$ & $\begin{array}{c}4.39 \pm 0,75 \\
(3,73)\end{array}$ & $\begin{array}{l}0.30 \\
0.05\end{array}$ & $\begin{array}{l}\text { NS } \\
\text { S }\end{array}$ \\
\hline S-OH-D & $\begin{array}{c}2.21 \pm 0.41 \\
\quad(1.92)\end{array}$ & $\begin{array}{c}1.99 \pm 0.38 \\
(1.96)\end{array}$ & $\begin{array}{l}0.70 \\
0.27\end{array}$ & $\begin{array}{l}\text { NS } \\
\text { NS }\end{array}$ \\
\hline diclofenaco & $\begin{array}{c}1.69 \pm 0.65 \\
(1.13)\end{array}$ & $\begin{array}{c}1.47 \pm 0.47 \\
(1,00)\end{array}$ & $\begin{array}{l}0.78 \\
0.45\end{array}$ & $\begin{array}{l}\text { NS } \\
\text { NS }\end{array}$ \\
\hline
\end{tabular}

valores em $X \pm E P M$ (mediana)

*: teste " $\mathrm{t}$ ", paramétrico

*: teste de Wilcoxon, não-paramétrico

$+N S$ : diferença não-sıgnıficativa

$\ddagger S$ : diferença sıgnıficatıva 
Tabela 3: Excreçào renal de diclofenaco inalterado e seus produtos de biotransformação hidroxilados em voluntarios sadios após dose única peroral de diclofenaco de sódio expressa por meio da fração da dose administrada excretada na unna durante o penodo do estudo $\left(\mathrm{Fel}_{\mathrm{T}}\right)$.

A. Faíxa de vanação (X - DP - X + DP).

\begin{tabular}{|l|c|c|}
\hline \multirow{2}{*}{ Produto } & \multicolumn{2}{|c|}{$\mathrm{Fel}_{\mathrm{T}}(\%)$} \\
\cline { 2 - 3 } & diclofenaco & $\begin{array}{c}\text { diclofenaco } \\
+ \\
\text { ranitidina }\end{array}$ \\
\hline \hline 4'S-OH-D & $1,99-5,63$ & $1.83-5.39$ \\
3'-OH-D & $0.11-1.55$ & $0.20-1.24$ \\
4'-OH-D & $2.88-8.82$ & $2.42-6.36$ \\
5-OH-D & $1.13-3.29$ & $0.98-3.98$ \\
diclofenaco & $0.00-3.42$ & $0.21-2.71$ \\
\hline
\end{tabular}

B: Valores minimos e máximos

\begin{tabular}{|l|c|c|}
\hline \multirow{2}{*}{ Produto } & \multicolumn{2}{|c|}{ Fel $_{\mathrm{T}}(\%)$} \\
\cline { 2 - 3 } & diclofenaco & $\begin{array}{c}\text { diclofenaco } \\
+ \\
\text { ranitidina }\end{array}$ \\
\hline \hline 4'5-OH-D & $1,96-6.79$ & $0.90-6,33$ \\
3'-OH-D & $0,00-2,11$ & $0.00-1,25$ \\
4'-OH-D & $2.85-11.83$ & $1.99-7.83$ \\
5-OH-D & $0.83-3.77$ & $0.27-3.22$ \\
diclofenaco & $0.13-5.30$ & $0.00-3.76$ \\
\hline
\end{tabular}

A excreção renal mostrou-se significativamente reduzida pela associação com a ranitidina apenas para o produto de biotransformação 4'-OH-D, com $p \leq 0,05$, com diminuição da fraçāo eliminada total $\left(\mathrm{Fel}_{\mathrm{T}}\right)$ de $5,85 \pm 1,12(5,06)$ para $4,39 \pm 0,75(3,73) \%$ (valores em X \pm EPM (med)) (Tabela 2). A faixa de 
variação da fração eliminada total ( $\mathrm{Fel}_{\mathrm{T}}$ ) deste produto foi reduzida de 2,88 - 8,82 quando o diclofenaco foi administrado isoladamente para 2,42-6,36 quando o diclofenaco foi associado à ranitidina (Tabela 3A) e os valores minimos e máximos foram reduzidos respectivamente de 2,85 e $11,83 \%$ quando o diclofenaco foi administrado isoladamente para 1,99 e $7,83 \%$ quando o diclofenaco foi associado à ranitidina (Tabela 3B).

Os outros produtos de biotransformação hidroxilados nāo apresentaram redução significativa de sua excreção renal pela associação com a ranitidina (Tabelas 2, 3A e B). Acredita-se que a diminuição da excreção renal de produtos de biotransformação do diclofenaco só seja detectável a nivel do produto 4'-OH-D por ser este o produto de biotransformação hidroxilado de maior excreção urinária e de maior contribuição na depuração hepática do diclofenaco $[2,17]$.

Apesar da ausência de estudos na literatura reporando tal interação, os resuultados obtidos no presente trabalho referentes à excreção urinária $\left(\mathrm{Fel}_{\mathrm{T}}\right)$ estāo de acordo com investigaçōes anteriores, em que a eliminaçāo de diclofenaco sob forma de produtos hidroxilados é descrita na seguince ordem, do produto mais excretado para o menos excretado: 4'-OH-D, 4',5-OH-D, 5-OH-D e 3'-OH-D $[2,17]$. Devido à sua lenta eliminação, o produto $3^{\prime}-\mathrm{OH}-4^{\prime}-\mathrm{MeO}-\mathrm{D}$ é detectado em pequenas quantidades na urina em estudos de excreção urinária realizados em periodos de até 96 horas. Isto não significa, no entanto, que este seja um produto de biotransformação menos importante que os outros, já que ele apresenta valores de àrea sob a curva "concentração plasmática vs tempo" superiores aos de todos os produtos de biotransformação hidroxilados [2]. 
Não foi observada alteração significativa na excreção renal de diclofenaco inalterado pela associação com a ranitidina (Tabelas 2, 3A e B). A depuração renal do diclofenaco é de pequena imporància, uma vez que porcentagens inferiores a $5 \%$ da dose administrada $[2,17]$ são eliminadas na urina sob forma inalterada Os resultados do presente trabalho estāo de acordo com os anteriormente reportados para o homem evidenciando eliminação na faixa ao redor de 3,4 e $2,7 \%$ da dose administrada sob forma de produto inalterado na urina após administração isolada ou associada, respectivamente (Tabela 3A). Entretanto, devido a variações individuais da biotransformação hepática valores minimos de $0.13 \%$ e máximos de $5.30 \%$ foram obtidos na presente investigação (Tabela 3A e B). A Figura 9 ilustra a fração eliminada de diclofenaco inalterado em função do tempo. Observa-se, na Fase 1 (diclofenaco isolado), um decaimento mais acentuado da fração eliminada que o observado na Fase II (diclofenaco associado à ranitidina). Quando a ranitidina foi associada ao diclofenaco (Fase II) observou-se um prolongamento da meia-vida de eliminação do diclofenaco em plasma (Tabela 1 . Figuras 2 e 3) comprovada pelos resultados obtidos a partir da excreção urinária deste produto expressa em fraçăo eliminada no intervalo 0-4 e 4-8 horas (Figura 9) A diminuição na biotransformação, evidenciada pela diminuiçào na excreção renal de 4'-OH-D, é responsável pelo prolongamento da meia-vida de eliminação do diclofenaco quando associado à ranitidina.

A literatura repona diversos valores para o parâmetro $\mathrm{Fel}_{\mathrm{T}}$ (fração da dose administrada eliminada na urina) dos produtos de biotransformaçāo do diclofenaco, valores estes que não coincidem com os obtidos neste trabalho. Acredita-se que isto tenha ocorrido provavelmente devido à falta de sensibilidade e 
seletividade da metodologia empregada para as dosagens nos estudos anteriores $[8,14]$.

Um perfil da excreção urinária de diclofenaco inalterado e seus produtos de biotransformação hidroxilados após administração do produto isolado (Fase I) ou associado à ranitidina (Fase II) é ilustrado nas Figuras 10 e 11 respectivamente em médias e medianas. Da mesma forma, a depuraçāo renal e hepática do diclofenaco após administração peroral do prođuto farmacêutico estão ilustradas nas Figuras 12 e 13 respectivamente em médias e medianas. Nenhum estudo anterior reportou dados relativos aos parâmentros $\mathrm{Cl}_{\mathrm{f}}$ ("clearance" de formação) dos produtos 4'-OH-D, 4',5-OH-D, 5-OH-D e 3'-OH-D, quer após administração isolada do diclofenaco, quer após associacăo com outros fármacos e, mais especificamente, com a ranitidina. Assim sendo, os valores para este parâmetro obridos na presente investigação foram apenas comparados entre si ("Fase I vs Fase 13"). 


\section{FRAÇĀO ELIMINADA ACUMULADA}

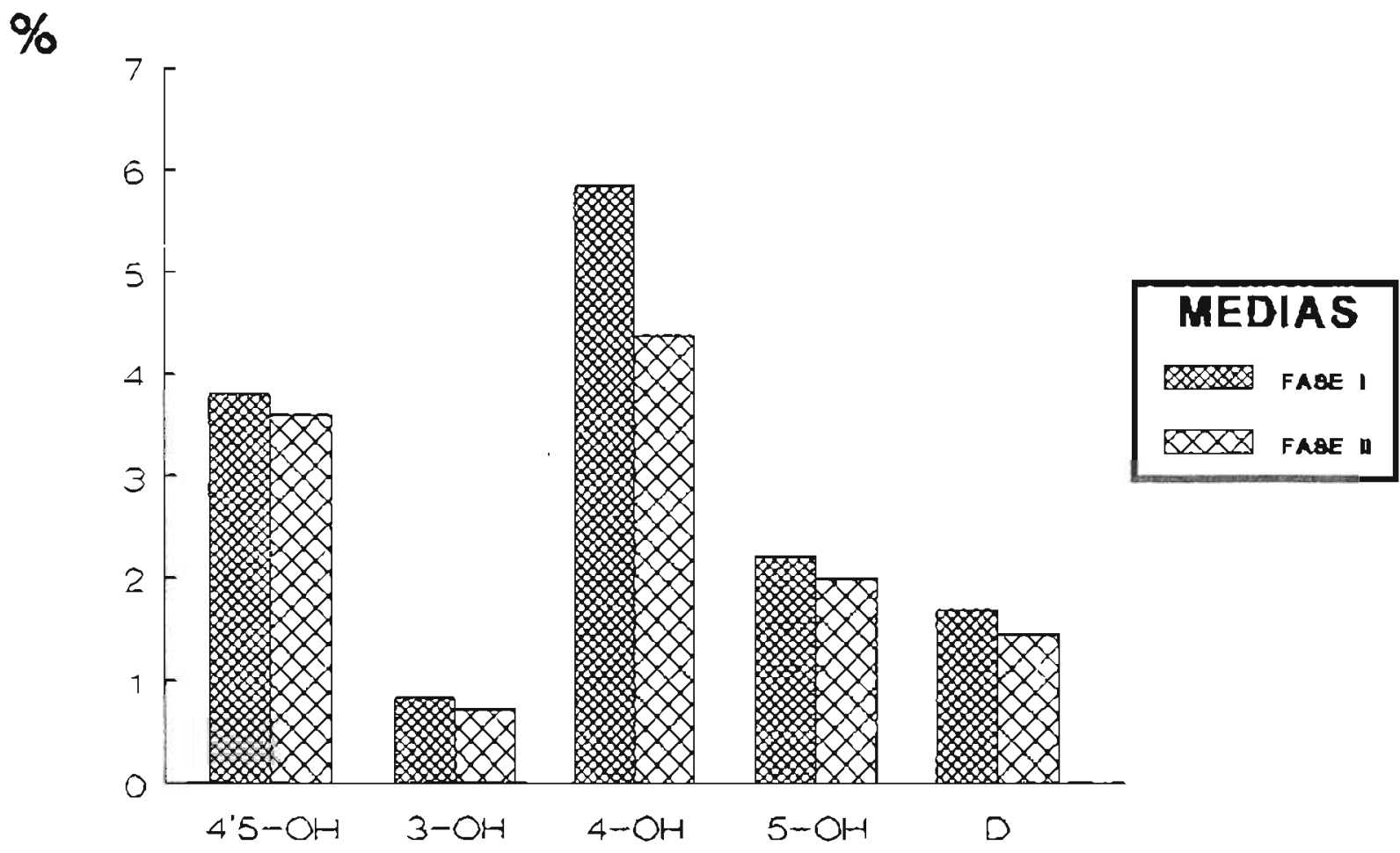

Figura 10. Excreção uninàna de diclofenaco e seus produtos de biotransformação apos administracão peroral de dose única de diclofenaco isolado (Fase I) ou associado a ranitidina (Fase II) - médias. 


\section{FRAÇĀO ELIMINADA ACUMULADA}

$\%$

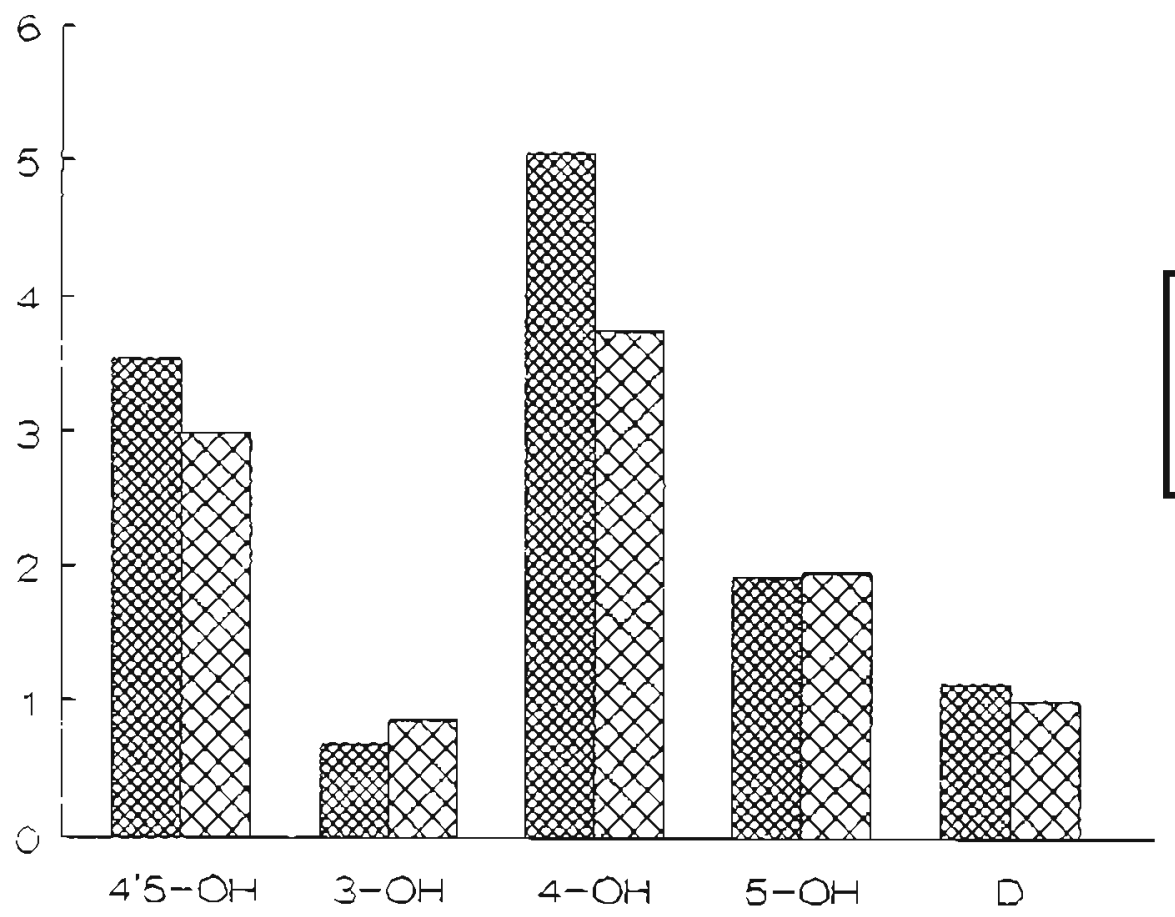

MEDIANAS

FASE I

QXX FAGE U

Figura 11: Excreção urinária de diclofenaco e seus produtos de biotransformação após admunistração peroral de dose única de diclofenaco isolado (Fase I) ou associado a ranitidina (Fase II) - medianas. 


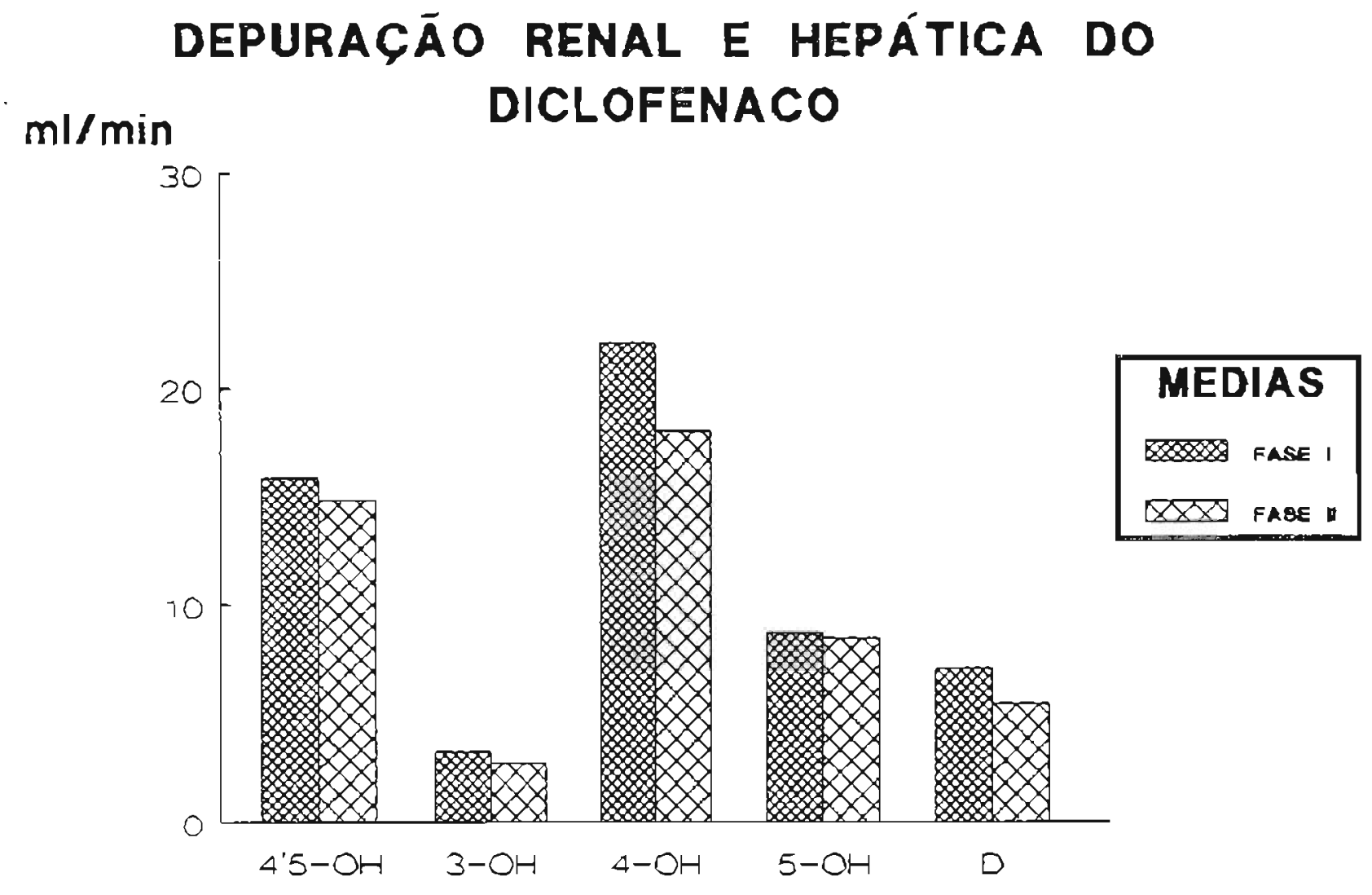

Figura 12: Depuração renal e hepàtica de diclofenaco e seus produtos de biotransformaçăo após admunustração peroral de dose única de diclofenaco isolado (Fase I) ou associado à ranıtidina (Fase II) - médıas. 


\section{DEPURAÇĀo RENAL E HEPÁTICA DO DICLOFENACO \\ $\mathrm{ml} / \mathrm{min}$}

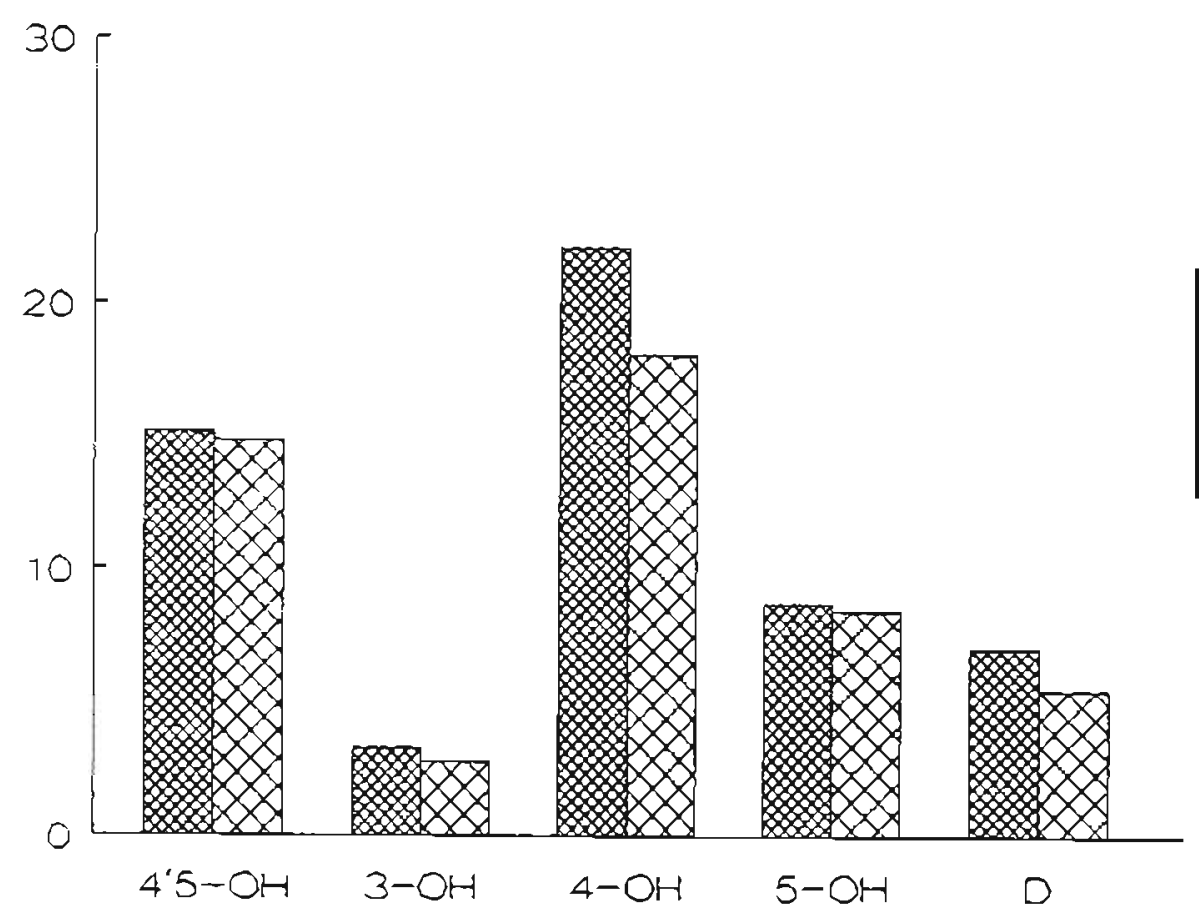

Figura 13: Depuraçào renal e hepática de diclofenaco e seus produtos de biotransformação apos administraca peroral de dose ínica de diclofenaco isolado (Fase I) ou associado à ranitidina (Fase II) - medianas. 
A depuraçào renal do diclofenaco é de pequena imponància uma vez que porcentagens da dose inferiores a $5 \%$ são excretadas na urina sob forma inalterada. Não houve alteração significativa de depuração renal pela associação com ranitidina (Tabela 4), entretanto observa-se larga variaçăo individual uma vez que foram obtidos valores múnimos de 0,4 e máximos de $23,3 \mathrm{mV} / \mathrm{min}$ referentes ao "clearance" renal $(\mathrm{Cl} r)$ do diclofenaco após administração de diclofenaco isolado e valores minimos de 0,0 e máximos de $14,6 \mathrm{mV}$ min após associação com ranitidina (Tabela 5B). Não se demonstrou qualquer acúmulo digno de nota para o diclofenaco, uma vez que sua depuração renal se manteve inalterada pela coadministração. 
Tabela 4 Depuração renal do diclofenaco inalterado $\left(\mathrm{Cl}_{r}\right)$ e dos seus produtos de biotransformação hidroxilados $\left(\mathrm{Cl}_{\hat{f}}\right)$ em voluntarios sadios após dose única peroral de diclofenaco de sódio.

\begin{tabular}{|c|c|c|c|c|}
\hline \multirow[t]{2}{*}{ Produco } & \multicolumn{2}{|c|}{ Clearance (mU/min) } & \multirow[t]{2}{*}{$\boldsymbol{p}$} & \multirow[t]{2}{*}{ significância } \\
\hline & diclofenaco & $\begin{array}{c}\text { diclofenaco } \\
+ \\
\text { ranitidina }\end{array}$ & & \\
\hline $\begin{array}{c}4^{\prime}, 5-\mathrm{OH}-\mathrm{D} \\
\left(\mathrm{Cl}_{\mathrm{f}}\right)\end{array}$ & $\begin{array}{c}15.9 \pm 2.9 \\
(15.2)\end{array}$ & $\begin{array}{c}14.9 \pm 2.7 \\
(15.3)\end{array}$ & $\begin{array}{l}0.79 \\
0.55^{*}\end{array}$ & NSt \\
\hline $\begin{array}{r}\text { 3'-OH-D } \\
\left(\mathrm{Cl}_{\mathrm{f}}\right)\end{array}$ & $\begin{array}{c}3.3 \pm 0.9 \\
(2.6)\end{array}$ & $\begin{array}{c}2,7 \pm 0.7 \\
(3,3)\end{array}$ & $\begin{array}{l}0.64 \\
0.40\end{array}$ & NS \\
\hline $\begin{array}{r}4^{\prime}-\text { OH-D } \\
\left(C l_{f}\right)\end{array}$ & $\begin{array}{c}22.1 \pm 5.9 \\
(23.5)\end{array}$ & $\begin{array}{c}18.1 \pm 3.2 \\
(17.6)\end{array}$ & $\begin{array}{l}0.56 \\
0.27\end{array}$ & NS \\
\hline $\begin{array}{r}\text { 5-OH-D } \\
\left(\mathrm{Cl}_{1}\right)\end{array}$ & $\begin{array}{c}8.7 \pm 1.4 \\
(7.4)\end{array}$ & $\begin{array}{c}8.4 \pm 2,4 \\
(6,1)\end{array}$ & $\begin{array}{l}0.91 \\
0.40\end{array}$ & NS \\
\hline $\begin{array}{c}\text { diclofenaco } \\
\left(\mathrm{Cl}_{\mathbf{r}}\right)\end{array}$ & $\begin{array}{l}7.1 \pm 2.8 \\
(5.1)\end{array}$ & $\begin{array}{c}5.4 \pm 1.9 \\
(3,5)\end{array}$ & $\begin{array}{l}0.64 \\
0.45\end{array}$ & NS \\
\hline
\end{tabular}

valores em $X \pm$ EPM (mediana)

*. teste " $t$ ", paramétrico

**: teste de Wilcoxon, não-paramétrico

$\dagger N S$ : diferença nào-significativa 
Tabela 5: Depuraçào renal do diclofenaco inatterado $\left(\mathrm{Cl}_{r}\right)$ e dos seus produtos de biotransformação hidroxilados $\left(\mathrm{Cl}_{f}\right)$ em voluntários sadios após dose única peroral de diclofenaco de sodio

A: Faixa de vanaçào (X - DP, $X+D P)$.

\begin{tabular}{|l|c|c|}
\hline \multirow{2}{*}{\begin{tabular}{l} 
Produto \\
\cline { 3 - 4 }
\end{tabular}} & \multicolumn{2}{|c|}{ Clearance (ml/min) } \\
\cline { 2 - 3 } & diclofenaco & $\begin{array}{c}\text { diclofenaco } \\
+ \\
\text { ranitidina }\end{array}$ \\
\hline \hline 4'.5-OH-D $\left(\mathrm{Cl}_{\mathrm{f}}\right)$ & $8,2-23.6$ & $7.8-22,0$ \\
3'-OH-D $\left(\mathrm{Cl}_{\mathrm{f}}\right)$ & $0.9-5.7$ & $0.8-4.6$ \\
4'-OH-D $\left(\mathrm{Cl}_{\mathrm{f}}\right)$ & $6,5-37.7$ & $10.0-26.6$ \\
5-OH-D $\left(\mathrm{Cl}_{\mathrm{f}}\right)$ & $5.0-12.4$ & $2.1-14,7$ \\
diclofenaco $\left(\mathrm{Cl}_{\mathrm{f}}\right)$ & $0-14.5$ & $0.4-10.4$ \\
\hline
\end{tabular}

B: Valores minimos e máximos

\begin{tabular}{|l|c|c|}
\hline \multirow{2}{*}{ Produto } & \multicolumn{2}{|c|}{ Clearance (m/min) } \\
\cline { 3 - 4 } & diclofenaco & $\begin{array}{c}\text { diclofenaco } \\
+ \\
\text { ranitidina }\end{array}$ \\
\hline \hline 4'.5-OH-D $\left(\mathrm{Cl}_{\mathrm{f}}\right)$ & $5.4-29.8$ & $2.4-23.2$ \\
3'-OH-D $\left(\mathrm{Cl}_{f}\right)$ & $0-6.7$ & $0-4.4$ \\
4'-OH-D $\left(\mathrm{Cl}_{f}\right)$ & $2,6-52.0$ & $5,3-30.5$ \\
5-OH-D $\left(\mathrm{Cl}_{f}\right)$ & $5.1-16.6$ & $1.3-20.3$ \\
diciofenaco $\left(\mathrm{Cl}_{\tau}\right)$ & $0.4 \cdot 23.3$ & $0-14.6$ \\
\hline
\end{tabular}

Apesar da excreção urinàia do principal produto de biotransformação hidroxilado do diclofenaco (4'-OH-D) apresentar redução significativa pela associação com a ranitidina (Tabela 2 ) e do seu "clearance" de formaçāo $\left(\mathrm{Cl}_{\mathrm{f}}\right)$ estar 
reduzido em cerca de $25 \%$ na Fase II (diclofenaco associado à ranitidina) em relação à Fase 1 (diclofenaco isolado) (Tabela 4) não se observou diferença significativa nos valores de "clearance" de formação deste produto pela associação com a ranitidina, provavelmente devido à grande variação individual na população investigada (Tabela 5A e B), evidenciando valores minimos de 2.6 e máximos de $52,0 \mathrm{ml} / \mathrm{min}$ na Fase I do estudo e de 5,3 e $30,5 \mathrm{ml} / \mathrm{min}$ na Fase II do estudo..

Os outros dois importantes produtos de biotransformação hidroxilados do diclofenaco, 4', 5-OH-D e S-OH-D, também não mostraram redução significativa do seu "clearance" de formação $(\mathrm{Cl})$ pela associação com a ranitidina (Tabela 4), quer em vista da menor contribuição na biotransformação do diclofenaco que o produto referido anteriomente (4'-OH-D), quer devido à larga variação individual deste parâmetro na população investigada (Tabela 5A e B).

Finalmente, o produto hidroxilado de menor contribuição na biotransformação do diclofenaco, 3'-OH-D, da mesma forma que os anteriores, não mostrou redução do seu "clearance" de formação $\left(\mathrm{Cl}_{\mathrm{f}}\right)$ pela ranitidina.

O perfil de excreção uninária mostrou serem os paràmetros fraçāo eliminada no intervalo de coleta $\left(\mathrm{Fel}_{\Delta \mathrm{t}}\right)$ e fração eliminada total $\left(\mathrm{Fel}_{\mathrm{T}}\right)$ na urina, paràmetros mais sensiveis que o "clearance" $\left(\mathrm{Cl}_{\mathrm{f}}\right)$ para o estudo de interação proposto inicialmente.

Uma vez que a ranitidina mostrou-se inibidor pouco potente do metabolismo do diclofenaco sugere-se, com base nos resultados da presente investigaçāo, que a ranitidina afete a via principal de hidroxilação do diclofenaco, reduzindo a excreção do maior produto de biotransformação, o 4'-OH-D. Apesar 
disso, a associação mostra-se segura e vantajosa para pacientes em tratamento crònico com este antiinflamatorio e que possuam história de úlcera péptica [4]. Apesar da interação farmacocinética registrada no presente trabalho não se espera qualquer efeito adverso de relevância clínica pela associação de diclofenaco e ranitidina.

\section{Conclusão}

Com base nos resultados obtidos sugere-se que a ranitidina reduza a biotransformação do diclofenaco afetando o principal caminho metabólico envolvendo a hidroxilação de anel na posição 4' (4'-hidroxidiclofenaco, 4'-OH-D) com consequente prolongamento da meia-vida de desaparecimento plasmático do diclofenaco e redução da fração da dose administrada eliminada na unina sob forma de 4'-OH-D. Entretanto, apesar desta interação farmacocinética, não se espera qualquer conseqüẽncia de relevância clinica decorrente desta associação.

\section{Referências bibliográficas}

1. BURROUGHS, A.K., WALT, R.P., DUNK, A.A., JENKNS, W.J., SHERLOCK, S. Effect of cimetidine on portal hyperension in cirrhosis patients. Br. Med. J., London, v. 284, p. 1159-1160, 1982. 
2. DEGEN, P.H., DIETERLE、 W., SCHNEIDER, W., THEOBALD、W., SINTERHAUF, $U$ Pharmacokinetics of diclofenac and five metabolites after single oral doses in healthy volunteers and after repeated doses in patients. Xenobiotica, London, v. 18, n. 12, p. 1449-1455, 1988.

3. DUNK, A.A. JENKINS, W.J., BURROUGHS, A.K., WALT, R.P. OSUAFOR, T.O.K. The effect of ranitidine on the plasma clearance and hepatic extraction of indocyanine green in patients with chronic liver disease. Br. J. Clin. Pharmacol., London, v. 16, p. 117-120, 1983.

4. EHSANULLAH, R.S.B., PAGE, M.C., TRDESLEY, G., WOOD, J.R. Prevention of gastroduodenal damage induced by non-steroidal anti-inflammatory drugs: controlled trial of ranitidine. Br. Med. J., v. 297, p. $1017-1021,1988$

5 FAIGLE, JW, BÖTTCHER, I., GODBLLON, J., KRIEMLER, H.P., SCHLUMPF, E., SCHNEIDER, W., SCHWEIZER, A., STIERLIN, H., WINKLER, T. A new metabolite of diclofenac sodium in human plasma. Xenobiotica, London, v. 18, n. 10, p. 1191-1197.

6. FEE, J.P.H., COLLIER, P.S., HOWARD, P.J., DUNDEE, J.W. Cimetidine and ranitidine increase midazolam bioavailability. Clin. Pharmacol. Ther., St. Louis, v. 41 , n. 1, p. 80-84, 1987.

7. GIBALDI, M. Biopharmaceutics and clinical pharmacokinetics. $4^{\mathrm{a}}$ ed. Philadelphia: Lea \& Febiger, 1991. p. 203-233. 
8. GODBILLON, J. GAURON. S. METAYER J P. High periormance liquid chromatographic determination of diclofenac and its monohydroxilated metabolites in biological fluids. J. Chromatogr. Amsterdam. v. 338. p. $151-159,1985$

9. HALABI, A. NAHOUI, R., KIRCH. W. Influence of ranitidine on kinetics of nitrendipine and on noninvasive hemodynamic parameters. Ther. Drug Monit., Edimburg, v. 12, n. 3. p. 303-304, 1990.

10 HOENSCH, H.P, HUTZEL. H., KIRCH, W. OHNHAUS, E.E. Isolation of human hepatic microsomes and their inhibirion by cimeridine and ranitidine. Eur. J. Clin. Pharmacol., Berlin, v. 29, p. 199-201

11. KIRCH. W, HALABI, A., LINDE, M., SANTOS, S.R., OHNHAUS, E.E. Negative effects of famotidine on cardiac performance assessed by noninvasive hemodynamic measurements. Gastroenterology, New York, v 96 , p. $1388-1392$

12. KIRCH, W., HOENSCH, H., JANISH, H.D. Interactions and non-interactions with ranitidine. Clin. Pharmacokinet., Auckland. vol 9, p. 493-510, 1984

13. KIRCH, W, JANISH, H.D, HEIDEMANN, H., RAEMSCH, K.D., OHNHAUS. E.E. Einfluss von Cimeridin und Ranitidin auf Pharmacokinetic und antihyperensiven Effekt von Nifedipine. Dtsch. Med. Wochenschr., Stuttgan, v. 108, p. 1757-1761. 1983.

14 LANDSORP, D., JANSSEN, T.J., GUELEN, P.J.M., VREE, T.B. High-performance liquid chromatographic method for the determination of 
diclofenac and its hudroxy metabolites in human plasma and unne. J. Chromatogr.. .tmsterdam, v. 528. p. 487-494. 1990

15. MASFORD, M.L. HARMAN, P.J.K., MORPHETT, B S. BREEN, K.J., DESMOND. P.V Ranitidine does not affect chlormethiazole or indocyanine green dispodition. Clin. Pharmacol. Ther., St. Louis. v. 34, p. $231-233,1983$.

16. MENASSÉ, R., HEDWALL, J., KRAETZ, J., PERICIN, L., RIESTERER, L. SALLMANN, A., ZIEL, R. JAQUES, R. Pharmacological properties of diclofenac sodium and its metabolites. Scand. J. Rheumatol. Suppl., Stockhoim, v. 22, p. 5-16, 1978.

17. RIESS, W , STIERLIN, H. DEGEN, P, FAIGLE, J.W., GERARDN, A.. MOPPERT, J., SALLMANN, A., SCHMID, K., SCHWIZER, A., SULE, M., THEOBALD, W., WAGNER, J. Pharmacokinetics and metabolism of the anti-inflammatory agent Voltaren. Scand. J. Rheumatol. Suppl. Stockhoim, v. 22, p. 17-29., 1978.

18. RITSCHEL, W.A. Bandbook of basic pharmacokinetics. $3^{\mathbb{2}}$ ed., Bethesda: Drug Intelligence Publications, 1986.

19. ROBSON, R.A., WING, L.M.H., MINERS, J.O., LILLYWHTE, K.J., BIRKETT, D.J The effect of ranitidine on the disposition of lignocaine. Br. J. Clin. Pharmacol., London, v 20, p. 170-173. 1985.

20. SACHS, L. Applied statistics. $2^{\mathbf{a}}$ ed., New York: Springer, 1984. 
2). SANTOS, S.R C.J., DONZELLA, H., BERTOLINE, M.A. PEREIRA, M.D. OMOSAKO. C.E., PORTA. V. Simplified micromethod for the HPLC measurement of diclofenac in plasma. Braz. J. Med. Biol. Res., Ribeirăo Preto, v, 25, p. 125-128, 1992.

22. SANTOS, S.R., STORPIRTIS, L., MOREIRA-FILHO, L., DONZELLA, H, $\mathrm{KIRCH}, W$ Ranitidine increases the bioavailability of nitrendipine in patients with anerial hypentension. Braz. J. Med. Biol. Res., Ribeirão Preto, v. 25, p. 337-347, 1992.

23. SCHNEIDER, T.H. NUERNBERG, B., DIETZEL, K., BRUNE, K. Biliary elimination of non-steroidal anti-inflammatory drugs in patients. Br. J. Clin. Pharmacol, London, v. 29, p. 127-131, 1990

24. SMITH, S.R., KENDALL, M.J. Ranitidine versus cimetidine. A comparison of their potential to cause clinically imporant drug interactions. Clin. Pharmacokinet. Auckland, v. 15, p. 44-56, 1988

25. SOMOGYI, A., GUGLER, R. Drug interactions with cimetidine. Clin. Pharmacokinet., Auckland, v 7, p. 23-41, 1982.

26. STIERLN, H., FAIGLE, J.W. Biotransformation of diclofenac sodium (Voltaren(8) in anima's and in man. II. Quantitative determination of the unchanged drug and principal phenolic metabolites, in urine and bile. Xenobiotica, London, v. 9, n. 10, p. 611-621, 1979. 
27 STIERLIN. H. FAIGLE. J.W. COLOMBI. A. Phamacokinetics of diclofenac sodium (Voltaren) and merabolites in patients wish impaired renal function. Scand. J. Rheumatol. Suppl.. Stockholm, v. 22, p. 30-35, 1978.

28. STIERLIN. H., FAIGLE, J.W., SALLMANN, A, KUENG. W., RICHTER W.J., KRIEMLER H.P., ALT, K.O., WINKLER. T. Biorransformation of diclofenac sodium (Voltaren() in animals and in man. I. Isolation and identification of principal metabolites. Xenobiotica. London, v. 9, n. 10, p. $601-610,1979$

29. TODD, A.P., SORKIN, E.M. Diclofenac sodium. A reappraisal of its pharmacokinetic properties. and therapeutic efficacy. Drugs, Auckland, v.35. p. $244-285,1988$

30. TYDEN, G., THULIN, L., NYBERG, B. The effect of cimetidine on liver blood flow in anaesthetized man. Acta Chir. Scand. Stockholm, v 149, p. 303-305, 1983

3) WILLIS, J.V., KENDALL, M.J. Pharmacokinetic studies on diclofenac sodium in young and old volunteers. Scand. J. Rheumatol. Stockholm, v. 22, p. $36-41,1978$

32. ZIMMERMANN, R., HARENBERG, J., KRAMER, H.J., KOMMERELL, B Interaktion von Famotidin mit der oralen Antikoagulation. Dtsch. Med. Wochenschr., Stuttgar. v. 27, p. 1097-1098, 1985. 


\begin{abstract}
The pharmacokinetic interaction between diclofenac and ranitidine was evaluated in 8 healthy volunteers after peroral single administration of Voltaren $^{2} 50$ in a two-phase study protocol. On phase I, diclofenac was administered alone, while on Phase II the volunteers were submitted to a chronic treatment with ranitidine for seven days; then a dose of diclofenac was administered and ranitidine continued for three days afterwards. Blood and urine samples were collected at time intervals 0.72 hours after diclofenac administration. Diclofenac and its hydroxylated metabolites in biological fluids were determined by two independent profiles using HPLC technique after a single extraction with organic solvent in acidic medium. Enzymic hydrolysis was necessary for the cleavage of conjugates in urine. Diclofenac elimination half-life was increased by $43 \%$ ranging from $1.01 \pm 0,13 \mathrm{~h}$ to $1,44 \pm 0,34 \mathrm{~h}(\mathrm{X} \pm \mathrm{SEM})$ when ranitidine was coadministered. Significant decrease on $\mathrm{Fel}_{\mathrm{T}}$ of $4^{\prime}-\mathrm{OH}-\mathrm{D}$ ranging from $5,85 \pm 1,12$ $(5,06) \%$ to $4.89 \pm 0.75(3.73) \%(X \pm S E M$ (med)) was obtained by ranitidine association. $\mathrm{Cl}_{\xi}$ of metabolites expressed as $\mathrm{X} \pm \mathrm{SEM}$ (med) were, in $\mathrm{ml} / \mathrm{min}$ : $15,9 \pm 2,9(15,2)$ for $4 ', 5-O H-D, 3,3 \pm 0,9(2,6)$ for $3 '-O H-D, 22,1 \pm 5,9(23,5)$ for 4 - $\mathrm{OH}-\mathrm{D}$ and $8.7 \pm 1.4(7,4)$ for $5-\mathrm{OH}-\mathrm{D}$ after peroral single dose of diclofenac alone. These data showed no significant difference when ranitidine was administered. Diclofenac renal clearance $\left(\mathrm{Cl}_{r}\right)$, expressed as $\mathrm{X} \pm \mathrm{SEM}$ (med), was $7,1 \pm 2,8(5,1) \mathrm{ml} / \mathrm{min}$ after diclofenac and $5,4 \pm 1,9(3,5) \mathrm{m} / \mathrm{min}$, ranitidine. Based on these data, гanitidine decreases the biotransformation of diclofenac by inhibition of hydroxylation affecting urinary excretion of its main hydroxy metabolite, 4'-hydroxydiclofenac. In spite of this pharmacokinetic interaction, without clinical relevance. patients with a history of peptic ulcer and more susceptible to recument ulceration. could benefit from the association diclofenac-ranitidine.
\end{abstract}


Apêndice 
Quadro a.1: Caracteristicas dos voluntarios.

\begin{tabular}{|c|c|c|c|c|c|c|c|}
\hline Voluntário & & sero & $\begin{array}{l}\text { idade } \\
\text { (anos) }\end{array}$ & $\begin{array}{l}\text { altura } \\
\text { (cm) }\end{array}$ & $\begin{array}{c}\text { peso real } \\
(\mathrm{kg})\end{array}$ & $\begin{array}{c}\text { peso ideal" } \\
(\mathrm{kg})\end{array}$ & $\begin{array}{c}\text { DPI** } \\
(\%)\end{array}$ \\
\hline $1(\mathrm{HD})$ & $\mathrm{gt}$ & $F$ & 25 & 168 & 68 & 61 & 11 \\
\hline $2(V P)$ & $N F t$ & $F$ & 24 & 165 & 58 & 59 & -2 \\
\hline 3 (SS) & NF & $F$ & 43 & 172 & 65 & 65 & 0 \\
\hline$f(\mathrm{LM})$ & NF & $M$ & 33 & 193 & 97 & 84 & 15 \\
\hline$S(E P)$ & NF & $M$ & 21 & 183 & 73 & 75 & -2 \\
\hline $6(S P)$ & NF & $M$ & 20 & 178 & $6+$ & 70 & -9 \\
\hline $7(A L)$ & NF & $F$ & 23 & 150 & +7 & 45 & 4 \\
\hline $8(\mathrm{CE})$ & NF & $F$ & 33 & 156 & 54 & 49 & 10 \\
\hline
\end{tabular}

"peso ideal $=($ altura $(\mathrm{cm})-100) \times 0,9$

* DPI = desvio porcentual do peso ideal

$D P I=[$ (peso real - peso ideal $) /$ peso ideal $) \times 100$

$+F=$ fumante

${ }_{+} \mathrm{N}=$ nāo-fumante 


\section{Termo de Consentimento Pós-informaçảo}

Nome do voluntáno / Idade

Regisuro e / ou documento de identificação

Títula do projeto. Estudo de interaçăo entre a ranitidina e o diclotenaco em voluntários sadios após adminisuraço peroral de Volcaren 50

Declaro que em _l_ ' __ concordei voluntariamente em participar. como voluncano. do projeto de pesquisa acima referido. Fui devidamente informado em decalhes que:

1. O esiudo jmplica em que eu me submeta a procedimentos. exames complementares e ratamentos devidamente planejados. cujos eventuais nscos me foram explicados:

2. Os procedimenıos nào incluem. necessanamente. os já reconhecidos como aplicáveıs e podem visar à avaliação de tratamentos novos ou a compará-los com os iradicionais:

3 Não sou obrigado a continuar paricipando do projelo e posso. a qualquer momento. sair do mesmo:

+ Meu consentimento aplica-se, igualmente. a parucipar da pesquisa como componente do grupo controle. podendo receber substâncias inócuas ou inauvas, com a finalidade de dimensionar o "efeiro placebo":

5. A pesqusa nāo sera feita se houver. relacionados à mesma. grandes riscos para mim. Da mesma forma. caso algum risco proibitivo venta a se revelar no decurso do estudo. o pesqusador se compromete a me alertar sobre o fato e a suspender de imediato minha paricipaçào como voluntáio.

Observaçōes complementares:

assinatura do voluntáio

Sło Paulo de de 
VOLUNTARIO 1 - H.D.

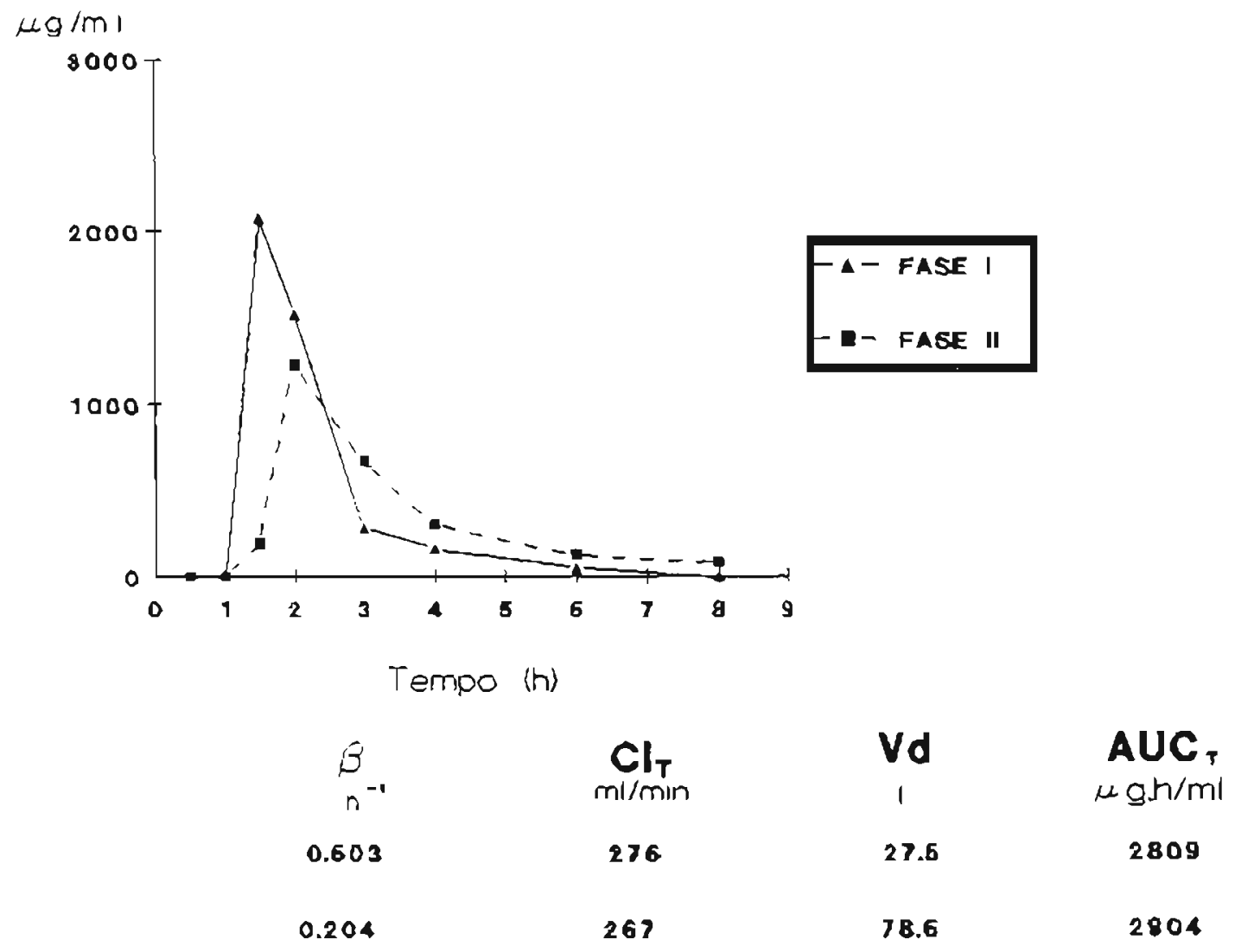

Figura a.1: Curvas de decaimento plasmático do diclofenaco após administração peroral de Voltaren ${ }^{\circledR 0}$ isolado (Fase I) ou associado à ranitidina (Fase II) - Voluntáno 1. 
VOLUNTARIO 2 - V.P.

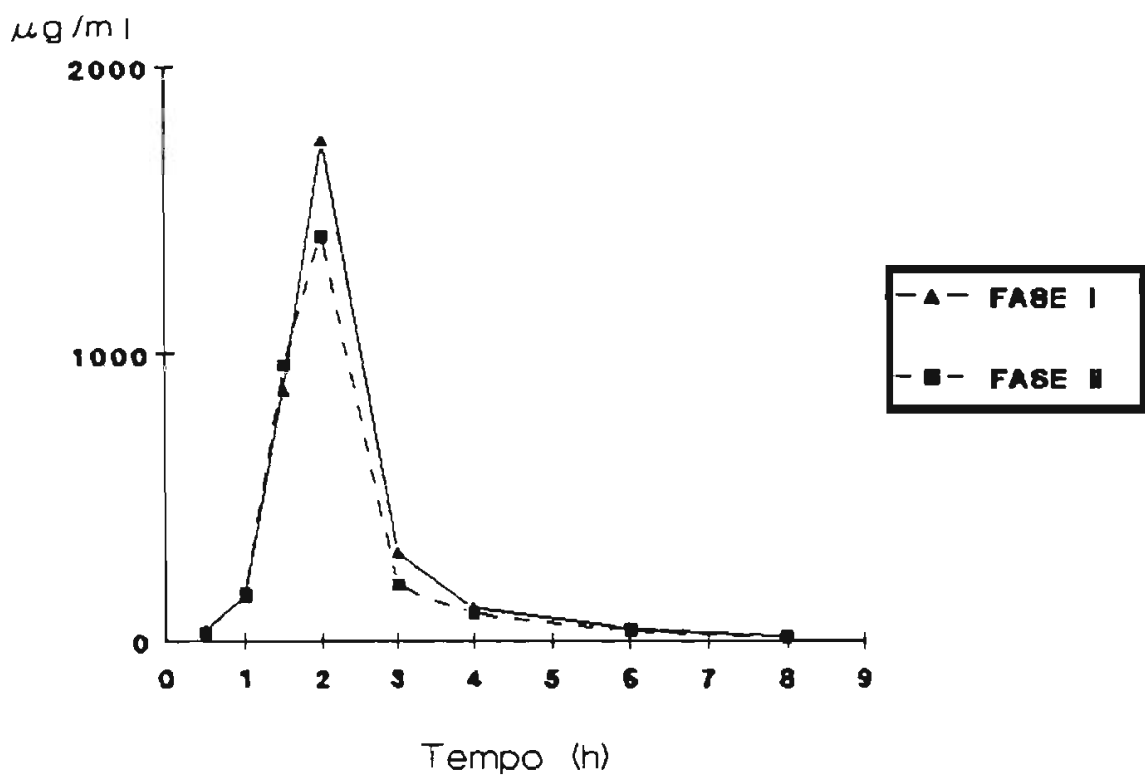

$\begin{array}{ccccc} & \beta & C_{\mathbf{T}} & \text { Vd } & \text { AUC, } \\ \text { FASE 1 } & \mathrm{n}^{-1} & \mathrm{mi} / \mathrm{min} & 1 & \mu \mathrm{g} . \mathrm{h} / \mathrm{ml} \\ \text { FASE II } & 0.495 & 315 & 38.2 & 2460 \\ & 0.433 & 367 & 50.8 & 2113\end{array}$

Figura a.2: Curvas de decaimento plasmático do diclofenaco após administração peroral de Voltaren ${ }^{\circledR} 50$ isolado (Fase I) ou associado à ranitidina (Fase II) - Voluntário 2. 


\section{VOLUNTARIO 3 - S.S.}

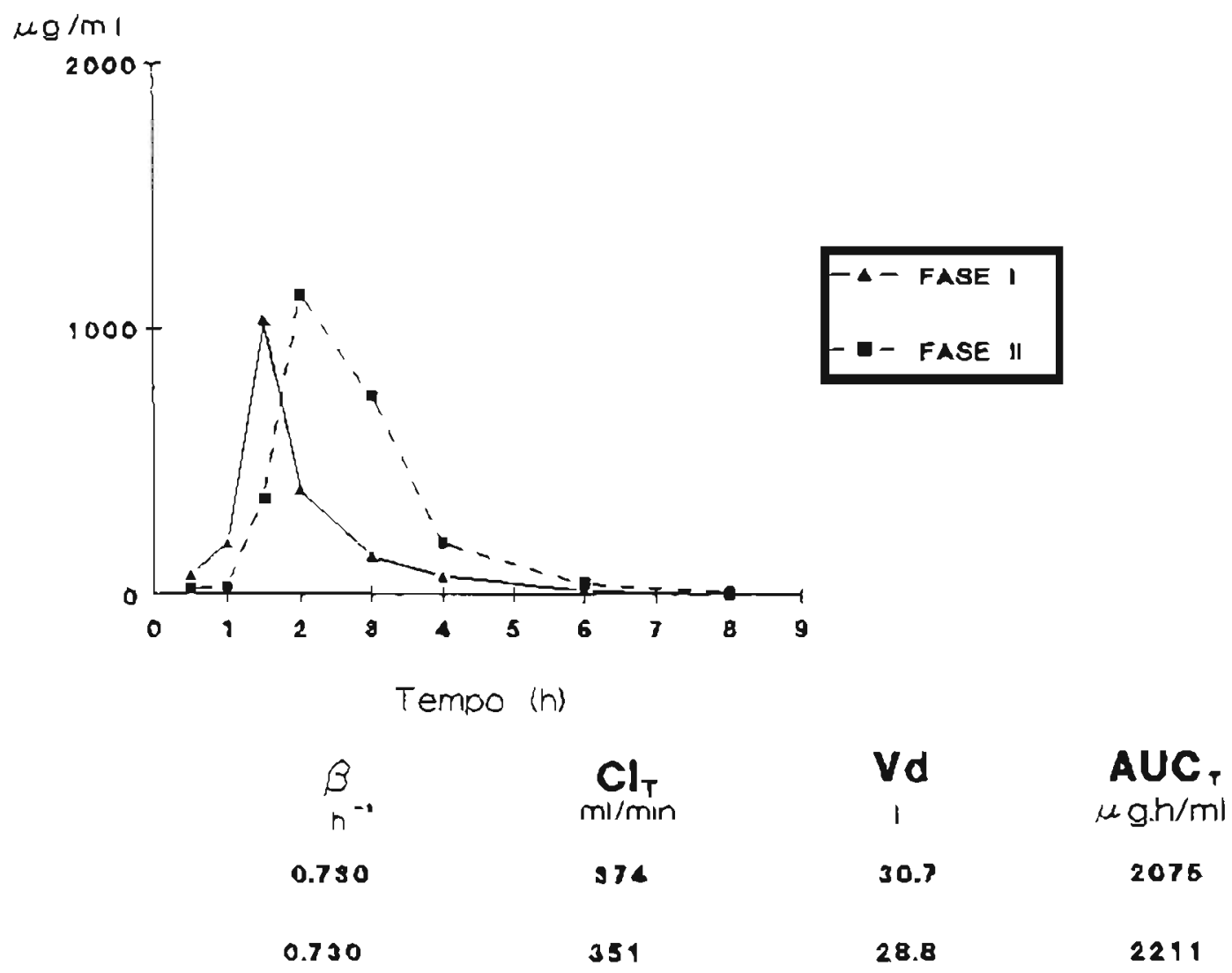

Figura a.3: Curvas de decaumento plasmático do diclofenaco apos administracão peroral de Voltaren ${ }^{\circledR} 50$ isolado (Fase 1) ou associado à ranitidina (Fase II) - Voluntáno 3. 


\section{VOLUNTARIO 4 - L.F.}



Figura 8.4: Curvas de decaimento plasmático do diclofenaco após administração peroral de Voltaren ${ }^{\mathbb{B}} 50$ isolado (Fase I) ou issociado à ranitidina (Fase II) - Voluntario 4. 


\section{VOLUNTARIO 5 - E.P.}

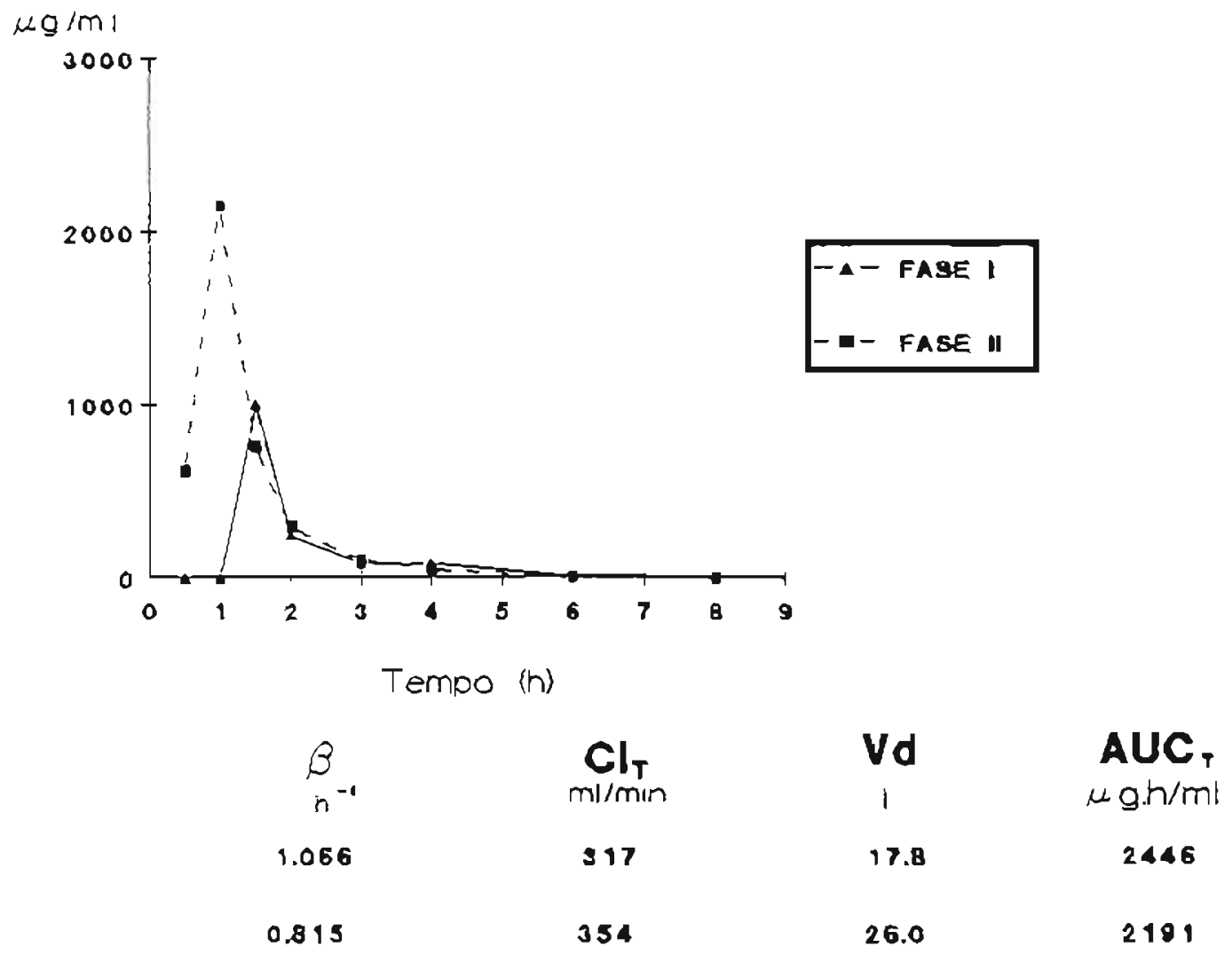

Figura a.5: Curvas de decaimento plasmático do diclofenaco após admenistracão peroral de Voltaren ${ }^{\mathbb{B}} 50$ isolado (Fase I) ou associado à ranitidina (Fase II) - Voluntáno 5. 


\section{VOLUNTARIO 6 - S.P.}



Figura a.6. Curvas de decaimento plasmárico do diclofenaco após administraçāo peroral de Voltaren ${ }^{\circledR} 50$ isolado (Fase I) ou associado à ranitidina (Fase II) - Voluntano 6 


\section{VOLUNTARIO 7 - A.L.}

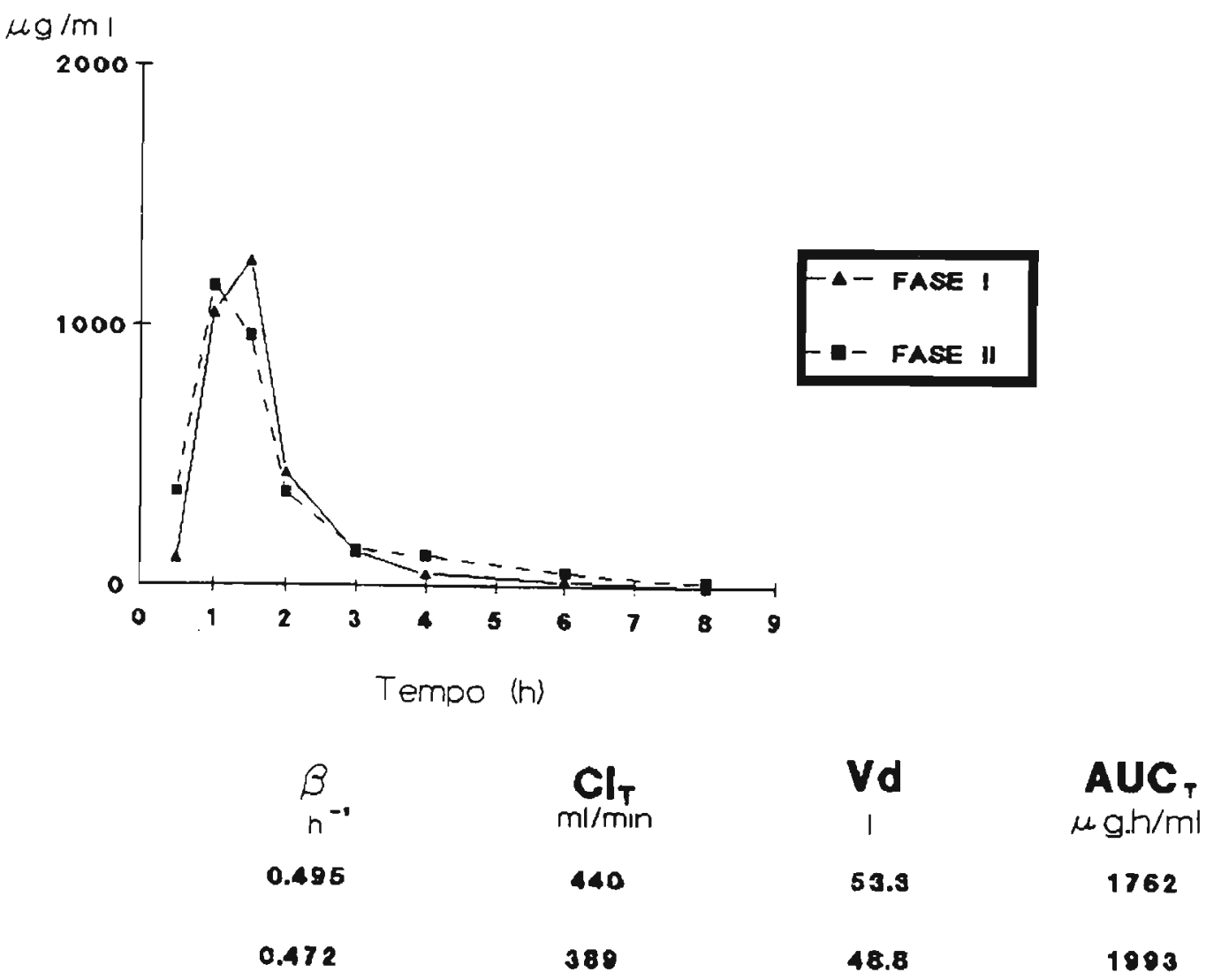

Figura a.7: Curvas de decaimento plasmático do diclofenaco após administração peroral de Voltaren ${ }^{\mathbb{B}} 50$ isolado (Fase I) ou associado à ranitidina (Fase II) - Voluntário 7. 